Illinois State University

ISU ReD: Research and eData

Theses and Dissertations

3-3-2021

\title{
Womanist Ways In A Man'S World: Unpacking Anti-Blackness In Higher Education Enrollment Management Roles
}

Mesha C Garner

Illinois State University, meshacgarner@gmail.com

Follow this and additional works at: https://ir.library.illinoisstate.edu/etd

Part of the African American Studies Commons, and the Feminist, Gender, and Sexuality Studies Commons

\section{Recommended Citation}

Garner, Mesha C, "Womanist Ways In A Man'S World: Unpacking Anti-Blackness In Higher Education Enrollment Management Roles" (2021). Theses and Dissertations. 1369.

https://ir.library.illinoisstate.edu/etd/1369

This Dissertation is brought to you for free and open access by ISU ReD: Research and eData. It has been accepted for inclusion in Theses and Dissertations by an authorized administrator of ISU ReD: Research and eData. For more information, please contact ISUReD@ilstu.edu. 


\title{
WOMANIST WAYS IN A MAN'S WORLD: UNPACKING ANTI-BLACKNESS IN HIGHER EDUCATION ENROLLMENT MANAGEMENT ROLES
}

\author{
MESHA C. GARNER
}

\section{Pages}

This study evaluated the phenomenon of anti-Black womanism in enrollment management at Historically White Institutions (HWIs) for Black women professionals. The qualitative study was conducted to understand dialectical functions of enrollment management and the dialectical responsibilities that Black women have while working in enrollment management. The theoretical framework of anti-Black womanism guided this study. Anti-Black womanism is a dual lens of BlackCrit (Dei, 2017; Dumas and Ross, 2016) and Womanism (Phillips, 2006). Furthermore, this study comprised the historical perspective and acknowledged the settler-colonial complex to best conceptualize the perceptions of Black people, particularly Black women. This study included 10 participants, all who have worked in enrollment management at the divisional level or a sub-level in the offices of financial aid, registrar, or admissions. Narrative inquiry was used as the method for data collection. Four themes emerged that revealed the consistent duality that Black women experience within their positions.

KEYWORDS: anti-Blackness, Black women, enrollment management, perception bias, higher education 
WOMANIST WAYS IN A MAN'S WORLD: UNPACKING ANTI-BLACKNESS IN HIGHER EDUCATION ENROLLMENT MANAGEMENT ROLES

MESHA C. GARNER

A Dissertation Submitted in Partial

Fulfillment of the Requirements

for the Degree of

DOCTOR OF PHILOSOPHY

Department of Educational Administration and Foundations

ILLINOIS STATE UNIVERSITY

2021 
(C)2021 Mesha C. Garner 
WOMANIST WAYS IN A MAN'S WORLD: UNPACKING ANTI-BLACKNESS IN HIGHER EDUCATION ENROLLMENT MANAGEMENT ROLES

MESHA C. GARNER

COMMITTEE MEMBERS:

Pamela Twyman Hoff, Chair

Lydia Kyei-Blankson

Sherri Ann Charleston

Stacy Otto 


\section{ACKNOWLEDGMENTS}

First, I want to thank God for keeping and providing me with the resources needed on this journey. Nothing has been possible without the grace and mercy that God has had upon my life. I found and re-found my spirituality throughout this dissertation process. I could not have been more grateful for the groundedness I have gained and the capacity to stay the course. Jeremiah 29:11 is my mom's and my favorite verse, "For I know the plans I have for you," declares the LORD, "plans to prosper you and not to harm you, plans to give you hope and a future." My mom used to buy me everything that had the scripture stamped on it. Who would have known that it would lead to me here, now an emerging scholar and higher education leader. For as long as I could remember until this moment in my academic career, I believed that my perspective was not valued in class. However, I am so thankful for the strength to preserve and go for my doctorate anyway.

Thank you to my family for listening to me vent and ramble about this journey and for being flexible with me. Michelle, Robert, Anaya, Kyla, Ken, and Kenzie, I love you all. I know most of y'all did not know what I was doing-living on my computer for the last 5 years--but you knew and respected that I was sensitive about my work and would never give up. My ancestorangels in heaven, my dad, my brother, and especially my mom, thank you for always looking over me. I miss you all dearly and this is for you. Nothing will ever make me cease to believe that my family in heaven has not transcended heaven and earth to be protectors on my behalf.

Thank you to my participants. You are all amazing women, and I am thankful that you decided to be a part of my research study. Without you, I would not be here. I have gained sisterfriends in the process with my participants; the vulnerability it takes to be one with your professional and personal lives with me displays how strong you all are. 
To my chair... the one and only, Dr. Pamela Twyman Hoff, I would like to express my deepest and most sincere admiration and appreciation. You have been an anchor in my life longer than you may know. I am so gracious that we have taken this journey together. Your advocacy has led you to be a conductor but also an initiator. You are absolutely brilliant. Your intellect is one that inspires the soul and activate the brain. The fire that flames in you to do good in the world has lit many others to become critical thinkers and most important, critical doers. God really showed out when you and I crossed paths. Also, I thank you for gifting me with my cohort siblings; I would not have built a community with such amazing emerging scholars without you.

To the rest of my committee, thank you all. I admire everything about all of you, and I am grateful that I have had the opportunity to work with you. From the first day I met all of you (virtually or not), I have been at awe with all that you do and for whom you do it. I admire every single one of you as people in my corner and as professionals who have amazing expertise. I could go on and on about how much you all means so much to me. I also have to honorably mention the chair of my department, Dr. Sutton. Thank you for covering me and extending mentorship over all these years and allowing me to pop in your door at almost any time.

M. C. G. 


\section{PREFACE}

As I am about to wrap up the completion of my doctoral degree, I started a new position. This new position has led me out of the state I have called home for 3 years. Like every other employee who resigns, Human Resource personnel asked me to participate in an exit interview. My direct supervisor and a few colleagues asked me to be honest during the process. They know I can placate racist and sexist situations to mitigate intrapersonal tension. I never had the intent to be anything but $100 \%$ honest during the interview. I did not know what I would say, which is unlike me. I always anticipate what people will say or ask so that I can never get caught slippin'.

So, I virtually sat down with the HR representative and talked. We began because we have grown to work great with each other. I walked in the conversation optimistic because I was genuinely excited about my new opportunity and moving on to something new. I awaited a welldeserved position that reflected my hard work and where I should be professionally. So, I have no hard feelings at my core about everything I experienced at my prior job. I still believe I made (a) a business decision and (b) a decision that aligns more with my passions and complements my talents. I say all this to say, I walked in my virtual exit interview with a pure heart.

The HR rep began asking questions, and 90 minutes in I was asked the question: Did you feel your workload was balanced equally with others in similar roles? Without hesitation, I said no. We starred at one another, and then she asked, "Do you want to share more?" I did not know where to start. Eventually, through my rambling of words, which by then did not reflect a pure heart, I responded that a great deal of why my workload was not equally balanced. I carried the emotional burdens of 64 other people, a task that I can for sure attest that no one else had.

I gave examples of when colleagues slighted me or worked behind my back. My previous role heavily focused on compliance; it was my responsibility to tell people when they were 
wrong about procedures and reteach them to make things right. A significant part of my job was to teach other people how to treat me, which was not a measurable responsibility or in my job description. What should we have used to show how many conflicts Mesha has mitigated while trying to do her job? While we talked, I had the internal conflict of should I have word vomit of all the secrets that I have kept over the years or be diplomatic to ensure that I do not portray myself as the institution's victim.

I remember telling the HR representative a few times, and I am aware of the role that I have played in my career and my colleagues' perceptions of me. Verbatim, I said, "When they bark, I bite," I worked in an environment where they always tested me, and often anticipatory things happened, believing I would blow my gasket. I truly believe that my colleagues expected my bite to match more of a dog, a vicious, loud, gruesome bite: one that often did not end deadly but could be. Honestly, my bite was more like the combination of a butterfly, a skua bird, and Livingstone's Cichlid fish. In the Amazon basin, butterflies, what we know to be beautiful delicate creatures, turn into predators. They seek tears from other animals and usually go for slow animals, like turtles, to consume sodium from their tears. I worked with many people who were not emotionally mature. I learned what they meant for me. Skua birds use their "bird's-eye view" to find their prey. I was placed in a position where I had to put my feelings aside to nurture those less emotionally mature than myself. That opened my insight into my office structure and the institution and changed how I became strategic. And last, the Livingstone's Cichlid fish plays dead and waits for their prey. I had to disengage. My ability to disengage was not always intentional. There became a time when all life was taken from me, and I only saved enough strength when I had to fight as a Black woman and leader on a very white campus. 
I recognize the hypocrisy and the anti-Blackness of comparing myself to animals. I intend never to compare myself to animals as if I am one myself, but to acknowledge their perspectives in survival: the tactics that creatures have and use to live another day. If anything, my examples show how I had to be prepared at different levels, sea level, ground level, and sky. I had to position my resiliency and resistance to fit the day and the level.

It is insightful to be finalizing my manuscript with the newfound knowledge that I have gained and eagerly cannot wait to share with other practitioners and intellectuals. During my exit interview process as the interviewee, I still analyzed my words and my feelings with the lens of anti-Black womanism. Anti-Black womanism is pervasive. Even for me, as an emerging scholar who is well skilled in theory, I witnessed how I was complicit to the perceptions that other people had of me. While reading my dissertation, I hope it gives you, the reader, the insight that I experienced while talking to the participants and hearing the words that slid out my mouth about Black women professionals in enrollment management. 


\section{CONTENTS}

Page

ACKNOWLEDGMENTS

i

PREFACE

iii

CONTENTS

vi

TABLES

xi

CHAPTER I: INTRODUCTION

Situating Myself in the Literature

3

Purpose of the Study

Statement of the Problem

Research Questions

Background

The More Things Change, the More They Stay the Same: Analyzing Legislation Regarding Higher Education

Theoretical Framework

Invisibilizing Blackness in CRT

Theorizing Blackness

Blackness as A Socio-Political and Cultural Phenomenon

Markings Of Activism Defined By Theories 
Crossing Boundaries and Bridging Concepts: BlackCrit and Womanism Is

$\begin{array}{ll}\text { Anti-Black Womanism } & 24\end{array}$

Significance of the Study 25

$\begin{array}{ll}\text { Definition of Terms } & 27\end{array}$

CHAPTER II: INNERWORKINGS OF INSTITUTIONALIZING THE ACADEMY 29

The Forced Beginnings: How Black People and Higher Education Converged 29

The Bodies That Built American Higher Education Institutions 30

Anti-Blackness Amid the Separation of Church and Education 31

Institutionalizing an Anti-Black Academy Structure 33

Education Accessibility Evolving by its Bootstraps and Neoliberal Regimes 35

The Year 1965

Black Education Owed Meritocratic Payments. 39

$\begin{array}{ll}\text { Neoliberalist Ideology } & 39\end{array}$

$\begin{array}{ll}\text { Free Markets } & 40\end{array}$

$\begin{array}{ll}\text { Summary } & 42\end{array}$

CHAPTER III: BLACK WOMEN'S UNDYING PRESENCE 43

The Herstory of Our Ancestors: “Ain’t I a Woman?” 43

Black Femalized Embodiment 48

Saartjie Baartman Objectified. $\quad 48$

Hotttentot Venus-Jezebel trope $\quad 52$

Implications of Black Women in Education 53 
Black Women and HWIs $\quad 55$

Breaking Down White Words for Black Realism 56

Miseducation of Underrepresentation $\quad 56$

$\begin{array}{ll}\text { Password to Discrimination } & 58\end{array}$

$\begin{array}{ll}\text { Concepts Conformed by Objectification } & 58\end{array}$

$\begin{array}{ll}\text { Invisibilized Notions } & 58\end{array}$

$\begin{array}{ll}\text { Summary } & 61\end{array}$

CHAPTER IV: RESEARCH METHODOLOGY 62

$\begin{array}{ll}\text { Overview } & 62\end{array}$

Significance of the Study $\quad 63$

$\begin{array}{ll}\text { Research Questions } & 64\end{array}$

$\begin{array}{ll}\text { Methodology } & 64\end{array}$

$\begin{array}{ll}\text { Narrative Inquiry } & 65\end{array}$

Researcher's Position to the Research and Reflexivity 66

$\begin{array}{ll}\text { Participant Recruitment and Selection } & 67\end{array}$

$\begin{array}{ll}\text { Data Analysis } & 70\end{array}$

$\begin{array}{ll}\text { Preliminary Coding } & 70\end{array}$

$\begin{array}{ll}\text { In Vivo Coding } & 70\end{array}$

$\begin{array}{ll}\text { Emotion Coding } & 71\end{array}$

$\begin{array}{ll}\text { Pattern Coding } & 71\end{array}$

$\begin{array}{ll}\text { Thematic Analysis } & 71\end{array}$ 
Trustworthiness

Consideration of Ethical Issues and Reciprocity

Summary

CHAPTER V: FINDINGS AND ANALYSIS

Research Problem and Questions

Data Collection

Participant Profiles

Findings from Research Questions

$\begin{array}{ll}\text { The Road Less Taken } & 81\end{array}$

$\begin{array}{lr}\text { Birthright Outside Boundaries } & 87\end{array}$

$\begin{array}{ll}\text { To Be Seen } & 93\end{array}$

$\begin{array}{ll}\text { Plays of Perception } & 98\end{array}$

$\begin{array}{ll}\text { The Circle in the Square } & 102\end{array}$

$\begin{array}{ll}\text { Emerging Themes } & 105\end{array}$

Theme 1: A Credit to the Race and Levels of Awareness 106

Theme 2: Under Her Wing and Institutional Mammying 110

Theme 3: Institutional Gatekeeping and Moving the Needle 114

Theme 4: Black Girls Must Die Exhausted and Space Negotiations 118

CHAPTER VI: FINDINGS AND RECOMMENDATIONS 122

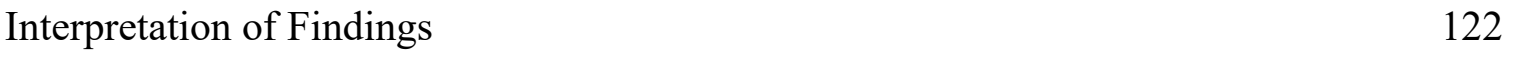

A Credit to the Race and Levels of Awareness 122 


\section{TABLES}

Table $\quad$ Page

1. Participant Demographic Data 69 


\section{CHAPTER I: INTRODUCTION}

In the wake of racial unrest, American institutions and companies have shifted to diversify their hiring strategies (Kaufman, 2020; Stevens, 2020). The sentiments follow true in institutions of higher education including the historically white institutions (HWIs). Institution administrators are publicizing their efforts to diversify their campuses through student class, faculty, and staff positions (Milem et al., 2015; A. Smith, 2018). Hiring efforts include a specific interest in the recruitment and retention of Black women, a group that is disproportionately underrepresented more than any other race and gender (Cobbs-Roberts \& Agosto, 2011; McChensney, 2018; Mosley, 1980). Discrimination, sexism, underrepresentation, invisibilization, tokenism, and pay equity are issues that Black women historically experience, and these issues were all readdressed during the time of heighten tensions in our nation (Gardner, Barrett, \& Pearson, 2014; Mosley, 1980; Steele, 2018). HWI administrators believe that hiring Black women will help mediate racial climates on campus. Yet, Black women still indicate they face similar discrimination and racism just as their predecessors and other Black women before them: proving that adding more Black women does not fix the problem. Facetiously, Black women and other people of color are often not included in the conversation to improve racial relations on campus (L. Burke, 2020; Jackson \& Rajai, 2021) but are expected to show up every day.

One particular group of people who are expected to show up every day consists of Black women enrollment professionals at HWIs. Black women enrollment management professionals have a dichotomous relationship with the institution (Giddings, 1984), as they are expected to work through issues of discrimination, sexism, and underrepresentation while working to recruit and retain all students on campus, including the special interests of students of color. The racism 
and sexism that Black women experience are socially mitigated through diversity and inclusion language such as underrepresentation, imposter syndrome, tokenism, pay equity, and discrimination (Nader, 1993). These terms do legitimize issues that Black women experience; however, they deflect attention from the underlying issues that perpetuate Black women's experience of racism and sexism in enrollment management roles in higher education (Dei, 2017; Dumas \& Ross, 2016; Nader, 1993). Flathery (2021) and Turnbull (2014) concur that diversity work is an illusion of inclusion because diversity work appears to serve the interest of white campus partners rather than for people of color. Nevertheless, HWI administrators call attention to Black women's experiences with data reports and soundbites intending to romanticize the resilience and archetype identities of Black womanhood as they endure racism and sexism (Bih, 2020).

The creation of HWIs centered on elite, white men's advancement and networking (Thelin, 2011). Since its creation, the system has not changed. Administrators at HWIs often disregard their institutions' historical background, and subsequently, they deny the implications of the institution's history for Black women. Administrators choose to continue to uphold a culture that perpetuates racism and sexism (Ferguson, 2017; Wilder, 2013).

Enrollment management is a heavily neoliberal, bureaucratic niche of administrative positions that exists at any higher education institution. The division of enrollment management is sometimes overlooked, although it is central to the operation of the institution (Huddleston, 2000). This division establishes markers for how each new student class by demographics, ethnicity, academic readiness, and gender. The administrative bureaucracy of enrollment management is significant and influential in how it affects the institutional and structural that impede students' success. Black women who are enrollment management professionals are 
expected to represent the institution's identity while they recruit and help retain all students; however, they find themselves consistently immersed in a culture which, in many ways, is contrary to that of Black women; yet they are expected to succeed as professionals.

\section{Situating Myself in the Literature}

Students often ask me what made me pick higher education as a profession. I told one student that I find purpose in providing access through the enrollment management process. To me, my profession and position in higher education are more than just a job; it has become a part of my purpose to ensure, within my capacity, that students that look just like me have the opportunity to attend college. Days after speaking with this student, I pondered the ways I am similar to my foremothers and what their work has done to create access for me. I reflected on how at times my role feels self-sacrificial as I advocate for the recruitment, retention, and graduation of Black students and other students of color.

My reflection led me to think about the beginning of my career. I began graduate school and needed money for tuition and to supply my daily needs. I applied for a few positions and landed a graduate assistantship in a financial aid office. My graduate assistantship was hard work but rewarding at times because of the student interactions I encountered. The small emotional rewards I received helped me decide to make this path a part of my professional journey. But this has not come without a cost, and I have become a selfless professional. I realized that I put my work before myself; it was my source of income and my financial security to pay for tuition. The way I prioritized my work back then has followed me throughout my career. It was not until recently, that I realized that selflessness is self-deprivation if I allowed the institution to run me dry. 
I say that I find myself similar to my foremothers because, like them, I value education. Contrary to societal belief, Black people, especially Black women, have always found value in education. Education has been and will always be considered a tool of liberation and social transformation. I learned that obtaining an education is something that could never be taken away from me.

Like my foremothers, I have experienced higher education spaces where I was "the only one" facing racial and gender underrepresentation in the workspace and the classroom. And at times, I experienced hostile environments and unrealistic and demanding expectations to perform. I found myself frequently asking rhetorical questions such as, "Am I wrong for thinking (or feeling) this way?" or "Now tell me, am I the crazy one here?" while talking to a confidant about an occurrence at work. The professional slights I experienced often made me question if I were hypersensitive —again asking colleagues, “Am I crazy?” This type of questioning comes from deeply embedded, anti-Black womanism.

More than a job, I began working in higher education to provide a better experience for people who looked like me. Throughout my academic journey, I was not educated about loans and interest rates and the implications of borrowing money. I did not understand why I was advised to enroll in 12 credit hours when my white roommates were enrolled in 15 credit hours. I learned to advocate for myself through trial and error and I did not want to keep my acquired knowledge on navigating HWIs to myself. If I continued to take 12 credit hours each semester, I would not have graduated in 4 years, which is advertised to students. I would have needed 5 years to graduate because of the 120-credit hour requirement rather than the 4 years.

My experiences as a student and as a professional have expanded my perspective and understanding about the inner workings of the institution. The various experiences and 
observations led me to pursue a doctoral degree and inspired my dissertation topic. The experiences rewarded me with the necessary skills and insight to navigate the enrollment management space in the HWI. Black women professionals in enrollment management, which includes me, use these spaces to become daily advocates for students. It is important to understand the role that Black women fulfill in enrollment management positions to understand further how the institution works and how anti-Black womanism is manifested.

As tiring as it was at times, I knew that as a full-time professional, I had to keep showing up for Black students. I went to almost every single event for Black students or students of color. But that did not stop me from expressing how I felt exploited or tokenized. It is also tiring to be the person responsible to tell Black students why they cannot financially afford to go to college or that they missed deadlines for free money. Black women like me bear the burden of working on behalf of students while experiencing not being trusted, undervalued, overworked, overlooked, and muted. Consider this. I am the first person in my state to receive all 17 national credentials in my field, yet my ability to make a decision on content is questioned.

Before my doctoral journey, I did not have the language to articulate what I was experiencing. I used my intuition to seek out what I felt was not right and made me feel uncomfortable. Clearly, I was not comfortable when meeting with parents about their student and I get asked how old I am. I was unsettled by families asking me about my hair while informing them about their official aid offers. I was also unsettled and offended at event fairs when families chose to wait for my white supervisor rather than talk to me because they presumed that I could not provide the correct answer. Although I must admit, I felt vindicated when my supervisor needed me to help the family that insisted on waiting.

While employed at an institution that I thought I loved, my intuition inclined me to 
research salaries in my department. I remembered countering back and forth on my starting pay prior to accepting the position. I thought I settled on a fair rate. However, once I researched the pay scale, I discovered the inequity between my pay and my counterparts. My discovery left me angry and insulted especially since I had to negotiate my starting pay. I left the institution. All of my experiences are embedded in my story of anti-Blackness in enrollment management at an HWI. I also acknowledge that this experience I just shared is the epitome of anti-Black womanism.

\section{Purpose of the Study}

The purpose of this study was to explore how Black women enrollment management professionals navigate the manifestation of anti-Blackness perceptions at HWIs. To accomplish this, I introduced the theoretical frame anti-Black womanism as a means to interpret the process that Black women experience daily. In this study, enrollment management professionals include mid-level and higher organizational ranking administrators and full-time administrative staff members. Traditionally, enrollment management as an institutional unit includes financial aid and admissions departments and the registrar's offices (Huddleston, 2000).

Research found that Black women who work at HWIs indicate that their experiences include racist and sexist concepts, underrepresentation, and tokenism; they also reported that they are overworked and underpaid (Lloyd-Jones 2009; Mays, 2013; Munden, 2015; Sobers, 2014; Wright, Taylor, Burrell, \& Stewart, 2006). However, research has not focused specifically on enrollment management professionals nor used the lens of anti-Black womanism. Also, existing research does not discuss anti-Blackness, nor acknowledge that anti-Blackness reinforces hemogenic, white, colonial structures of power in enrollment management (Dancy \& Edwards, 2021; Dumas, 2016). My study is layered and complex in that it addresses the 
relationship of Black women, systemic and institutional barriers of racism, and anti-Black perception in higher education in HWIs.

\section{Statement of the Problem}

Black women enrollment management professionals' work experiences center on dialectical standpoints of resistance and repression (Ferguson, 2017; Giddings, 1984)). HWIs perpetuate the interlocking systems of oppression of anti-Black racism and sexism to uphold whiteness through institutional practices, culture, and campus environment. Black women who work in enrollment management jobs are hired and expected to fulfill anti-Black tropes of Black womanhood. The anti-Black perception biases of Black womanhood and professionalism marginalizes Black women's careers (Harris-Perry, 2011; Rodney, 2020). Perception biases are formed from social cognition cues of the world around us. These biases have created ideals or prototypes of what Black women can and are willing to take and accept as professionals. Amidst the adversities that Black women face in their enrollment management administrative roles in higher education, they are expected to advocate for students and the campus community to maintain the institution. Sexism and anti-Black racism are socially mitigated through concepts such as microaggressions, discrimination, implicit bias, and underrepresentation to downplay the reality of how oppressive HWIs are for Black women. The dichotomous work-lives that Black women lead have placed them in the median of two roads where they are forced to evaluate how they experience anti-Black racism and sexism.

\section{Research Questions}

The following research questions I used to conduct the study:

1. In what ways do Black women navigate their administrative roles in enrollment management at HWIs? 
2. How does anti-Blackness manifest in enrollment management positions for Black women?

3. How do anti-Black womanist perceptions affect workload and performance?

4. What are the self-perceptions of Black women who work in enrollment management?

5. What strategies, knowledge, and skills do Black women employ to do their jobs in enrollment management at HWIs?

\section{Background}

The purpose of this section is to provide insight and contextualize enrollment management at HWIs. To begin this discussion, it is important to define enrollment management. Researchers (Duniway, 2012; Huddleston, 2000) claim that enrollment management is the central administration for the student operations of the institution. According to Duniway (2012), "The work of enrollment management is central to the operation of any college or university" ( $p$. 25), and Huddleston (2000) state that enrollment management is the gateway to the university. A higher education institution is metaphorically similar to a bike wheel. In the epicenter of the bike is the hub; the hub is enrollment management and its purpose is to keep the spokes and the frame of the wheel together. The hub of enrollment management connects to the spokes of the institution. The spokes are comparable to departments such as student affairs, athletics, housing, and academic affairs that are vital to provide a well-rounded college experience for students (Thelin, 2014). The hub might seem inconsequential, but without it, the wheel falls apart. The same sentiment applies to enrollment management at higher education institutions where enrollment management is integral for the life of an institution.

Traditionally, the core offices that comprise enrollment management are admissions, financial aid, and the registrar (Duniway, 2012). Each office has responsibility for the 
recruitment and retention of students. The recruitment and matriculation of students is the main focus of these offices, but these offices are also essential to retaining students. McDonough and Robertson (2012) claim that enrollment management professionals have moved from gatekeepers to marketers. Their critique of enrollment management discusses the shift that occurred in the institution's responsibility: from disregarding students they deem less desirable to attracting those students deemed college ready.

Research in the field consists of two conversations; the first conversation defines what enrollment management is from a historical standpoint and the second conversation discusses how enrollment management has evolved over time (Coomes, 2000; Crouteau \& Maginnis, 2005; Duniway, 2012; Hossler \& Bontrager, 2015; Huddeston, 2000). Both conversations focus on the concept of gatekeeping as an admissions and enrollment management practice (Coomes, 2000; Crouteau \& Maginnis, 2005; Duniway, 2012; Hossler \& Bontrager, 2015; Huddeston, 2000; McDonough \& Robertson, 2012).

The evolution of enrollment management and the birth of enrollment management dates back to the early 1970s (Schultz \& Lucido, 2011a). Gatekeepers for higher education existed long before titles were associated with the role. Gatekeeping is a repressive tactic that institutions use in enrollment management to control who attends the institution. Gatekeeping is synonymous with the bouncer at the door of a nightclub and fit is used to determine who is allowed to attend the institution as a student. What is different from the night club and higher education is who is at the door. Typically, a big muscular man is at the entrance of the club, but at the entrance of many institutions are strong Black women. Historically, gatekeepers sought out students and relied heavily on the economic status of the students' family and their ability to share intellectual thought (Kendi, 2020; Thelin, 2014; Wilder, 2013). 
American higher education institutions date back to the mid-17th century (Thelin, 2011). Originally, enrollment for new students consisted of an informal process to determine if the selected wealthy, young, white men could share religious, philosophical, and philanthropic conversations about the country. Goldin and Katz (1999) conclude that the formative years for higher education occurred between 1890 and 1940. The colonial era, specifically the colonial revival, focused on enlightenment. Elite American higher educational institutions-Yale, Harvard, and the College of William and Mary—were considered as places of thought and order. Within this 50-year span, two monumental acts of legislation was passed and created more access for students.

Before the 1940s, higher education was the epitome of the old boys' club - a place that only made room for young, wealthy, white men. Professors would actively seek young white men who believed they would be able to share intellectual and philosophical thoughts. By the 1970s, administrators of private institutions created the role of dean of admissions who was assigned to handle the enrollment of students. This process shaped the demographics of the institution. Over time, public institutions and community colleges followed the trend and created their own admissions processes (Huddleston, 2000).

Duniway (2012) shares that enrollment management consists of functions such as recruitment, retention, and the completion and graduation of students. Coomes (2000) notes, In a 1984 book, Hossler suggested that enrollment management incorporates the following activities: (a) student marketing and recruitment; (b) pricing and financial aid; (c) academic and career counseling; (d) academic assistance programs; (e) institutional research; (f) orientation; (g) retention programs; and (h) student services. (p. 13) To provide a practical context, traditional offices in enrollment management are admissions, 
financial aid, and the registrar. Some institutions might include their billing offices (student accounts or bursar's office) under the enrollment management division. The responsibilities that comprise enrollment management not only shape the image of the student population but also control the institution administratively in a fashion that is incomparable to any other experience with other units across campus.

\section{The More Things Change, the More They Stay the Same: Analyzing Legislation Regarding Higher Education}

Two transforming acts of legislation changed student access to higher education: The Morrill Acts of 1862 and 1890 (Coomes, 2000; Haynes, 2006; Thelin, 2011). The first Morrill Act, also known as the Land Grant Act, expanded higher education institutions-from places focused on scholarly thought and discussion to include schools of professions and career vocations. The Morrill Act of 1862 allowed white men of lower economic status to attend college. The Morrill Act of 1890 created what we now know as historically Black colleges and universities (HBCUs) for Black people to attend college. State governments were promised land and financial allocations if the land was used to build higher education institutions. State and higher educational institution administrators alike were interested in land acquisition and the financial gains helped to expand higher education and create access for a broader population (Coomes, 2000). The growth of higher education institutions created a need for structure. In addition, HWIs did not want to integrate institutions with Black students (Haynes, 2006). Because of racist segregation ideologies, institutions' boards built structures with bureaucracies that controlled who could attend which institution and maintain white supremacy.

The first federal student grant was a part of the G.I. Bill of 1944. The G.I. Bill offered financial resources to students, specifically American veterans coming back from war, to attend 
institutions. During this time, the institutions opened financial aid offices to manage the paperwork. The Higher Education Act of 1965 is another prominent piece of educational legislation. It completely changed higher education and essentially made college more accessible to more students, particularly military personnel, who were returning home from fighting World War II (Schultz \& Lucido, 2011b). Before World War II, higher education was highly selective and only attainable to the sons of the wealthy (Coomes, 2000). Enrollment management, preWorld War II, did not exist in the structured form known today because higher education was not available for the masses. The Higher Education Act of 1965 is the legislation that formed enrollment management into a bureaucratic structure. Bureaucracy, a product of neoliberalism, demanded that administration be the nucleus of the university (Ferguson, 2017; Giroux, 2015).

The bureaucratic nature of these administrative offices are hidden in plain sight. Ferguson (2017) argues that the expansion of administration functions was two-fold, as "it was an expansion of both ideological and repressive systems" (p. 24). The expansion of enrollment management synchronously expanded when higher education became more accessible to Black and Brown students. Philanthropists, government leaders, and higher education-institution leaders were savvy enough to control who went to what type of institution. After the Higher Education Act of 1965, higher education institutions formed alternative institutions such as junior colleges and community colleges (Thelin, 2011). Community colleges were created to redirect the increase of students who were not deemed college-ready. Community college students were encouraged to enroll in programs that focused on trade so they could acquire skills to join or rejoin the workforce. However, desirable Black and Brown students were spotlighted for their exceptional academics and admitted to prestigious institutions. 
While the Morrill Act of 1890 made higher education more accessible to Black students (Muthusamy, n.d.; Thelin, 2011, 2014), the Higher Education Act of 1965 provided financial aid to students from low-income backgrounds and veterans rather than to the institution so they could enroll in higher education institutions (Watkins, 2001). As federal policy and legislation shifted to create access to higher education for people of middle- and low-income status, including women, structure for the admission into higher education institutions became an essential function. Scholarships existed before the Higher Education Act 1965 but grant monies did not. Historically, and even today, many scholarships include some merit-based components. However, grant monies are funded by the federal government and are presented as entitlement programs for veterans, students from low-income backgrounds, and Black and Brown students. The introduction of the Pell grant created a sense of competition between institutions since they had to attract students from low-income families to receive federal subsidies. Access to federal grants allowed students to choose where they wanted to attend school (Coomes, 2000). While school choice provided students the opportunity to shop around, it became necessary for institutions to expand administrative functions. Federal financial aid funding programs began the commodification of Black and Brown students in higher education; the federal subsidies provided access to students and simultaneously created a revenue source for higher education institutions. The body count of Black and Brown students are monetized, and the institution's efforts to cash out are manifested through efforts to diversify the campus body (Wilder, 2013). In the 1960s, Black students demanded to see professionals and faculty members on campus who looked like them (Farmer, 2017; Ferguson, 2017; Rodgers, 2012). In turn, there was a rise of Black professionals who worked in higher education, but they were frontline workers such as secretaries, administrative assistants, and the advisors or counselors. 
The commodification of Black professionals and faculty mirrors the guiding philosophy used for Black students; higher education personnel want to recruit only the best and brightest. As institutions have become entrenched in neoliberalism, commodifying Black students, faculty, and professionals became automated. Neoliberalism did not only birth academic capitalism (Levidow, 2005) but created a transactional culture, wherein students were viewed as material whose value was measured by the institution (Giroux, 2005).

As higher education became more accessible, the matrix of domination and oppression materialized (Ferguson, 2017). The division of enrollment management took on two roles: expanding enrollment of the college-ready applicants and repressing enrollment for those less desirable for the university setting. Until the Morrill Act of 1962, there was one person at the institution who recruited students by networking. Today, enrolling a student into a higher education institution takes bureaucratic machines designed to recruit and retain.

\section{Theoretical Framework}

The theory of anti-Black womanism was applied to analyze this study. Anti-Black womanism dually integrates Black critical theory (BlackCrit) and Womanism. Individually, neither BlackCrit nor womanism can convey fully the phenomenon of what Black women experience while working in enrollment management at HWIs. Anti-Black womanism focuses on the nuances of both theories collectively.

\section{Invisibilizing Blackness in CRT}

In the 1970s, legal scholars theorized CRT with basic tenets to engage activists and scholars alike in studying and transforming the relationship among race, racism, and power (Delgado \& Stefancic, 2012). The emergence of CRT began right after the civil rights movement and was created to provide different strategies to combat racism (Bell, 1995a/1995b; Freeman, 
1995). There are five basic tenets of CRT: (a) racism is ordinary, (b) interest convergence, (c) race is a social construct, (d) use of counterstories, (e) whiteness as property (Delgado \& Stafancic, 2012). CRT has provided context for how we look at racial issues within systems of oppression to allow for change of course; how to respond, discuss, and combat issues around race. As awareness of CRT expanded, other historically marginalized people incorporated it in their historical stories and counternarratives. What Derrick Bell (1995a/1995b) and Alan Freeman (1995) initially conceptualized as the experiences of Black people with the legal system are now conflated and out of touch with its intended purpose, which acknowledge the experience of Black people.

\section{Theorizing Blackness}

Dumas' (2016) critique of CRT suggested that it does not make visible the specificities of the Black experience. Furthermore, CRT has moved away from race and is addressing antiBlackness. Dumas claims that BlackCrit is necessary to address the Black experience of structural and cultural racisms. "BlackCrit helps us to explain precisely how Black bodies become marginalized, disregarded, and disdained, even in their highly visible place within celebratory discourses on race and diversity" (p. 417). Although the founding principles of BlackCrit are evolving, the theory is based on the following foundational ideas:

1. Anti-Blackness is endemic to, and is central to, how all of us make sense of the social, economic, historical, and cultural dimensions of human life.

2. Blackness exists in tension with the neoliberalism-multicultural imagination.

3. BlackCrit should create space for Black liberatory fantasy and resist a revisionist history that supports white racial dominance. 
BlackCrit is used as a means to address anti-Blackness explicitly and how it "informs and facilitates racist ideology and institutional practice”' (p. 417). Dumas (2016) states, “AntiBlackness is not simply racism against Black people. Rather, anti-Blackness refers to a broader antagonistic relationship between Blackness and (the possibility of) humanity" (p. 429). Beyond the racialization of Black people, anti-Blackness dehumanizes and objectifies Black bodies (Ross, 2021). Anti-Blackness attacks the humanity of Black people and demeans their lives by questioning their physical, social, and cognitive abilities, while demanding civility through perpetuating white standards and whiteness. Carruthers (2018) defined anti-Blackness as "a system of beliefs and practices that destroy, erode, and dictate the humanity of Black people" ( $p$. 8).

The second guiding idea of BlackCrit acknowledges that Blackness is disregarded in the neoliberal-multicultural agenda of assimilation. Blackness is essential. Dumas (2016) argues that Blackness is epistemic and should not be conformed to a multicultural identity. Dei (2017) theorizes Blackness using anti-colonizing and decolonizing lenses. He suggests the following:

Understand that our social identities are not always defined in relation to others; but also, upon the recognition and affirmation of self- and collective-shared histories, and as an exercise of intellectual agency of the marginalized to know and define ourselves and our communities (p. 34).

The third guiding idea of BlackCrit is a call to action the requires one to dismiss and resist Westernized recalls of history of Black people. Revisionist history promotes white dominance and Black subserviency. Dei urges Black people to have Black racial and cultural pride because, "to be Black is to understand one's racial existence as a socio-political and historical condition" (p. 67). 


\section{Blackness as A Socio-Political and Cultural Phenomenon}

Dei (2017) identifies 10 theorizing principles of Blackness. The purpose of the principles is to counter anti-Blackness and anti-Black discourse with goals to advance a shared Black identity. The principles are as follows:

1. Acknowledge the coloniality of white power and whiteness in advancing knowledge about the existence of different races.

2. Acknowledge the problematic discourses of biology, specifically the sub-human justification to enslave Black people.

3. Call for critical reading of embodiment.

4. State advancing a theory of Blackness as intellectual and political counterpoints to antiBlackness must work with both the idea of race as identity as the beginning [not the end] of politics, as well as the urgency consciously to challenge and subvert the construction of Black/African identity within Euro-American hegemony (Dei, 2017, p. 72).

5. Frame an intellectual and political project for affirming Blackness in the context of complexities of identities. The principle acknowledges that anti-Blackness is a strategic practice/political (Dei, 2017, p. 75)

6. The ideas of hybridity and in-betweenness as liminal spaces are constructed as significant within particular historical and colonial contexts.

7. Speaking about Blackness and anti-Blackness addresses how social existence is essentially about asymmetrical power relations among groups.

8. Assert that speaking about Blackness and anti-Blackness on settled/stolen Lands is also about colonial-settler oppression politics. 
9. Have a global/transnational understanding of Blackness, reinventing an Africanness in diasporic contexts and ways in which the politics of diaspora inform community building and solidarities (Dei, 2017, p. 76).

10. Be read and understood in the prism of collective anti-colonial resistance.

The ten principles are based from a historical context, first by acknowledging the effects of the settler-colonial complex and the long-lasting implications that colonialism has globally. The social construction of anti-Blackness is political, intellectual and social. Anti-Blackness survives from the tension of power and desires of white dominance through race. Anti-Blackness provided reason to enslave Black people through biological and scientific violence, deeming Black people as subhuman (Washington, 2006). Dei (2017) declares the only way to combat anti-Blackness is through embracing Blackness. The celebration of Blackness is used as a form of resistance. Because Black bodies are politicized as much as objectified and dehumanized, Dei makes the call to action to embrace Blackness. For example, Angela Davis and her infamous afro provides an example of intentional resistance. "Representation and images of Blackness and Black people are important to critique because they define not only how we are seen but also how we see ourselves, since we can internalize negative images" (Dei, 2017, p. 35). More than a form of resistance, embracing Blackness reminds Black people to love their image of themselves without needing the approval of white hegemonists. Dei's ten principles demonstrate how important it is for Black people to understand the constructs of anti-Blackness so they can authentically embrace their Blackness.

\section{Markings of Activism Defined by Theories}

Black women advocating for themselves have a complicated history in America. Black women are political agents (Berry \& Gross, 2020; Cooper, 2018; A. Davis, 1981; Harris-Perry, 
2012; Taylor, 2017) and acknowledge that the identity of being a Black woman has interlocking oppressions (Crenshaw, 1989; C. Davis, 2018; Taylor, 2017). Inherently, the activism that Black women practice against anti-Blackness and sexism goes beyond gender and race. Although early efforts of activism were perceived as binary choices, Black women had to choose to advocate for either being a woman or being Black (Cooper, 2018). However, Black women continue to persist and advocate for both, even when one oppressed group would benefit more than another (A. Davis, 1981). In the wake of women's suffrage and feminism, Black women situated themselves alongside white feminists to mobilize advocacy for all women's rights (A. Davis,1981; Kendi, 2016).

Sojourner Truth, abolitionist and women's rights activist, is one of the first Black women that positioned herself to be in spaces to fight and defend women's rights relentlessly (Berry \& Gross, 2020; A. Davis, 1981; Kendi, 2016). Once white feminists such as Elizabeth Cady Stanton became aware that Sojourner's mission included the liberation of Black people, there was a quick shift in what was identified as feminism within the Black community and who truly benefited from the efforts of white women's rights (Berry \& Gross, 2020; A. Davis, 1981;

Kendi, 2016). The early beginnings of theorizing Black feminism began when activist Sojourner Truth recognized the racism of the women's suffrage movement superseded efforts of equality (A. Davis, 1981; Kendi, 2016). Over time, Black women continued to advocate for their rights. Similar to the advocacy for Black freedom and liberation, although Black men were subjected to racism, they still historically held a level of privilege through patriarchy and gender (Crenshaw, 1989; A. Davis, 1981; Harris-Perry, 2012). Black male patriarchy has not and does not authentically support the advancement of Black women (A. Davis, 1981). Feminist scholar Ida 
B. Wells criticized white female leaders of the suffrage movement for their anti-Black initiatives and lack of support for the Black community (A. Davis, 1981).

C. Davis (2018) argues that it is a critically conscious process for Black women to grow into their activism. Activism for some Black women is academic discourse. During the late 1980s and early 1990s, more Black women theorized (e.g. Black feminism (Combahee River Collection, 2017), Black feminist thought (Collins, 1989), and intersectionality (Crenshaw, 1989)), their experiences and the experiences of other Black women. The conversation that all Black feminists contributed to our world of knowledge has had a great impact and provides a guide as to how to address past and present issues that Black women experience as the people we are right now. However, Black feminism and all of Black feminism's adjacent frames leaves out a few important aspects of Black women's lives that are not to be forgotten.

Scholars such as Kimberle Crenshaw (1989), Patricia Hill Collins (1989), the Combahee River Collective (2017) group, and others have made significant contributions to building conceptualizations of Black women with the praxis of gender and race. Crenshaw (1989) introduced intersectionality, in which she theorizes Black women are consistently at the crossroads of oppression that intersect because of both of their marginalized identities: being Black and being a woman. Intersectionality is a viable option to use with the theoretical framework for this study; however, I would be eliminating critical insight from personal anecdotes about how Black women navigate their lives and their careers. For the purpose of my study, intersectionality has the potential to conflate and relinquish the voices of Black women simultaneously as they share their stories to prioritize the critique of institutional structures. Another viable option for the theoretical framework of my study would be Black feminist thought (BFT) by Patricia Hill Collins. Collins's work is a reiteration of Black feminism, which 
centers the experiences of Black women and values Black women's self-defined knowledge and standpoints (Collins, 1989). While BFT is an option, BFT has the potential to conflate the experiences of Black women in enrollment management in relation to whiteness rather than center their experiences regardless of what their relation is to whiteness. Also, BFT has the goal to form generalizable statements about Black women; Collins (1989) stated that BFT must be legitimate and credible within the academy. My research does not seek credibility from the institution, as it challenges the institution.

\section{Womanism}

Womanism is a term that is borrowed from the African American colloquium, womanish, which specifically addresses how Black mothers would remind their daughters when their feathers were bolstered in the wrong places (D. Smith, Caruthers, \& Fowler, 2019; D. Smith, 1996). Womanish is a way for Black girls to navigate a world that hates them. Black mothers teetered the fine line of showing their daughters the reality of the world without stripping them of all of their child-like innocence (D. Smith et al., 2019). Womanism was first defined by Alice Walker (1983) in her literary piece, "In Search of our Mothers' Gardens: Womanist Prose”; however, evidence exists that the frame existed before Walker's work, even though it did not have a name (Collins, 1996; Phillips, 2006). Womanism is a social theoretical framework that values and centers the everyday experiences of Black women as they make sure of their world. Womanism is a social change perspective rooted in Black women's and other women of color's everyday experiences and everyday methods of problem solving in everyday spaces, extended to the problem of ending all forms of oppression for all people, restoring the balance between people and the environment/nature, and reconciling human life with the spiritual dimension. (Phillips, 2006, p. xx) 
Womanist theorists oppose matrices of domination such as race, gender, and class as well as all forms of oppression that dehumanize and marginalize people (Beauboefu-Lafontant, 2007). According to Phillips (2006), "Womanism does not emphasize or privilege gender or sexism, rather, it elevates all sites and forms of oppression, whether they are based on social-address categories like gender, race, or class, to a level of equal concern and action" (p. xx). Because womanism intersects beyond racism and sexism, its theorists acknowledge all the ways that Black womanhood is marginalized. Womanists do not ignore systems and institutions of oppression; rather, their efforts and energies focus on how to navigate systems of oppression rather than live according to white standards.

Womanism is a theoretical frame that centers Black women as human; womanism dismisses the idea of Black woman monolithism. Further, womanism does not affirm that the liberty of Black women is at the expense of another marginalized group's oppression. "A womanist is triply concerned with herself, other Black women, and the entire Black race, female and male — arc of political concern, empathy and activism" (Phillips, 2006, p. xxii). Just like many of the Black women who work in enrollment management at HWIs, the passion to see students succeed crosses color lines. Phillips (2006) describes five overarching characteristics of womanism:

1. Antioppressionist-womanism acknowledges the class, race, gender, and matrix of domination and also acknowledges other forms of oppression which may or may not have labels and identities.

2. Vernacular situates womanism in everyday experiences for everyone. A womanist is more likely to be in the trenches or a part of grassroot efforts to fight oppression. Womanism is 
removed from elitism, which includes the academy. Womanism lives on the premise that we are human and is an epistemology of the masses.

3. Nonideological-womanism, unlike feminism, does not disregard personal beliefs to align perfectly with womanist tenets; womanism is inclusive and relies on building positive interrelationships.

4. Communitarian-womanism has a common goal for the masses and centers itself in community of others and the benefit of all. "Womanism views commonweal as the goal of social change" (Phillips, p. xxv).

5. Spiritualized-womanism has a metaphysical component, and womanist are in tune with their spiritual well-being. There is spiritual conviction that gives hope for a better life. Womanism takes account of Black womanhood and the holistic beings who are Black women. More than acknowledging systems of oppression and how they marginalize Black women, womanism allows for receptiveness of how Black women navigate the world even when their resistance aligns with whiteness. Often, womanism is conflated with Black feminism and many believe that womanism and Black feminism are one-in-the-same; however, they are not (Collins, 1996; Phillips, 2006). Though, one can say that they are sisters, the premise of the conceptualized frame of both are different, even though both have the same goal. Higher education has appropriated Black feminism and adjacent theories, while womanism is not traditionally used in academic spaces. Unlike Black feminism, womanism intentionally moves away from structures and institutions of power that perpetuate oppression and focuses on relationships to create change in the world: All forms of oppression are denounced (Phillips, 2006). Womanism is also centered and made for Black women and does not have room to be gentrified or appropriated. 


\section{Crossing Boundaries and Bridging Concepts: BlackCrit and Womanism Is Anti-Black}

\section{Womanism}

While BlackCrit does not exclude Black women from its discourse, I argue it is imperative to acknowledge Black women's everyday experience. Black girlhood and womanhood are traditionally disregarded and their experiences co-opted by interlocking oppressions of anti-Black racism and sexism. Discussions of women, typically center white women, while conversations about race and Blackness center men. Therefore, I will share the importance of incorporating womanism to the framework of this study. The goal of the study is to center Black women's experience using a dual lens of Anti-Blackness and womanism since I argue "anti-Blackness and anti-Black racism are intertwined” (Dei, 2017, p. 67).

I use anti-Black womanism as the theoretical frame for this study because it allows space for Black women enrollment management professionals to share their everyday stories. Their stories contextualize the navigation that Black women must experience while working at HWIs. Anti-Black womanism acknowledges the systems of oppression and matrices of domination that are embedded in HWIs, without judging Black women for what their survival and resistance looks like, regardless if it aligns with whiteness.

I theorize that anti-Black womanism is institutional or systemic practices of oppressive ideologies that exploit, objectify, silence, and dehumanize Black women. Researchers suggest seven basic principles of anti-Black womanism exist (Carruthers, 2018; Dei, 2017; Dumas \& Ross, 2016; Hull \& Smith, 2015; Phillips, 1996; Weinbaum, 2019; White, 1999).

1. Womanism exists on the premise that Black womanhood and Black woman personhood is threatened.

2. Blackness exists in tension with the neoliberalism-multicultural imagination (Dei, 2017). 
3. Understand that the bodies of Black women are political sites (Hull \& Smith, 2015; Weinbaum, 2019; White, 1999).

4. Assert that speaking anti-Black woman tropes stems from colonial-settler oppression.

5. Acknowledge that anti-Blackness is embedded in systems, structures, and institutions globally (Dei, 2017; Dumas \& Ross, 2016).

6. Intersecting identities of Black women include but are not limited to race, gender, sexual orientation, adultification, ageism, sexism, classism, colorism, sizeism, and ability (Carruthers, 2018; Phillips, 1996).

7. Black womanhood is not monolithic; there are differences within Black womanhood. In summary, anti-Black womanism is theorized to provide contextualization to Black women's experiences and how they navigate through oppressive systems with the aid of their personal, everyday epistemologies. Black women experience adultification, objectification, and dehumanization (Phillips, 1996). Anti-Black womanism can be used to explain how Black women view the world around them (Dei, 2017; Dumas \& Ross, 2016; Phillips, 1996) and it helps women understand how they navigate anti-Blackness in HWIs (Rodney, 2020). Together, theories of anti-Blackness and womanism provide theory and practice within one. Studying the way anti-Blackness shapes institutions provides insight to interlocking oppressions, while womanism provides space for Black women to voice their everyday experiences.

\section{Significance of the Study}

Research about Black women tends to focus on issues that black women experience rather than the underlying problem (Barabino, 2019; Beckwith, Carter, \& Peters, 2016; Welch, 1992; B. Burke, Cropper, \& Harrison, 2000; Harlow, 2019; Lloyd-Jones, 2009; Mays, 2013; McChensney, 2018; Munden, 2015). Concepts of underrepresentation, tokenism, and 
microaggressions, among other racist manifestations, minimize and conciliate what Black women experience while working in higher education. In addition, research tends to focus on implicit bias and other concepts as primary problems rather than symptoms of anti-Black racism or sexism in the workplace (Eberhardt, 2019; Gladwell, 2005). Unlike many of these studies, my research focuses on the way Black women experience and navigate anti-Blackness in the context of enrollment management at HWIs. Not much, if any, research has intersected the combination of anti-Black social cognition and institutional racism specifically for Black women working as professionals in enrollment management at HWIs. Ferguson (2017) states the institution is a place that concurrently expands ideological and repressive systems.

This study addresses the gaps that exist in the literature, as current contributions about enrollment management centers the evolution of enrollment management as a profession. Current literature personifies the field to one individual rather than encompass the division (Hossler, 2006). Furthermore, literature does not center the experience of Black women who work in the field. Current research about Black women primarily focuses on symptoms of racism such as implicit bias, microaggressions and discrimination (Harlow, 2019; Mays 2013). Exploring how Black women in enrollment management navigate in a dual environment is of enormous importance to the field. I hope my research can add to the current literature that can provide us with a different theoretical frame while combating gender racism. Scholars of CRT and BlackCrit both attest that race is a social construct, but they do believe that the eradication of race is fanatical because race has become existentialist (Collins, 1998; Dei, 2017; Delgado \& Stefancic, 2001). My study will not eradicate racism, but it will unveil the complexities of matrices of domination. Womanism does not attempt to "fix" racism or any other oppression, but it does focus on how Black women have navigated the intersecting oppressions that they face. 


\section{Definition of Terms}

- Anti-Black: Carruthers (2018) defined anti-Blackness as "a system of beliefs and practices that destroy, erode, and dictate the humanity of Black people" (p. 8).

- Enrollment management: Enrollment management is the administrative function of higher education institutions to recruit and retain students (Coomes, 2000). The structure of enrollment management may vary at each institution, however, both formal and informal structures of enrollment management have varying degrees of centralization that share the goal to attract and make an incoming class of students using financial aid, marketing, admissions, registrar and records, and research (Schulz \& Lucido, 2009; Stewart, 2004).

- Black: Black collectively acknowledges the global-transnational identities from Africa and descendants of the African diaspora (Dei, 2017). Black includes "groups differentiated by gender, class, ethnicity, sexuality, culture, skin color, profession and nationality" (Kendi, 2016, p. 5). The 'B' in Black is capitalized as a declaration and a form of resistance (Laws, 2020).

- Enrollment management professionals: The title of enrollment management has evolved from a senior administrator to a more normative role that is now found at many private and public higher education institutions (Lucido, Hossler, O'Dowd, \& Massa, 2018). In this study, enrollment management professionals include administrators (mid-level and higher organizational ranking) and full-time administrative staff members.

- Historically White Institutions: HWI describes American higher education institutions that are rooted in conceptual, political, and historical foundations of settler colonialism and was intended to be a space only open for white males (Chatterje \& Maira, 2014). 
Traditionally, HWIs demographic composition over $50 \%$ or more students who identify as white.

- Neoliberalism: "Neoliberalism straddles a wide range of social, political and economic phenomena at different levels of complexity" (Saad-Filho \& Johnston, 2005, p. 1). While the inception of neoliberalism does not have a specific date, neoliberalism prioritizes individualism, privatization, free markets, capitalism, and meritocracy globally in policies and practices in government and the private sector (Giroux, 2005).

- Perception bias: The social cognition of the perceived world around viewing Black people or Blackness in an unjust manner. Specifically, the social cognition of Black people or unconscious bias may be intentional or unintentional based upon unconscious forces that does not require consent or awareness (Vendantuam, 2010); to reinforce generalized attitudes about characteristics such as race, gender, class (Jefferson \& Caldwell, 2002; Pecher \& Zwaan, 2005).

- Settler-colonialism: The settler-colonial complex acknowledges the racialized, economic, and cultural violence of the Euro-American conquest and acquirement of stolen indigenous land (Dei, 2017; Hixson, 2013). The Euro-American colonizers forced hegemony and assimilation, creating social hierarchy based upon whiteness and white supremacy (Chomsky, 2003). 


\section{CHAPTER II: INNERWORKINGS OF INSTITUTIONALIZING THE ACADEMY}

In this chapter I provide historical insight into the exploitation of Black labor that began during the colonial era. I first move through history while noting how the exploitation of Black people have shaped America and American higher education institutions. Finally, I turn my attention to the anti-Blackness that pervades throughout Neoliberalist waves in American higher education. My goal in this chapter is two-fold: to show the ways that Black bodies have been used to develop higher education in America and to lay the conceptual foundation that unveils and links the centrality of anti-Blackness to higher education.

\section{The Forced Beginnings: How Black People and Higher Education Converged}

European colonialists came to the Americas with the intent of conquest. Their intent was to colonize new lands through religious conversion and gain fortunes across the globe. European and Spaniard white men made significant attempts to conquer land and money by any means possible, including the exploitation of human labor through captivity and bloodshed (Berry \& Gross, 2020; Jordan, 1968; White, 1999: Wytsma, 2017). The birth of the transatlantic slave trade enslaved and commodified Black people from Africa and other indigenous areas of the Americas (Berry \& Gross, 2020; Kendi, 2017; Wilder, 2013). Slave traders captured Black people and forced them into slavery (Camp, 2004; Jordan, 1968). The enslavement and labor exploitation of Black people provided economic gain (Camp, 2004; DeGruy, 2005; Kendi, 2016; Wilder, 2013; Wytsma, 2017), because Black people were considered property rather than humans (M. Berry, 1971; Mills, 1998; Wytsma, 2017). The American economy exponentially grew from the use of enslaved labor (Coates, 2014). Quickly, slavocracy became a system and functioned with the aid of slave and plantation owners. Enslaved Africans were brought to the New England area before moving westward and south (Berry \& Gross, 2020; Fields \& Fields, 
2014). Enslavers used exploited labor for personal and household needs as well as on field plantations; exploited labor was also used for the construction of higher education institutions (Wilder, 2013). Without the exploitation of enslaved Black labor, America could not have sustained to become the superpower republic as it is known as today (Coates, 2014).

\section{The Bodies That Built American Higher Education Institutions}

The exploitation of enslaved labor in higher education institutions dates to the early 1800s (Berry \& Gross, 2020; Dancy \& Edwards, 2021; Kendi, 2016; Wilder, 2013; Williams, 2005). Enslaved laborers built American higher education institutions in two ways. First, the blood, sweat, and tears of enslaved people constructed and maintained the physical buildings of the institutions. Enslaved laborers were involved in groundskeeping, food service, secretarial work, maid service, and personal assistance (Wilder, 2013). Second, enslaved people were victimized when their bodies were dissected and used for research and lab experiments. As slavery was institutionalized, scientific racism emerged (Kendi, 2016). Eugenicists eagerly wanted to find ways to distinguish Black people from white people (Kendi, 2016; Washington, 2006). Black people were considered as sub-human (Dancy \& Edwards, 2021) and their physical features and abilities were dehumanized and studied as medical experiments (Kendi, 2016; Fields \& Fields, 2014; Washington, 2006).

Paradoxically, enslaved Black people worked at higher education institutions but were forbidden to read. According to Williams (2005), prohibiting enslaved people from reading was more than custom; it was a law. Enslavers also went as far as to punish and kill enslaved Black people for teaching other enslaved Black people (Berry \& Gross, 2020; Kendi, 2016). Even though literacy had potentially dangerous repercussions, Black people continued to persist with learning and literacy as a symbol of resistance (Williams, 2005). Colonialist enslavers thrived off 
the presumed docility of Black bodies (Kendi, 2016), which created a hierarchy and gave the enslavers a sense of power for white people.

To deepen social and economic power structures, scientific racism emerged to justify white supremacy and Black inferiority (Jordan, 1968; Mills, 1999: Wytsma, 2017). Black bodies were dehumanized in the name of science to find distinctions between Black and white people (Murray, 2020). The medical scrutiny and terror that Black bodies received resulted in perceptions, language, and superficial social and racial hierarchies that negatively affect Black

people generationally (Washington, 2006). The long-standing implications from Black bodies being used for science still pervades education and society today. Words such as barbaric, savage, animalistic were all used as adjectives to describe Black people (Gates, 2010; Jordan, 1968). The language used back in the 1700s still permeates today. This anti-Black language directed at Black people is used to dehumanize Black bodies and create a hegemonic voice for all under whiteness (Hill, 2008). In addition, today's use of anti-Black rhetoric is recognized in academic spaces and aimed at Black students and Black professionals. Phrases such as "college ready," "best and brightest," and "fit" (Golden, 2019) are used to covertly imply how Black people do not belong.

\section{Anti-Blackness Amid the Separation of Church and Education}

As anti-Blackness deepened, the fetishization grew to "fix" Black people. Other colonialists, particularly colonial evangelists, believed that the only way to save Black people would be by religion (Cannon, 2008; Fields \& Fields, 2014; Kendi, 2016). The white-savior complex (Hughey, 2012) blankets Black people today, while some white people proclaim their ally-ship in Black spaces: They essentially reinforce whiteness because they do not let Black people embrace their Blackness (Dei, 2017). As the white savior comes, Black people are saved 
from themselves (Kendi, 2016). This belief that Black people needed to be saved from themselves and educated justifies anti-Black perceptions (Jordan, 1968). Any attributes of Blackness have been considered a negative (Dei, 2017; Jordan, 1968) and always needed to be corrected by white people. Furthermore, the white savior complex reinforces power dynamics of superiority and inferiority. Beliefs during this time went as far as rationalizing that Black people made good Christians because of their docility (Kendi, 2016). Education as a tool of civility and assimilation was not limited to Black people, whites attempted to "save" indigenous Indians, Germans, Eastern Europeans, Catholics, and eventually women (Wilder, 2013).

Throughout history, education has served as a middle ground between oppression and resistance (Ferguson, 2017; Williams, 2005). While white people have used education as a means of civility and assimilation, Black people have used education as a means of resistance (Williams, 2005). White people used the civility rhetoric to assimilate others into the social structure of whiteness. Colonialists did not believe the customs, beliefs, and practices outside of whiteness were civil and humane (Kendi, 2019). During the colonial era, whiteness reigned atop of the social hierarchy, the standard, and the norm (DeGruy, 2005; Mills, 1999); force and power was used to ensure that whiteness' hegemonic power was protected. Watkins (2001) states, "Too few scholars have emphasized slavery's contribution to the emergence of America's rise to world power" (p. 12).

Anti-Black rhetoric carries white people's assumption that education can be a tool of civility. Anti-Blackness emerged during the colonial period and created institutional, structural, and systematic systems of oppression (Dei, 2017). When education was not seen as a tool of civility, Black people faced educational suppression as a means of social order (Kendi, 2016; Watkins, 2001). The suppression of Black people's education reflects today in many urban cities 
and low-income areas (Ross, 2021). Although the law does not prohibit anyone from acquiring an education today, educational suppression is still an issue (Dancy \& Edwards, 2021; Dumas \& Ross, 2016). Educational suppression is reflective in higher education institutions, especially when many Black students are labeled as not college ready, which translates into an underlying message that they are neither ready nor deserve to go to college (Golden, 2019).

\section{Institutionalizing an Anti-Black Academy Structure}

I focus the literature review in this section on the pervasiveness of anti-Blackness and how it permeates through higher education institutions. However, it is essential to understand how anti-Blackness is centered in higher education institutions in the matriculation and enrollment processes. I focus this section on three institutional operations that shape the perception of Black students and the higher education experience: the admissions process, the application of financial aid, and measures of academic success.

This conversation begins with the admissions process because admissions begin the life cycle of a student's higher education experience (Selingo, 2020). Before the 1960s, higher education institutions did not formalize an admissions process (Ferguson, 2017; Giroux, 2015; Huddleston, 2000; Steinberg, 2002). It was not until after the first wave of non-elite white men gained access to federal financial support to attend school that the bureaucracy of admissions developed. Regardless of the type of institution, students are required to complete an application process to demonstrate they are eligible and ready to attend a postsecondary institution. Many universities operate only as "closed enrollment" institutions, which means students have specific times where they can apply and enroll for the upcoming academic term (Selingo, 2020; Wycoff, 2020). Closed-enrollment institutions are selective about the student population they admit and often is seen as a form of status (Markovits, 2019; Wycoff, 2020). Students are expected to meet 
a minimal level of academic success to be considered for admission. The more selective the institution, the higher the base for the minimal level is raised for academic success, thereby creating a smaller pool of students for admittance (Wycoff, 2020). Selective institutions are also known as elite or premier institutions (Carnegie Classification of Higher Education Institutions, 2020; Markovits, 2019; Selingo, 2020; Steinberg, 2002). Other higher education institutions such as community colleges and for-profit institutions are more likely to have open enrollment, where students are able to apply and enroll at almost any given time before the semester begins, also called rolling admission (Lenhoff, 2020; Wycoff, 2020). Students who attend open enrollment institutions are still required to demonstrate eligibility; however, they are not subjected to the depths of the admissions process.

Closed-enrollment institutions require the submission of a combination of supplementary documents: standardized test scores, personal essays, high school transcripts, résumés, references, and interviews (Guinier, 2015). During the admissions process, the admissions processor is looking for students who meet their selectivity criteria and are perceived to be "a good fit on campus" (Golden, 2019). The admissions process is an extraordinarily subjective process (Steinberg, 2002). Because of this, affirmation action legislation was passed to decrease discrimination against students of color (Katznelson, 2006). Yet, Golden (2019) states,

The number of whites enjoying preference far outweighs the number of minorities aided by affirmative action. At least one-third of the students at elite universities, and at least half at liberal arts colleges, are flagged for preferential treatment in the admissions process. (p. 4)

Perceived fit and academic success are two standards embedded in anti-Blackness and dates back to the inception of higher education in America (Kendi, 2016). The idea of fit is 
contingent upon the secreted ideals of the institution and those who they would like to see as leaders in the world (Golden, 2019; Markovits, 2019). Fit is also related to campus image: Admissions teams are required to take snapshots of students' applications and supplementary documentation to determine if their criteria align with the institution's ideal (Silver, 2020). Individual admissions professionals' perceptions are often used when determining whether to admit a student into a closed-enrollment institution. Personal essays from Black students often share cultural capital that non-Black people might not understand, and Black students' personal essays are often perceived as divisive (Espenshade \& Radford, 2009). High school transcripts are weighted differently depending upon the zip code of the school. High schools located in areas where people are living in poverty are not deemed academically challenging, and students from those schools with high grade point averages are subjected to second-hand devaluations. According to Espenshade and Radford (2009), résumés, references, and interviews are also subjective, yet practitioners are trained for objectivity. With training, the admission teams remain autonomous and have the ability to impose their personal views as they build an entering class based on the ideals of the institution.

\section{Education Accessibility Evolving by its Bootstraps and Neoliberal Regimes}

Black people have always resisted education suppression (Ferguson, 2017). Enslaved Black people secretly taught each other how to read and write even though it was prohibited for them to learn: Being discovered could lead to harsh punishment or death (Berry, 1971; Berry \& Gross, 2020; Williams, 2005). Before the Morrill Act 1890, Black people attended higher education institutions on the basis of an exceptionalist ideology (Katznelson, 2006). Exceptionalism implies that some Black people are "better than" or "different from" the rest Black people. The Morrill Act of 1890 provided federal financial support to 19 institutions 
(HBCUs) dedicated to Black people (Muthusamy, n.d.). Initially, entry to these institutions was limited to men (Evans, 2007). The creation of HBCUs changed what higher ed access looked like for Black people (Evans, 2007; Gasman \& Geiger, 2012). However, HBCUs did not have the same intellectual prowess and purpose as HWIs. HBCUs positioned Black people to learn trades, vocations, and other specializations to become workers (Katznelson, 2006). Despite the educational inequities in higher education settings for Black people, they still took the opportunity and continued to advocate and fight for equality.

\section{The Year 1965}

Federal Supreme Court cases, Plessy v. Ferguson (1896) and Brown v. Board of Education (1954) demonstrated that Black people consistently fought to dismantle the Jim Crow laws and gain access to resources (M. Berry, 1971; Katznelson, 2006; Markovits, 2019; Rothstein, 2017). Both Supreme Court cases were monumental as they set the tone for all levels of education. Because of those landmark cases, the pathway for the Higher Education Act of 1965 was somewhat foreseeable for access to higher education for Black people. The Higher Education Act of 1965 is the first, all-encompassing federal legislation that provided financial allocations to students directly. Millions of students complete the free application for federal student aid (FAFSA) annually (U.S. Senate Committee on Health, Education, Labor \& Pension (2017). The FAFSA is a federal application that computes family's income to determine if students are eligible for supplemental federal funding to pay for college. Higher education is now a considerable financial investment, it can cost upwards of six figures to attain an undergraduate degree. When students choose a higher education institution, they submit an application, receive admittance then secure the financial aid by way of grants, scholarships, and loans necessary to 
cover tuition, room, and board. Once enrolled, administrators are able to request money or draw down funds on behalf of the students to pay their tuition.

The Higher Education Act of 1965 created regulations about the administration of higher education institutions and federal financial student aid programs. Not only did the Higher Education Act of 1965 create a bureaucratic structure to surveille higher education institutions, but the act also created administrative requirements that impeded the ability for marginalized students to attend college. The creation of federal programs such as the Supplemental Educational Opportunity Grants, Basic Educational Opportunity Grants (now Pell Grant), College Work Study (now Federal Work Study) and National Direct Student Loan Program (Federal Direct Loan Program) were all created with stipulations. Students are required to complete file-review processes such as verification, which primarily validates their financial information shared on the FAFSA application. Verification requires documentation from the IRS and a professional who reviews the documents to verify the accuracy of students' applications. Although the Servicemen's Readjustment Act of 1944, which is commonly referred to as the G.I. Bill of 1944 (Thelin, 2014) was the first form of federal student aid for veterans, the bill was only intended use was for white veterans (Katznelson, 2006). The intent of the G.I. Bill was to re-assimilate veterans into civil society after fighting in World War II by way of education and vocation. Along with the federal student aid programs, the FAFSA process was created. FAFSA used family income as an indicator to determine eligibility for needs-based grants or to determine if students could afford college without federal subsidies. While federal student aid programs are available to all students, the perceptions are that Black students were the only recipients of federal dollars (Harris-Perry, 2011). 
At the time the Higher Education Act of 1965 was enacted, the federal government created and strengthened a series of welfare programs (i.e., Medicare, Medicaid, Food Stamps, Section 8 housing, Head Start), which contributed to the notions associated with anti-Black tropes. Welfare queen is one trope, in particular, that emerged in the creation of welfare programs in the 1980s under former President Reagan (Harris-Perry, 2011). While the publicized intent of these programs was to combat poverty, I argue that these programs and policies deepened anti-Black perceptions, which also affected how Black students are viewed in higher education.

The social programs and policies in the 1960s deepened distrust of Black people and perpetuated anti-Black language such as being lazy, freeloaders for using public assistance (Cooper, 2018; Giroux, 2015; Harris-Perry, 2011;). The perceptions generated by the social programs and Daniel Moynihan's 1965 Moynihan Report reinforced the negative image of Black people (Harris-Perry, 2011). While the report provided statistics for whites, Asians, and Latinos, the Moynihan report specifically targeted and scrutinized the Black family structure. The Moynihan Report is considered anti-Black for the following reasons: (a) Black families were compared to other races, (b) the report viewed Black families from a deficit lens, (c) the report denounced Black people rather than institutional structures and blamed Black people for not overcoming institutional racist structures, and (d) Black people who desired liberty and equality were viewed as a racial crisis in America. The Moynihan Report is reminiscent of scientific racism since science and research were used to justify racism and anti-Blackness (Kendi, 2016; Harris-Perry, 2011). The Moynihan Report in tandem with welfare programs created the narrative that Black people were waiting for a handout (Harris-Perry, 2011). 


\section{Black Education Owed Meritocratic Payments}

As resources and access began to change for Black people, the neoliberalist ideology, meritocracy, centered anti-Black conversations about Black people (Dumas, 2016). Nationally, there was the rhetoric to "bring yourself up by the bootstraps;" however, welfare provided the opposing depiction of Black people. The bring-yourself-up-by-the-bootstraps metaphor aligns with neoliberalism's tenets of working off your own merit and individualism (Dumenil \& Levy, 2005; Levidow, 2005). The bootstraps metaphor implies that Black people have not and will not do their fair share and are not owed anything, especially government handouts (Harris-Perry, 2016). Individualism accompanies meritocracy; individualism strongholds correspond with the belief that all is owed to one's own strengths and capacities (Chomsky, 1999). Individualism assumes that if one fails, then it must be because they did not try (Giroux, 2015). However, in reality the social capital that whiteness is associated with has created an interconnected world that excludes marginalized people of color, where there is an illusion of individualism and merit. Markovits (2019) states that "merit itself is not a genuine excellence but rather-like the false virtues that aristocrats trumped in the ancient regime - a pretense, constructed to rationalize an unjust distribution of advantage" (p. xxi).

\section{Neoliberalist Ideology}

Anti-Black perceptions deepened as the neoliberalist ideology swept over America. These perceptions morphed into institutional concepts that would dictate organizational culture and norms. Giroux (2015) argues:

Neoliberalism as a form of economic Darwinism attempts to undermine all forms of solidarity capable of challenging market-driven values and social relations, promoting the virtues of an unbridled individualism almost pathological in its disdain for community, 
social responsibility, public values, and the public good. (p. 7)

Schulze-Cleven and Olson (2017) argue that the market-driven higher education sector has created academic capitalism. Neoliberalism is based on the following tenets: meritocracy, individualism, free markets, privatization, militarization, and globalization, all of which privilege institutions over people. Each tenet of neoliberalism is seen through manifestations of regulations within higher education institutions.

According to Levidow (2005), modern reform of higher education centers on privatization, deregulation, and marketisation. Federal programs such as the Pell grant carry much perplexity; these programs commodify Black bodies in the higher education sector and perpetuate the freeloading, lazy anti-Black perceptions of Black students going to school, while giving more Black students financial means to attend higher education institutions. Black students are viewed for body count and revenue - mirroring slavocracy. Federal programs also elevate the idea of the free market by giving the students options to choose where they attended for their higher education. Because Black students and other students of color presumptuously benefit more from federal grant programs, additional policies and procedures were established to control the misuse of funds; hence, the creation of the financial aid office (Jackson, 1990; Melguizo \& Chung, 2012). The anti-Black rhetoric of distrust follows Black and Brown students throughout the higher education process; these students have to prove that they are poor and continually prove they are smart enough and deserve to attend the institution.

\section{Free Markets}

The idea of free markets has drastically removed higher education from its initial intention of sharing intellectual thought; higher education is a marketplace for ideas and the construction of knowledge and has become big business (Levidow, 2005). Administrators at 
higher education institutions face duality of morality. They want institutions (a) to become marketplaces that support the ideology of the nation and (b) to continue to uphold the historical culture in which their institutions were built. HWI administrators have incorporated diversity initiatives, strategic plans, and conversations as a marketing strategy (Flathery, 2021). The diversity-driven plans are enacted because of the interest convergence that diversity brings. Institutions are able simultaneously to uphold anti-Black structures of oppression while commodifying Black bodies to mitigate the appearance of white supremacy. Admissions offices grew recently as well. Rather than only recruiting students, admission officers actively have turned to attracting students whose profiles align with the image of the institution. More barriers were put in place such as applications and standardized testing to control which student goes to which institutions (Steinberg, 2002).

Although higher education institutions are proponents of deregulation and decentralization (Giroux, 2015), there was an exception made for the context of federal funding to students for higher education. Federal education legislation significantly contributed to the growth of the bureaucratic structures of the administration of recruiting and retaining students in higher education institutions. I argue that the anti-Blackness of power structures run so deep that ideologies contradict and prohibit Black people from succeeding. The repressive structures that are embedded within bureaucratic structures consistently create barriers for marginalized students. These systems create the imagination that education is accessible; however, the reality reflects that it takes much effort and resiliency to overcome structures intentionally placed to impede Black students from attending institutions that were not initially intended for them (Thelin, 2014; Wilder, 2013). Black women professionals must also apply the same resiliency as 
students while employed at HWIs to combat the anti-Blackness reflective of the colonial era (Wilder, 2013).

\begin{abstract}
Summary
Black people have relentlessly fought to be on the other side of the classroom in higher education institutions. Black people's presence in higher education has always existed but has also changed to provide opportunities for Black students to get an education. Throughout the chapter, there are two vital frames of the evolution of anti-Blackness invading the lives of Black people. First, colonization served as the primary source to create systems of oppression for Black people. The settler-colonial complex provides some context of the exploitation of Black people and how anti-Blackness emerged in higher education. The latter conversation that expands how neoliberalism has changed higher education provides context for how anti-Blackness perceptions have deepened, and systems of power have become more perplexed-requiring the creation of the primary offices that make the enrollment management division.

My literature review is continued in Chapter III and the conversation primarily follows Black women. I begin the conversation by acknowledging the colonial-settler entrapment that created anti-Black rhetoric of Black women and follows how the language is used throughout events in history. Honor is extended to Black women activists who have spent their lives serving.
\end{abstract}




\section{CHAPTER III: BLACK WOMEN'S UNDYING PRESENCE}

She had nothing to fall back on; not maleness, not whiteness, not ladyhood, not anything. And out of the profound desolation of her reality she may well have invented herself.

—Toni Morrison (1971)

In Chapter III, I accomplish three conversations about Black women's history in America. I lead the discussion with my synopsis of the American history of Black women using a settler-colonial perspective. Following that, I unpack the embodiment of the Black female body through the life of Saartjie Baartman. In the next conversation I focus on the history of Black women in higher education. Lastly, I discuss the implications of anti-Black racism and sexism that Black women experience. My goal in this chapter is to conceptualize the experiences that Black women encounter in and out of academia and how anti-Black womanism is manifested in their everyday experiences.

\section{The Herstory of Our Ancestors: “Ain't I a Woman?"}

The history of Black women is often overshadowed by white women's history and feminism (A. Davis, 1981; hooks, 1984; Hull \& Smith, 2015; White, 1999), romanticized (Camp, 2004), or invisibilized (White, 1999). While Black women have shaped history long before any feminist movements (A. Davis, 1981; Combahee River Collective, 2017; Giddings, 1984; Ladner, 1995; Nash, 2019) and their stories truly depict the reality of America at any given time in history, unveiling disparities are magnified by systems of power such as sexism and racism. Without the account of other marginalized identities other than race and sex, Black women are at the intersection of two significant systems of oppression (Collins, 1991; Crenshaw, 1989; A. Davis, 1981; hooks, 2015; White, 1999). Zora Neale Hurston (1937) tells us that "De 
nigger woman is de mule uh de world so fur as Ah can see" (p. 23). In other words, Hurston acknowledges how Black women are expected to carry the brunt of the world on their backs; unfortunately, it is something that she did not see changing. In the hierarchical structures of race and patriarchy, Black women experience multiple points of oppression that places them on the lowest rung of the hierarchical ladder (Cooper, 2017). Because of the hierarchy of race, paternalism, and patriarchy, Black women have consistently fought for their humanization and freedom (Camp, 2004). Scholars note that a Black woman experiences double jeopardy (HarrisPerry, 2011) or carries double the burden of racism and sexism (St. Jean \& Feagin, 1999; White, 1999). hooks (2015) explains that "Sexism was an integral part of the social and political order white colonizers brought with them from their European homelands, and it was to have a grave impact on the fate of enslaved Black women" (p. 15). Before colonization, Black women explored the Americas as free people (B. Berry \& Gross, 2020). According to B. Berry and Gross, Black women "came with Spanish and Portuguese explorers, and many could be classified as indentured servants, missionaries, interpreters, or simply leaders" (p. 9). The arrival of Black women occurred before the British colonists' arrival and Black women were not enslaved until the British colonized the Americas (B. Berry \& Gross, 2020). With that, the transatlantic slave trade began, changing forever the trajectory of Black women and their experiences in the Americas (Camp, 2004; White, 1999).

When the transatlantic slave trade began, only men were enslaved and traveled to the Americas (B. Berry \& Gross, 2020; Ladner, 1982). But once slavery became a form of profit, women and children were also captured and enslaved (B. Berry \& Gross, 2020; Camp, 2004; Fields \& Fields, 2014; Kendi, 2016; Ladner, 1995; White, 1999). Reproduction and child rearing were primary reasons to enslave Black women (Camp, 2004; Jacobs, 1861; Rifkin, 2019). B. 
Berry and Gross state, "By the turn of the eighteenth century, slavery was defined and carried out through Black women's bodies” (p. 33). Black women's salability relied heavily on their ability to reproduce more children, which increased the slave owner's inventory (Weinbaum, 2019; White, 1999). Even though Black women's capacity to bear children was the primary reason their enslavement, Black women's labor was also exploited in every way conceivable. Black women labored in homes as well as in the plantation fields (Hartman, 2006). The in-home labor exploitation included but was not limited to (a) raising and breastfeeding enslavers' children; (b) cooking, cleaning, sewing, teaching; and (c) performing sexual acts on enslavers (Hartman, 2006: White, 1999).

The antebellum era politicized Black women's bodies (Hull \& Smith, 2015; Weinbaum, 2019; White, 1999) and this politicization is reflected in modern culture (Harris-Perry, 2016). Beyond the exploitation of labor, the bodies of Black women became sites of domination; a vehicle for terror, humiliation, and pain; and a site of pleasure and resistance (Camp, 2004; Weinbaum, 2019). The politicization of Black women's bodies stems from them being viewed as non-human objects—as cattle (Kendi, 2016; Rifkin, 2019; Weinbaum, 2019; White, 1999). Kendi (2016) indicates ethnic racism created hierarchies of people and classified Black ethnicities as inferior. Patriarchy also plays a major role in the status of Black women since women were not viewed as equal to men (Giddings, 1984). The bodies of Black women have faced over 400 years of trauma and this dehumanization of serves as the primary reason Black women's bodies served as a site of trauma (Camp, 2004; Hartman, 2006; Weinbaum, 2019). The whippings and punishments received describe some of the trauma that Black women experienced; their abuse included rape, sexual assault, subjects of scientific medical experiments, and objects of barter. Even in older years, Black women's enslaved labor did not cease (Camp, 
2004; Giddings, 1984; White, 1999).

Black women's resistance was more apparent as stories of terror emerged about their experiences upon arrival to British colonies in Jamestown, Virginia. The types of resistance varied drastically as some women jumped the slave ships, fought their enslavers, protected their children, escaped or attempted to escape, stayed behind as a lookout for other enslaved people who ran away, and even slept with their enslaver as a means of preservation (B. Berry \& Gross, 2020; M. Berry, 1971; Camp, 2004; White, 1999). Throughout the life of enslaved Black women, they had the responsibility to tend to their enslaver, their community, and their own families (Camp, 2004; Giddings, 1984; White, 1999).

Anti-Black perceptions of Black women emerged during the antebellum era and the perceptions have strengthened throughout time. Black women were portrayed as hypersexual beings when in fact they were victims of rape, sexual abuse, and sexual exploitation (B. Berry \& Gross, 2020; Lomax, 2018; White, 1999). Not only were the bodies of Black women objectified, but shift in perceptions blamed them, which further dehumanized and vilified them.

Other negative perceptions of Black women include the mammy trope (White, 1999). Mammy loved her enslaver and catered to her enslaver's needs with joy (Collins, 2009; Hills, 2019; White, 1999). There is also the Jezebel trope; this perception of Black women characterized them as devilish, lacking morality, and hypersexual (Collins, 1989; Harris-Perry, 2011; Lomax, 2019; White, 1999).

In 1851, Sojourner Truth's speech, “Ain’t I a Woman?” embodied the fight that Black women would still face in 2020. While her speech is often associated with both white and Black feminist activism (Combahee River Collective, 2017; hooks, 2015; Nash, 2019), it is truly a call to action to recognize Black women as more than workers, but as women—Black women. 
Sojourner calls attention to the system of slavery, the mistreatment of Black women, and the women's human right to stop being treated as less than a man. She and many other Black women were activists who fought for liberation. In the $21^{\text {st }}$ century, Black women are still asking to be treated as a human (Harris-Perry, 2011). "Ain't I a Woman?” epitomizes the experience of Black women. hooks' (2015) book, ain't i a woman, analyzes further the experience of Black women captured during slavery:

Enslaved Black women were forced to labor as men and exist independently of male protection and provision did not lead to the development of a feminist consciousness. They did not advocate social equality between the sexes. Instead, they bitterly resented that they were not considered "women" by the dominant culture. (p. 48)

What hooks (2015) acknowledges is the contention that Black women experience dehumanizing mischaracterizations. The intersection of race and sex has dismissed Black women's womanhood and created a falsehood of sub-humanity. Black women have consistently fought against falsehood myths for themselves and have extended their efforts for the betterment of all Black people and other marginalized people (Harris-Perry, 2011; hooks, 2015). As decades passed, systems of oppression became more sophisticated (Harris-Perry, 2011). By the 1950s, Black people faced classism as another source of oppression; the division of rich and poor created the class system of oppression that also caused detriment to the personhood of the Black women (Lomax, 2018). Class further complicated the image of the Black women and Black families. In brief, Black women have always been central in Black families (Harris-Perry, 2011) even as they navigated the many iterations of the mammy and Jezebel tropes (Collins, 1989), which exploited and dehumanized their personhood and womanhood. The historical context of Black women in America prior to, during, and after the transatlantic slave trade is instrumental in 
understanding what Black women experienced in the past and how their experiences are relevant today. The intersection of racism, patriarchy, and paternalism have played a significant role in the exploitation of Black women. The dehumanization and politicization of Black women's bodies are issues that persist today.

\section{Black Femalized Embodiment}

Analysis of the Hottentot Venus/Jezebel trope provides background needed to explain the Black female body. The Black female body has been viewed as many things, but hardly ever as the body of a Black woman (Mitchell, 2020; White, 1999). During the slavocracy, "female" was used to describe a Black woman (Camp, 2004; Hull \& Smith, 2015). The word female is an anatomical and biological term used to define the sex of an organism (Washington, 2006). Female is directly corresponding with the capacity to bear children or eggs as it could be any organism that has a reproductive system. The word female dehumanizes Black women by use of disassociating language that removes human qualities. Moreover, the word female dissociates from acknowledging Black women's personhood (Hull \& Smith, 2015) because female is not limited to human life as is the word woman. The Black female bodies are used as vehicles of commodification and exploitation of labor and skill, as a site for sexual domination and medical experimentation, and seen as a piece of property (Ndlovu, 2011; Washington, 2006). Because of the dissociation of Black women being seen as female objects instead of Black women, their bodies are not protected; and Black women and Black womanhood were invisibilized and only viewed for their usefulness.

\section{Saartjie Baartman Objectified}

Historically, the physical features and characteristics of Black women have been objectified and appropriated (Kendi, 2016; Gordon-Chipembere, 2011). A primitive story of the 
objectification and appropriation of Black women's bodies is found within the experience of Saartjie Baartman, a South African Black woman who faced appropriation, commodification, exploitation, medical experimentation, sexual domination, and objectification all in one longstanding, 200-year experience (Dunton, 2015; Gordon, 1992; Washington, 2006; Wright, 2013). Saartjie Baartman, also known as Sara/Sarah Baartman or Hottentot Venus, is the most notable Black woman whose body became a world-known French museum exhibition (Dunton, 2015; Mitchell, 2020; Spies \& Spies, 2014; Washington, 2006; Wiss, 1994). In the early 1800s, British colonizers took an obsessive interest in the physique of Saartjie, from her facial features on down to the rest of her body (Wiss, 1994). When Frenchmen promoted the exhibition of her body, the exhibition was covertly advertised as a show to display her facial features, yet her the full front of her nude body was shown on pictures and posters (Spies \& Spies, 2014; Wright, 2013). Once the museum exhibition ended, Washington (2006) stated that Saartjie was "made to stand naked at parties of the wealthy and to impersonate a chained animal...they began by staring at her in disgust, progressed to laughing at her, and ended by being aroused by her" (p. 84). The fetishization of Black women's bodies is reflected in how the Black women are still as Jezebels or reiterations of the Jezebel trope.

The interest in Saartjie's body demonstrates white fetishization rather than a benign curiosity or admiration of her physique. Her body was placed for public display for years and upon her death, her body was disseminated in the name of science and research and placed back on exhibition (Dunton, 2015; Washington, 2006; Wiss, 1994; Wright, 2013). After first being displayed in the 1800s, her body was not removed from public viewing until the 1970s; her body was not laid to rest until the early 2000s (Gordon-Chipembere, 2011; Moudileno, 2009; Spies \& 
Spies, 2014). Her skull was deconstructed and her genitals were cut off for scientific medical study (Washington, 2006).

The purpose of the medical analysis of Saartjie's body was to prove that she was not human - to prove that her physical features were different from those of white women. Because she was categorized as subhuman, the postmortem scientific racism displayed as her body was analyzed was deemed within reason. Saartjie was identified as a Khoi woman; Khoi people are indigenous people from Southern Africa (Dunton, 2015; Washington, 2006; Spies \& Spies, 2014; Wright, 2013). According to Gordon (1992), the Khoi were determined to be genetically linked to apes. Mothoagae (2016) states that "since they represent the missing link between men and brutes, Black Bodies can be subjected to any form of violence, be displaced, penetrated, subjugated, and paraded as a form of entertainment" (p. 68). Khoi women were known for their large, thickset buttocks (Washington, 2006; Wright, 2013). Racist medical theories also saw a longer labia as a subhuman trait, a trait that Saartjie and many Khoi women shared (Dunton, 2015; Wiss, 1994). Saartjie's elongated labia and larger buttock were considered sources of hyper-sexuality in white gaze when in reality, she was victim of hyper-sexualization because of the obsession white men had with her body. White men then commodified and exploited their obsession. Mothoagae (2016) implies that Saartjie was an accomplice of her exploitation, because she believed she would receive payment (Spies \& Spies, 2014). However, records do not indicate that she was ever paid (Mothoagae, 2016; Washington, 2006; Wiss, 1994). What Mothoagae does not acknowledge is the empty promise that lured her into centuries of exploitation.

To this point in the discussion, Saartjie is intentionally called by her birth name. The stripping of her birth name is one of the many ways Saartjie is dehumanized. Saartjie was 
shortened or westernized to become Sara and Sarah (Dunton, 2015; Moudileno, 2009).

Furthermore, Saartjie was mischaracterized by a performance and the name of the exhibition, Hottentot Venus, rather than any of her three name variations (Dunton, 2015; Ndlovu, 2011; Washington, 2006). Hottentot Venus is a reiteration of the Jezebel trope of Black women and the bodies of Black women who are seen as objects of hyper-sexualization rather than personhood (Lomax, 2018). Gordon-Chipembere (2011) states, Baartman was never seen as a person with feelings; rather, it was her body through which her narrative was shared. The ensuing mythology provided a one-dimensional lens to witness her body as the epitome of African savagery, worthy of degradation. (p. 8) According to Mothoagae (2016), the difference between human life and Black life is based on the premise of value, because Black lives did not represent or align with whiteness beyond objectification. While Saartjie was not the only Black body ever to be put on display, her story became an example to share the medical exploitation of Black people (Washington, 2006).

Saartjie was one of many Khoi women, yet she was the one who was known for public exploitation. According to Gordon (1992), Khoi women were a part of an egalitarian society and household, which was very different from the patriarchal structure of European standards. This further created a falsehood that Khoi women were hyper-sexual and did not exemplify womanhood (Lomax, 2018). In fact, Gordon (1992) remarks that the inquisitiveness of European colonizers of the Khoi women's labia is offensive since showing their privates "was the most damning insult a Khoi could give" (p. 193). The offense of Khoi women was perceived as a shameless invitation to the white gaze. This is not the only cultural mischaracterization that occurred with European colonizers. "Hottentot is an onomatopoeic name invented by early 
Dutch colonialist to describe the inimitable clicking sounds of the Khoi language, but Westerners applied the term imprecisely to all short Southern Africans" (Washington, 2006, p. 83).

\section{Hotttentot Venus-Jezebel Trope}

Hottentot not only miscategorized Khoi people, but also mocked the Khoi people's native tongue. To further mischaracterize, Hottentot Venus was also portrayed as Cupid-like or Black Venus (Wright, 2013) who embodied an allure of bestial and grotesquely hyper-sexual attributes (Washington, 2006). The Hotttentot Venus-Jezebel trope has vilified the bodies of Black women by making them sites for hyper-sexualization and exploitation (Lomax, 2018). Gordon-Chipembere (2011) argues that "the 'Hottentot Venus' is a construction of a masculinist, colonial discourse on female sexuality that has a prevailing impact on the way that African and Diasporic women are represented in the twenty-first century" (p. 10). The archetype of Black women is characterized by the fullness of their lips, the wideness of their hips, and the roundness of the buttocks (Spies \& Spies, 1994). The physical traits of Black women are still viewed today as sites of hyper-sexuality and anti-Blackness (Ndlovu, 2011). Because Saartjie's body was deemed different from those of white women, her body and the bodies of many Black women were deemed racially inferior, yet still attractive. Saartjie's narrative is a prime example of how whiteness became an implicit standard that Black women lived by, and should they fail to live up to that standard, they were subjected to a devaluation of personhood.

The story of Saartjie Baartman offers a depiction of how Black women are still exploited, mischaracterized, hyper-sexualized, and dehumanized. There was no moment where Saartjie was viewed as a person or as a woman. After public exploitation and humiliation, her body was used medically and scrutinized to prove that she was subhuman, a reason to justify the degradation she experienced. The description of Saartjie's curvy body and physical features is now acceptable on 
white women but still shamed on Black women. Like Saartjie, Black women's bodies are impersonalized to justify exploitation.

\section{Implications of Black Women in Education}

The perception of Black women valuing education is a topic that has polarizing opinions and standpoints. In the white imagination, Black people do not value education. Meanwhile, education has always been central to the progress, resilience, and mobility of Black people (B. Berry \& Gross, 2020; Cooper, 2018; A. Davis, 1981; Howard-Vital, 1989; Kendi, 2017). Black women, in particular, have always valued education and positioned themselves to learn in any given environment: even environments that could be dangerous and life-threatening (B. Berry \& Gross, 2020; Williams, 2005). The misconception that Black people disregarded education is one historically perpetuated by the circumstances of oppression. While the praise of Black women obtaining degrees from higher education institutions is admirable, one may believe this praise, but out of disbelief rather than celebration. Education is used as tool of control. In the colonial era, enslavers intentionally separated Black people who spoke the same language to ensure there was not a possibility to communicate and revolt (Kendi, 2016).

Throughout the transatlantic slave trade era until today, Black women have been instrumental advocates for education (B. Berry \& Gross, 2020; Hartman, 2006: Evans, 2007). Initially, racism and sexism were integral in the prohibition of Black women attending higher education institutions (Evans, 2007). At one time, all women, regardless of race, were prohibited from attending higher education (Thelin, 2011). After white women were allowed to attend universities, Black women still could not attend. According to Evans (2007), the first Black woman to attain a bachelor's degree did so nearly 20 years after white women, and 40 years after Black men, and 200 years after white men. Although white people went to college to share 
intellectual thoughts and ideologies (Thelin, 2011, 2014; White, 2008), they knew that education could lead Black people to understand that they were oppressed (M. Berry, 1971; Kendi, 2016). Because education could provide solutions for Blacks to navigate racism, white people also determined that education could become a source of rebellion (B. Berry \& Gross, 2020; M. Berry, 1971; Kendi, 2016).

Once higher education institutions allowed Black student enrollment, Oberlin College was the first HWI that openly accepted Black people. According to Titcomb (2011), Lucy Ann Stanton was the first Black woman to receive an English certificate from Oberlin College in 1850. Mary Ann Patterson obtained a bachelor's degree from Oberlin College in 1862. Although Oberlin made an institutional commitment to admit Black students, the community members' and stakeholders' outrage impeded the acceptance and retention of Black students on campus (Horton, 1985). Mary Ann Patterson and other Black women who followed her were subjected to a different standard before they were granted admission to the university at which they planned to attend (Ihle, 1992). Lucy Ann Stanton's educational pursuits did not end once she attained her certificate; she became a major activist in changing the perception of Black women attending American higher education institutions (Evans, 2007).

According to Evans (2007), Julia Ann Cooper, another graduate of Oberlin College, believed that "Equal access to higher education was an essential part of human growth" (p. 1); however, Mary McLeod Bethune saw education as a right of all citizens in a democracy (Evans, 2007). Rather than the differentiating views of Cooper and Bethune polarizing their ideologies, they complimented one another, making a stronger case for education for all.

Black women's labor was exploited during the slavocracy at Ivy League higher education institutions; their enslaved labor is comparable to modern-day, hourly positions such as 
janitorial, secretarial, residential life positions, or lower-administrative work (B. Berry \& Gross, 2020; Wilder, 2013). Black women are centered in front-line positions that cater and service students. According to Wright et al. (2006), most of the administrative positions that Black women had in higher education were held at HBCUs from the creation of these universities and colleges until the 1960s. It was not until the inception of TRIO programs (i.e., Upward Bound, talent search, student support services) that Black women administrators would publicly work in HWIs (Wright et al., 2006). Lucy Diggs Slow is one of the first Black administrators in higher education. She became the first Dean of Women at Howard University (Wright et al., 2006). Mary McLeod Bethune, the founder and President of Bethune-Cookman College, was a prominent leader in education (McCluskey, 1999). Her advocacy reached the ears of the nation with her involvement in national organizations such as the National Association for Colored Women (NACW) and as an unofficial member of the Black cabinet for U.S. President Franklin D. Roosevelt (McCluskey, 1999).

\section{Black Women and HWIs}

Parker (2015) provides some historical context of Black women working in higher education before the 20th century. However, it is glossed upon that Black women were not deemed as professionals. According to Parker (2015), Black women worked at institutions, but many did not hold positions that were deemed elite such as doctors, professors, and decisionmakers for the institutions. Black women were then and are now still often employed in positions that lack authority by means of title or position (White, 2008).

Most of the research about Black women at HWIs focuses on Black women faculty and excludes administrators from the conversation (Munden, 2015). Black women faculty experience institutional barriers that slow down and prohibit Black women from gaining tenure-an action 
that devalues their work (Burke et al., 2000: Harlow, 2019; Hills, 2019; Jones, 2019).

Conversations about Black women working in HWIs acknowledges the disparities that Black women experience such as underrepresentation, discrimination, and silencing (Chapman, 2019;

Collier-Thomas, 1982; Howard-Vital, 1989; Matthews, 2019; Mays, 2013; McChensney, 2018);

however, these concepts consistently have served as social mitigators to protect whiteness rather than dismantle matrices of oppression and domination (Nader, 1993).

\section{Breaking Down White Words for Black Realism \\ Miseducation of Underrepresentation}

Black women have used education as a critical tool necessary for resistance and social transformation. Education has always been viewed as a top priority and a goal to attain, regardless of grade level. The shared value in education is demonstrative statistically; Black women are attaining more higher education degrees at a higher proportion than any other racial and gender group (National Center for Education Statistics, 2016). The Black women’s leadership and educational accolades do not privy them the opportunity to be proportionately represented in professional roles in enrollment management departments on HWIs. "As a Black woman in academia, our sheer presence challenges accepted norms in leadership" (Ifedi, 2019, p. 1). Black women traditionally have not been perceived as leaders in higher education (Parker, 2015), and often, the traditional rhetoric is perpetuated. Thus, underrepresentation happens as a means of protecting white supremacy.

While Black women face underrepresentation in both faculty and administrative sectors of higher education, statistical and demographic data are more accessible about faculty members. The National Center for Education Statistics (2016) data reveal that only 3\% of Black women nationwide are faculty members. During the 1960s, Black students protested on campus for 
better presentation of Black professionals and faculty (Ferguson, 2017; Farmer, 2017). In 1980, Mosley indicated that Black women administrators faced underrepresentation in higher education institutions. Yet, in 2018, the College and University Professional Association for Human Resources indicated that Black women are the least represented at colleges and universities (McChensney, 2018). Underrepresentation affects how Black women navigate higher education. Babarino (2019) shares experiences of being the "only one" and provided a literary context of being an outsider within (Henderson, Hunter, \& Hildreth, 2010). Tucker (2019) shares her story of how she has always been outspoken and a spark of fire. Her upbringing as a child allowed her to have a tempered fire that allowed her an insurmountable amount of agency that she carried throughout her adulthood. This characteristic was one that served her well and also made her feel the fire because of her outspokenness — often viewed as defiance. A fiery spirit is often associated with the Jezebel or angry Black woman trope (Cooper, 2018; Collins, 2009; Lomax, 2018), which does not align with the submissiveness that Black women are always expected to give.

Black women often feel doubly burdened while serving as a safe haven for Black students on campus, yet taxed with varied work initiatives as they perform the regular responsibilities of their full-time positions; for them, this is underrepresentation (St. Jean \& Feagin, 1999). Furthermore, underrepresentation intentionally perpetuates institutional mammying by creating a culture which coerces Black women to become self-sacrificial (Hill, 2019). The implications of underrepresentation reflect anti-Black womanism, which is the taxation that is placed on Black women's experiences when they are given less but expected to do more with what they have. 


\section{Password to Discrimination}

Discrimination in the workplace is a prominent issue for Black women, especially in higher education roles. Discrimination is a code word for racism, and the acts and intentions of discriminatory behaviors and practices are embedded in anti-Blackness, racism, sexism, or a combination of them all (Dumas \& Ross, 2016; Nader, 1993). Discrimination is demonstrated through the hiring, promotion, and tenure (Welch, 1992). Often, Black women are withheld from opportunities to succeed at their jobs in part because of the mammy trope that assumes Black women are to be submissive and the world's caretakers.

\section{Concepts Conformed by Objectification}

Black women experience microaggressions about their hair, their dialect, the shape of their nails, their names, which schools they attended, the clothes they wear, their tone of voice, the neighborhoods they are from, their size and culture (Cooper, 2018; Woods, 2001; Tucker, 2019). While Saartjie Baartman is one example of how historically Black women were mischaracterized and objectified by the white gaze (Mothoagae, 2016; Washington, 2006; Wiss, 1994), today’s Black women in higher education continue to face the task of navigating through others' perceptions. Harris-Perry (2011) discusses this debilitating experience as navigating and standing in a crooked room. The experiences that Black women have had outside of academia mirror what happens inside the ivory tower of the university.

\section{Invisibilized Notions}

Silencing the voice of Black women is one form making them invisible. "Silencing is a form of coercion that legitimized theft: the stealing of the labor and voices of captives in predatory societies" (James, 2019, p. xi). Tucker (2019) shares her childhood's household pedagogy; children should be seen and unheard; this happens to be foundational information that 
guides the understanding in how Black girls have been raised. Mothers silencing their Black daughters from their "womanish" ways was a form of protection and resistance from the world (D. Smith et al., 2019) and prepared Black girls to navigate a culture that hates Black women (Walker, 1989). Black women raising their daughters traipsed a fine line to avoid exposing their daughters to adult-like information prematurely. On the surface, a mother silencing her daughter may mimic the reinforcement and perpetuation of whiteness; however, a Black mother's goal is to protect her daughter (D. Smith et al., 2019).

The invisibilizing that occurs with Black women in higher education has the intention to instill and perpetuate whiteness. Black women are not honored when they give their opinions (James, 2019). If the opportunity arises that allows Black women to speak up for themselves, the image of Black women is often tainted through negative societal images that still make Black women invisible (Harris-Perry, 2011). Woods (2001) deals with the conundrum of invisibility, making herself hyper-visible: everything from being active in conference committees, presenting, making academic and journal contributions, all are actions that Woods intentionally takes to show that she exists in the world of academia and higher education. Jones (2019) shares similar sentiment as Woods. She explains that her resistance was for a bigger cause than just herself, and even then, she still felt unseen and unheard. Woods (2001) also shares how she observed that white tears trumped her tears: "Some people could cry and still be heard! Some people could cry and be comforted! Someone people had the power to stop a conversation for a minute, an hour, an entire semester, with a single salty drop!” (p. 119). Historically, white women are seen as muses of purity and righteousness: their existence carries fragility. The fragility of white women and their tears (Cooper, 2018) have held precedence over the existence of Black women. In comparison to the white gaze, white women are everything that Black 
women are not (Cooper, 2018). Historical perceptions of womanhood centers white women, while Black women are still held to immortal standards of strength and bruteness (Harris-Perry, 2011). Black women are often told to be strong throughout any situation—-do not display emotion. Rather, Black women often go unseen and unheard until they roar loudly. In a world that wants Black women to be docile laborers (Kendi, 2019; D. White, 1999), roaring also becomes a form of resistance (S. Davis, 2018; Smith et al., 2019).

Literature establishes that the bodies and lives of Black women are politicized (Mills, 1999; Roberts, 1999; D. White, 1999; White, 2008). Every perspective of Black women's lives is subjected to some form of scrutiny. An example of this scrutiny is Black women's hair. State polices and mandates have been enacted to decrease discrimination surrounding Black women's hairstyles (Powell, 2019). States such as California and New York have deemed it illegal to use ethnic hairstyles as a reason not to hire, promote, or to fire someone (Greene, 2017). Yet, there are studies that refute that such policies actually support Black women (Koval \& Rosette, 2020; Powell, 2019). Therefore, Black women teach their daughters how to maneuver in the world in which they live.

Understanding the many ways that Black women's lives are politicized and how their resistance intersects with their lives in America is vital to my research. I argue it is vital to understand how Black women view themselves and what their self-perceptions mean for their navigation in the world. Black respectability politics is a generalization for all Black people. Respectability politics is rooted in the basic understanding that perceptions matter (Cooper, 2017). Black people have always been viewed differently than white people, and Black women have struggled in social hierarchies because of the intersection of race and gender (Crenshaw, 1989). The idea of uplift suasion (Cooper, 2017/2018) has forced Black women to counter 
perceptions of them while standing in a crooked room (Harris-Perry, 2011). Therefore, Black women have had the responsibility to teach their Black daughters the same tools of navigation through systems of oppression.

\section{Summary}

In summary, Black women's history in America has demonstrated extraordinary strength throughout tumultuous times. Black women have always chosen to support their families even to their detriment. They have pioneered and used their voices with little or no fear while pushing to create the world they want for their families. The mammy and jezebel tropes have constructed mischaracterizations of Black women since the formation of slavery and Black women have consistently used whatever was necessary to resist the negative perceptions.

Chapter IV, I discuss the methodology I used to conduct my study. I first outline my methodology. Next, I identify the research design by describing the worldview and methodology to be used. Then, I discuss the intended participants and how participants were determined, later discussing the methods of data collection. I then outline the ethical considerations, reciprocity, and assumptions of my study. Following that, I define my positionality and reflexivity to the research. Finally, I describe how I worked to ensure validity and provide data analysis. 


\section{CHAPTER IV: RESEARCH METHODOLOGY}

\section{Overview}

Enrollment management is central to the operation of any given institution; however, discussions pertinent to higher education rarely cover that sector of operations. Black women professionals in enrollment management are in the crossfire of competing systems of oppression that construct higher education, particularly at HWIs. Black women face institutional, structural, and systematic, anti-Black, gendered racism daily as they navigate their roles to support students' recruitment and retention. Their roles demand that they contend with upholding the institution's culture and standards, become buffers for students to navigate some of the effects of institutional blowback, and provide much of the front-line service for students and other campus partners. Often, Black women are expected to be available whenever any of the institution's key stakeholders makes a demand. Anti-Black perceptions of Black women in enrollment have shaped their experiences within their professional roles.

In this chapter I present my research design, which includes the methodological approach and methodology, positionality, data collection procedures, and data analysis. I describe the qualitative paradigm and narrative inquiry methodology I used to understand how anti-Blackness interplays with Black women professionals who work in enrollment management at HWIs. A qualitative research approach allows for a deeper examination into the lives of Black women professionals working in enrollment management. This approach also allows me to understand the implications of Black women working in the intersection of whiteness and patriarchy. 


\section{Significance of the Study}

In this study I address several gaps in the literature; existing literature about enrollment management does not give voice to the profession as a whole, as prior research only speaks about a specific individual (Hossler, 2006). In addition, literature does not acknowledge Black women in higher education enrollment management roles (Harlow, 2019; Mosley,1980, Parker, 2015; Rodney, 2020; White, 1999; Woods, 2001). My study centers on a specific population of Black women who work in higher education and I employ the conceptual framework of antiBlack womanism. Much existing research primarily unpacks biases that exist in the workplace for Black women, focusing on implicit biases or discrimination. Unlike those studies, my research largely focuses on anti-Blackness and anti-Black perception. Current research intersects the combination of social cognition and addresses anti-Black rhetoric that creates such biases, specifically for Black women working in higher education administrative roles. My research contributes to the literature and helps others to understand the ways that Black women navigate institutional and structural violence encountered in enrollment management at HWIs. I want to reiterate that my study will not eradicate racism and sexism although my research explains phenomena that span beyond the workplace and expresses how sexism and racism affect the lives and decision-making of Black women outside the workplace. Through my study I aim to create a liberating experience for my participants and create an institutional space for substantive change in higher education. 


\section{Research Questions}

The following research questions guide my study:

1. In what ways do Black women navigate their administrative roles in enrollment management at HWIs?

2. How does anti-Blackness manifest in enrollment management positions for Black women?

3. How do anti-Black womanist perceptions affect workload and performance?

4. What are the self-perceptions of Black women who work in enrollment management?

5. What strategies, knowledge, and skills do Black women employ to do their jobs in enrollment management at HWIs?

\section{Methodology}

I conducted this study using a critical paradigm, which allows researchers to create an emancipatory experience as well as to challenge institutional and historical structures of power on behalf of marginalized groups (Bloomberg \& Volpe, 2019; Glesne, 2011; Merriam, 2009). According to Bloomberg \& Volpe (2019), a critical paradigm is intertwined with politics and "assumes society is structured by class, status, race, ethnicity, gender, and sexual orientation in order to maintain the oppression of marginalized groups" (p. 62). I use this paradigm in order to acknowledge the different roles that participants may have that lead to a more significant discussion about social structures that exist in higher education. A critical paradigm also provides me with an opportunity to explore Black women's experiences and higher education institution structures in tandem to make meaning of my participants' positions in their roles and perceived expectations. 
A qualitative study allows the researcher to integrate multiple perspectives According to Glesne (2011), qualitative research provides the opportunity to "make actions, narratives, and the ways in which they intersect" (p. 1). Qualitative research also allows the researcher to study and capture real-life experiences naturally. Fundamentally, qualitative researchers want to make meaning of the world that people have constructed (Merriam, 2009). In my study I aim to understand the phenomenon of Black women working at HWIs in enrollment management in order to provide the opportunity to share Black women's experiences and how they navigate the administrative side of academia.

\section{Narrative Inquiry}

Narrative inquiry was used as the method of data collection. Bloomberg and Volpe (2019) indicate that "narrative research is focused on how individuals assign meaning to their experiences through the stories they tell” (p. 58). The narratives the participants share is powerful and necessary to understand the context of their experiences within society, family, cultures, and other intersecting factors in their lives (Josselson, 2011). The participants' narratives also helped make meaning of their worlds (Bloomberg \& Volpe, 2019; Creswell \& Creswell, 2018; Glesne, 2011; Josselson, 2011). The meanings garnered from the narratives provide me with context to explain the phenomenon of participants' experiences. While narrative inquiry does not lead to summation and generalizations, it does help to build understanding of ways that others navigate life and their experiences.

Narrative inquiry allows for the voices of the participants to be centered through the analysis of the data. Applying a theoretical lens drawn from BlackCrit and womanism makes it possible for me to use anti-Black womanism to conceptualize the dissertation. Semi-structured 
interviews were conducted for each participant to share their own experiences; semi-structured interviews consist of open-ended questions (Muzaliwa \& Gardiner, 2014).

\section{Researcher's Position to the Research and Reflexivity}

My responsibility as a researcher is to acknowledge my positionality relative to the study. I am a Black woman who works in enrollment management at an HWI. Initially, I internalized my experience as a professional. As unsettling as it made me feel, I thought that it was normal to experience racial and gender slights as a professional, even though I knew it was not fair for me to endure. It was not until I began confiding in other Black women about my experiences that I knew it was not something to suppress and accept. Following a decade of experiences at three different institutions, I knew that it was not a recurring experience to shrug off. What I thought my role consisted of and what it was in reality created cognitive dissonance (Feastinger, 1962). My dissonance compelled me to learn more about the bureaucracy of enrollment, higher education as an institution and a structure, and the intersections institutional administrators create when they position Black women in HWIs. Once it was evident that current research had not explored Black women's enrollment management experiences, my interest piqued and transformed into action. I wanted to share the voices of historical Black women to encourage today's Black women to use their voices: show them that they did not have to navigate their professional lives questioning, in silence, if situations were okay or knowing that racial and gender slights should not be pacified and taken in silence. My experience as a professional provided a sense of awareness to acknowledge the experience of other Black women enrollment management professionals. I have a double role and membership in my research study, as a researcher and practitioner. Therefore, I acknowledge my insider-outsider relationship to my research (Dwyer \& Buckle, 2009). According to Dwyer and Buckle (2009), the insider-outsider 
allows me to play both my roles as a Black woman professional and researcher simultaneously. Because I am a Black woman who works in enrollment management at an HWI, I understand the innerworkings of the division. My experience aids me through the research process to better identify with my participants.

\section{Participant Recruitment and Selection}

Once IRB requisites were approved (see Appendix A), the data collection process began with the recruitment and selection of participants. The recruitment process began with identifying who should be included in the study. To conduct my study, I intentionally created the following eligibility criteria for the participants: (a) identify as Black, (b) identify as a woman, (c) worked full-time at an HWI for at least one year, and (d) worked in any enrollment management office (e.g., registrar, financial aid, or admissions).

The core unit of enrollment management consists of registrar, financial aid, and admissions offices; the organization frame of some institutions might not include other offices associated with enrollment management. Typically, very few Black women are employed in enrollment management at universities. My goal was to be inclusive and receptive to those who were interested in sharing their narratives. Black women professionals at any level in the HWIs were able to participate as long as they met the criteria of the study.

To recruit the research participants, I used the purposive snowball method. The snowball method is also known as the chain sampling or network sampling (Merriam, 2009). Snowball sampling is a recruitment method where the researcher asks enrolled participants if they can recommend additional potential participants who qualify for the study and would be interested and willing to participate (Merriam, 2009). Given my selection criteria, eligible potential participants are small in number; therefore, snowball sampling was the most efficient method to 
recruit participants. Because enrollment management is a small, niche profession, trust and insidership played a major role in the snowball recruitment. According to Dwyer and Buckle (2009), "the insider role status frequently allows researchers more rapid and more complete acceptance by their participants. Therefore, participants are typically more open with researchers so that there may be a greater depth to the data gathered" (p. 58).

Participants were invited to participate in the study by email (see Appendix B). Once participants were recruited and selected for the study, I distributed consent forms (see Appendix C). Upon receiving the consent forms, I used a survey (see Appendix D) to collect preliminary data from participants in preparation of the interviews. I recruited 11 participants; however, a total of 10 participants were selected for the study based on the study's criteria and their availability to partake in an hour-long interview. Table 1 reflects the demographic data gathered from the participants. The participants' age ranges from mid-twenties to late fifties with years of experience between 3 and 30 years in enrollment management. The participants worked at private, propriety, and public HWIs. Two participants work in admissions and one of these participants also works in the registrar's office. Four participants have consistently worked in financial aid throughout their careers. Each of the participants who worked in enrollment management had filled other roles within higher education. My participants have professional experience at public 4-year institutions, public 2-year institutions or community colleges, technical colleges, proprietary institutions, private 4-year institutions, and minority serving institutions. Notably, participants who worked at multiple institutions provided additional insight about their transition to or from an HWI. The highest academic degrees attained by participants are the Ph.D. and M.D. 
Table 1

Participant Demographic Data

\begin{tabular}{|l|l|l|l|l|}
\hline \multicolumn{1}{l}{$\begin{array}{l}\text { Participant } \\
\text { experience }\end{array}$} & Institution type & Division & Highest degree \\
\hline Bolanle & 6 & Private 4 year** & Admissions & Ph.D./M.D. \\
\hline Eshe & 21 & Public 2 year & Financial aid & Bachelor's \\
\hline Fayola & 5 & Public 2 year & Enroll mgmt. & Ph.D. \\
\hline Kadeesha & 5 & Private 4 year** & Enroll mgmt. & Master's \\
\hline Leal & 15 & Public 4 year & Admissions & Master's \\
\hline Mandisa & 15 & Public 4 year & Financial aid & Bachelor's \\
\hline Ramla & 3 & Public 4 year* & Enroll mgmt. & Master's \\
\hline Sakina & 30 & Public 2 year & Financial aid & Bachelor's \\
\hline Zarene & 27 & Private 4 year & Financial aid & Master's \\
Zena & 12 & Public 4 year* & Financial aid & Bachelor's \\
\hline
\end{tabular}

Note. *indicates R1 institution; Enroll mgmt. = enrollment management; ** indicates highly selective private institution.

After gathering preliminary demographic data with the survey, I scheduled and conducted interviews on Zoom with each of the 10 Black women using an interview protocol (see Appendix E), which consisted of eight fixed questions, with open responses (Weiss, 1994).

During the interviews, confidentiality of the participants was honored by giving them the opportunity to select a pseudonym. It took several weeks to conduct and transcribe the recorded interviews. The length of the interviews ranged from 52 minutes to 198 minutes. On average, the interviews lasted 101 minutes (1 1/2 hours). The pseudonyms were used in place of participant 
names as I transcribed and analyzed the data and shared their stories. All data collected for the study were kept on a secured, password-protected storage device.

\section{Data Analysis}

During data analysis, my goal as a researcher was to interpret the raw data that were collected (Bloomberg \& Volpe, 2019). Initially, I analyzed the data by coding; coding data allows the researcher analytically to interpret data (Bloomberg \& Volpe, 2019; Saldana, 2016) through patterns. According to Saldana (2016), “A code in qualitative inquiry is most often a word or a short phrase that symbolically assigns a summative, salient, essence-capturing, and/or evocative attribute for a portion of language-based or visual data" (p. 4). I used four coding methods: preliminary, in vivo (verbatim), emotion, and patterns. I conducted four rounds of coding to ensure the validity of the data and to ensure that the voice of the participants was highlighted. As a researcher, I wanted to ensure that my portrayal of the participants were aligned with their own self perceptions (Bloomberg \& Volpe, 2020). Saldana (2016) indicates that coding is a cyclical process and is rarely perfect within the first round.

\section{Preliminary Coding}

As I transcribed the interviews, I began with the preliminary coding process by highlighting notable quotes and repetitive phrases mentioned by the participants. By tracking my preliminary coding and note-taking, I was able to check my assumptions, positionality, and my personal points of contention with the data (Saldana, 2016).

\section{In Vivo Coding}

After I completed a preliminary coding cycle, I wanted to ensure that the participants' voices were included with earlier interpretation of the data. To accomplish this, I applied in vivo coding. In vivo coding places heavy emphasis on the participants' direct words so they become 
central in the analysis of the data. Saldana (2016) indicates that in vivo coding can also be called literal coding, verbatim coding, inductive coding, or natural coding. The core purpose of my research was to give voice to the participants and using in vivo as a coding cycle permitted that to occur.

\section{Emotion Coding}

During the third cycle of coding, I used emotion coding. Emotion coding is an affective coding method, which according to Saldana (2016), is a combination of in vivo coding and combined with the participants' emotional states and reactions. Emotion coding requires caution when making inferences about the transcriptions, audio recordings, and field notes. This cycle of coding is sensitive to the participants' tones, speech speed, and pitches. Emotion coding is also sensitive to the interpretations made from the narratives of the participants.

\section{Pattern Coding}

I used pattern coding for the last cycle. Pattern coding recognizes repetitive and consistent data points that happen more than twice (Saldana, 2016). Pattern coding helped me contextualize the experiences of the participants. Pattern coding can also "help confirm our descriptions of people's 'five R's': routines, rituals, rules, roles, and relationships”' (Saldana, 2016, p. 5). This method of coding also helps to determine "what goes with what" and "what is there" (Miles, Huberman, \& Saldana, 2014).

\section{Thematic Analysis}

After coding the data, I applied thematic analysis to help generate categories, subthemes, and then themes from the data to describe the participants' experiences. According to Maguire and Delahunt (2017), "The goal of thematic analysis is to identify themes, i.e., patterns in the data that are important or interesting, and use these themes to address the research or say 
something about an issue" (p. 3353). Thematic analysis allowed me to center the purpose of my study; the purpose of my study was to understand how Black women administrators navigate their roles in enrollment management at HWIs.

\section{Trustworthiness}

To ensure validity, I conducted member checking (Merriam, 2009). Member checking is essential and a means to ensure the correct message that the participants want to share is captured. Merriam (2009) stated that member checking is seeking feedback on the emerging findings. During the data analysis, I checked with 7 participants and peer audited data with my advisor and other women of color in enrollment management. I provided rich, thick descriptions of the narratives shared by the participants. Lastly, I have taken account and continuously stayed aware of my positionality and personal bias of the research topic, I am incredibly close to my research as a professional. My experience as a professional helps me to bridge the gap between research and practice. As a researcher, I also provide space to not impose my experience on any of the participants and thus distort their stories.

\section{Consideration of Ethical Issues and Reciprocity}

Throughout the study, I maintained respect for my participants' rights and dignity and minimized harm by being conscious of my role as researcher (Glesne, 2011). Data collection was conducted in a manner that allowed for intimacy and maintained participant confidentiality. Maintaining confidentiality was a priority in my study because confidentiality is key to building and maintaining trust (Bloomberg \& Volpe, 2019).

I upheld my social responsibility as a researcher to protect the identity of my participants by use of pseudonyms and characterizing their identities (Merriam, 2009). According to Glense (2011), researchers must morally uphold the voice of the participants of their study while 
protecting their privacy. For reciprocity, participants were empowered to share their stories by providing a mutual sense of identity and shared community (Glense, 2011). Also, my research provided an opportunity for participants to call for action on the part of higher education institutions, specifically HWIs, to help mitigate anti-Black perceptions and expectations of Black women.

\section{Summary}

In this chapter, I discussed the methodological details of the study and the critical theory worldview applied. Using the purposive snowball method, 10 participants completed the indepth virtual interviews via Zoom. Each participant was required to identify as Black, a woman, and work within enrollment management at an HWI full-time for at least one year. The data were analyzed through four coding cycles--preliminary, in vivo, emotion, and pattern coding--and thematic analysis. The purpose of this study was to understand how Black women navigate HWIs. 


\section{CHAPTER V: FINDINGS AND ANALYSIS}

The purpose of my qualitative study is to learn how Black women in enrollment management navigate at HWIs. I conducted ten semi-structured interviews to collect data from my participants. Their lived experiences help explain the phenomenon of being Black, identifying as a woman, and understanding how the intersection of their identities takes a role in their perception of themselves and how the personnel of the institution perceive them. Furthermore, I sought to reveal how Black women's identities meet at the cornerstone of resistance and oppression. I used the theoretical frame of anti-Black womanism to help understand the participants' experiences. Chapter V reintroduces the research problem and questions and introduces study participants. Findings from the study are revealed as the research questions are answered.

\section{Research Problem and Questions}

Black women enrollment management professionals have dialectical experiences. They face interlocking systems of oppression while simultaneously creating educational access for students. Black women are required to navigate polarizing ideologies of repression and resistance in enrollment management at HWIs. Because of this duality, Black women are positioned at the intersection of oppression while creating opportunities for students; Black women also suffer as they experience racism as they navigate the adversities that Black women face in their enrollment management administrative roles in higher education. Institutional, systematic, and structural barriers were created with the intention to perpetuate white supremacy. Although Black women have consistently made strides to overcome barriers in higher education, the barriers persist. Mitigating racism is clouded through concepts such as discrimination, underrepresentation, and microaggressions. I conduct this study to uncover racial mitigators to 
understand Black women enrollment management professionals' experiences.

This study uses the following research questions:

1. In what ways do Black women navigate their administrative roles in enrollment management at HWIs?

2. How does anti-Blackness manifest in enrollment management positions for Black women?

3. How do anti-Black womanism perceptions impact workload and performance?

4. What are the self-perceptions of Black women who work in enrollment management?

5. What strategies, knowledge, and skills do Black women employ to do their jobs in enrollment management at HWIs?

The goal is to use the responses to the research questions to develop a holistic perspective of Black women's experiences.

\section{Data Collection}

Interviews were conducted with the 10 participants' who work in enrollment management positions. The Black women's work experience spans throughout the enrollment management structure. Five participants work in financial aid, three participants work in enrollment management, and two participants work in admissions. Two of the participants have crossover experience in the registrar's office. The total years of service also varied by the participants from 3 to 30 years. All but two participants have worked at different institutions throughout their careers. The participants work at public 4-year institutions, private 4-year institutions, community colleges, and Minority serving institutions (MSIs). 


\section{Participant Profiles}

To counter anti-Blackness with Blackness, I used traditional African women names as pseudonyms for the study participants. These names all have meaning that resonated with each participant and their narratives. Each name was defined by the participant using a direct quotation. Overall, the descriptive profiles are brief to ensure the confidentiality and anonymity of the participant.

- Bolanle: finds wealth at home.

Bolanle is a senior administrator in admissions for a prestigious private institution. Bolanle is the mother of five school-age children. Her long commute to work has not changed her superwoman image to her family because everyone sees how she tries to juggle life's demands. Bolanle is dark-skinned with a mocha complexion and has big, round eyes and full lips. Her short pixie cut allows for her big smile to shine bright with a beautiful smile. Her voice carries a slight rasp but also holds a comforting tone. A true southern belle, Bolanle is grounded in pleasantries and wit. Bolanle is adapting to the northern higher education culture. She is well-established within her career. Early on, she decided to become an administrator shortly before she graduated with her terminal degree. Bolanle is well aware of institutional culture and the benefits of the education community. She finds much of her sanctity in her family and nurtures them. Her weekends are exclusively dedicated to her family.

- Fayola: good fortune and walks with honor.

Fayola joined the Zoom call from her home office with the brightest smile and a beautiful mustard yellow blouse that complimented her complexion. Her children shared the same bubbliness as she yelled down the hall to let them know she is on a call. Behind her smile is a woman who is about her business. She is in her mid-30s and began working full-time in 
education immediately after graduating undergrad. The optimistic realist that Fayola is also parts well with her take-no-shit personality. Life is all about balance with her. Fayola just did the big chop, so her hair is coiled in a baby fro. She wears big hoop earrings and a bold lip to bring her look together. Fayola is a director in enrollment management at a midwestern community college. Fayola's professional experience has allowed her to work in various education sectors including $\mathrm{P}-12$ and proprietary institutions. Fayola is well-respected and values a community with her leadership. She is the definition of grace and deference. When her name is called aloud, people run to her and value what she says.

- Eshe: life.

Eshe's smile and laughter are infectious. She is not one of many words until she is ready to share her thoughts. Her presence is welcoming, and she truly is full of life. Eshe is 5'2", brownskinned, medium build, and the definition of naturalista. Her big, kinky coils and fly eyeglasses enter the room before she does. Even with her reservation to open up, her presence fills the room. Eshe has worked at a selective, private HWI and community college. Her experience in enrollment management, specifically financial aid, spans over 20 years. Eshe's personality wins many over, and she is most proud of her calm demeanor. She is just as much of a family woman as a career woman. Eshe's name describes her perfectly: a person full of life but to others, short of words. When she does speak, she fills the room with wisdom and light.

- Kadeesha: trustworthy and respected.

The small but mighty Kadeesha is a powerhouse in a pencil skirt. Once a corporate maven, Kadeesha found purpose unbeknownst to her in higher education. Kadeesha is an executive, senior leader in enrollment management at a selective, private 4-year institution. Kadeesha knows her keen sense of planning and strategizing, at bird's-eye view, is her strength. She takes 
a pair of 4-inch heels everywhere because "if you stay ready, you never have to get ready." Kadeesha is the imagery of the modern-contemporary woman. She is caramel complexioned and has the silhouette of a curvy runner. Her haircut is a long bob, and she stays fresh with a weekly blow out. Kadeesha says that her hair maintenance is a part of her self-care. She is in her early 40s and has such a vibrant spirit. Kadeesha's personality is innately playful, so it is clear why people are automatically attracted to her energy. She always aims to bring the balance of jokes and laughter with her solemn leadership.

- Mandisa: sweet.

Mandisa is an associate director of her enrollment department. She has worked at both private and public HWIs with a considerably longer tenure at the public HWI where she is currently employed. Mandisa is tall, about 5'9", with a size 10 frame. A lover of dresses and heels, she elongates her legs even more with her 3" or higher heels. The queen of wash and go, she has long, beautiful curly hair that she wears naturally every day. Mandisa is known for her skill and expertise across her campus. She is a former student-athlete of the area. She went to college in the area where she currently resides, and her presence in the community has not changed. Mandisa's voice is soft, but she always has something to say and is not afraid to call out things that she might find unfair.

- Ramla: prophetess.

Ramla works in a specialty position within her enrollment management department. Ramla is relatively new to enrollment management with 3 years of experience as her first few higher education positions focused on student university housing. Hence, she is very familiar with being a higher education professional but now is privy to a different side of the institution. Ralma works at a selective 4-year public institution and truly brings a Tri-state state of mind in the mix 
of recruiting and retaining students. On-campus, the community often asks Ramla if she is a student. Ramla is a brown-skinned woman who wears her hair long with a side part to the left. Lip gloss and brow gel is the extent of her daily makeup routine. While Ramla is in her mid-late 20s, she gives a studious appearance with her round, full-frame glasses. She credits her youthful appearance to her students and states that they keep her young. Ramla is also full of energy and receptive to the world around her, which could also be attributed to the idea that she is young. She has a long-term, long-distance relationship with her partner and lives close to her family.

- Sakina: calm.

Instantly, seeing Sakina makes one want to embrace her because you know she would give the best hugs. Sakina is short and curvy; her figure is similar to that of Tamela Mann. She embraces her belly pudge because she birthed and raised three children. To her, it is a symbol of the gift of life. She is in her early $50 \mathrm{~s}$, but she can pass to be in her early to mid-40s. Her brown skin complements the few gray strands in her hair, which is layered and feathered. She dresses in a practical manner wearing plain shirts and trousers. She loves oversized cardigans and even wears them in the summer at work. Sakina has worked at her institution for 30 years. Because her institution is small, there are not very many people that she does not know. She has worked her way up to the director of her department within enrollment management. Sakina entertained the idea of working in different departments on campus but ultimately found her niche within enrollment management. Sakina's soft-spoken demeanor is not to be undermined or underestimated. She is well aware of the institution and its culture.

- Zarene: the golden one.

Zarene is named "golden one" because of her radiating energy. She has caramel skin and hair to match. She loves big necklaces to match her outfit of the day. Her midwestern accent slips out 
when she gets a little excited while talking. Zarene has over 30 years of experience and has worked at two private institutions. Zarene moved up the ranks of leadership quickly. She is now in a place of her life and career where she wants to "descend from the ranks" and recenter her attention on directly serving and interacting with students of a gifted student program. Zarene's work has come full circle. She is redirecting her attention to student interactions and providing them with assistance through their college careers. She lives life using the motto, "You are only as old as you feel." In her late 50s, all her experiences have helped to create meaning in her life.

- Zena: welcoming.

Zena, with the Angela Bassett arms, has over 10 years of experience in enrollment management. A former student-athlete and lover of sports, Zena's first experience with higher education was in athletics, and she found her way to enrollment management. Zena is cognizant of her professional growth. She has experienced various experiences while working in higher education and is currently using her experiences to navigate enrollment management. Zena loves being active and uses walking meetings as much as possible, especially when weather permits. She wears her hair in box braids to make her morning routine easier. She is the mother of three children: two girls and one boy. Zena wore her institution's branded half-zip pullover for our interview and a headband over her edges from her midday run.

- Leal: dependable

Leal reminds me of Cynthia Bailey from the Real Housewives of ATL, and there is not much she can do wrong when it comes to hairstyles. She also has a model-like stature that Cynthia has with high, strong cheekbones. Leal has invested over 15 years in enrollment management. She started as a student worker in the registrar's office and has remained in enrollment management duties. Now, Leal is an associate director of admissions for her current institution. While she gives 
$110 \%$ to her job at all times, she ensures that she gives herself the same effort after leaving work for the night. Life with her new fiancé calls for time to plan a wedding. Leal wishes to pursue other arenas of higher education once she finishes her doctoral degree.

\section{Findings from Research Questions}

\section{The Road Less Taken}

In what ways do Black women navigate their administrative roles in enrollment management at HWIs? After learning about each participant's journey to become a professional in enrollment management, each participant shared what her role(s) meant and how she navigated the role. The participants stressed the aphorism and Black credence of life, "work twice as hard to get half as far." While the participants prided themselves on their dedication to their work, they also acknowledged the realization and extent of labor on the other side of it. The participants also shared how they thought they had to prove themselves to stay in their space. The extensive labor and effort put forth are attempts to never get caught slacking and a way to showcase their knowledge - all to prove they belong. If there were any signs that they did not have their work together, their counterparts would view them unfavorably or as though they were incapable of doing their jobs. The underlying message of working twice as hard was more profound than just proving to their work colleagues that they could do the job; working hard was tied to their identities and their reputations. All participants cared about how they were viewed and what about their work ethic was recognized.

And it's those kinds of double standards that you have to deal with. And for me, I feel like I deal with not only, uh, the, uh, double standard, but I also deal with that whole doublebinary thing. Being a female and being an African American female, you're forever feeling that you have to prove yourself. —Kadeesha 
As a Black woman in enrollment management, Kadeesha, like many of the participants, understood their intersecting identities of being both Black and women. While having the opportunity to work in this space, at whatever capacity or level, having an awareness of being a Black woman does not fall short. It has pushed these women to be hyperaware and regulate what their work effort will be to sustain.

You know, it's always, I will work harder than anybody in the office. I, at least I try to, I am always worried about excellence. I'm always worried. I usually always spend the first year, year, and a half like not necessarily proving but establishing my reputation. And now I think faculty are like; she knows her shit, you know, so they don't really mess with me too much anymore. -Bolanle

The quote above from Bolanle shows that her knowledge and capacity are viewed and tied to a part of her identity. Not only is "work twice as hard" an aphorism for Black people to navigate life, but it is also an expectation.

Shakina reminds us that not only do Black women have the tendency to work harder, but they have fewer opportunities to make mistakes. Higher education institutions, specifically the office of enrollment management, has capitalized on Black women's efforts to perfect their craft. Conversely, institutional administrators implicitly tell Black women that they are not allowed to make mistakes and must be perfect. Thus, the participants perpetuate the expectation of the superwoman complex that many Black women entail as the core of their identity.

In addition to the superwoman complex (Evans, 2007), Black women are hyperaware of their surroundings as they consider the people and how they function, the institution and its culture, the students and their needs, and many other stakeholders and their priorities. Zarene provided insight into why it is so essential to understand the culture of the institution. She also 
indicated that she intentionally mentored newer administrators, specifically of color, about the culture to ensure they can navigate the institution as best as possible.

But I think as a Black woman, I had to conform to their ways, not so much of them conforming to me; but I had to conform to them, and it helped because I actually went to the school. So I knew the ways of the school. So it wasn't that hard of a transformation for me because I knew the culture already. - Zarene

Zarene talked about conforming to the institution's culture because her enrollment management position required building relationships across campus. For Zarene to successfully do her job, she thought she needed to be a person who others would feel comfortable when working with her. However, for Zarene it was the best way for her to learn the culture and environment of the campus.

It's basically learning what your environment is, and your environment is always changing. And I felt like my environment had changed over the years that it got to a point where I knew it was time for me to move on. Um, but for a new professional coming in, I would say, learn your environment, learn your...the people around you, and how they react to you. - Zarene

Zarene's ability to learn the environment helped her predict what would be said by her colleagues; and from there, she decided if she wanted to hear their remarks or not. According to Zarene, people say stupid things and then make excuses for them. So now, after learning the space, she knew what to say and to whom.

Leal acknowledged in this space as a professional in enrollment management that you must adhere to or adapt to their spoken and unspoken cultures. Many of the participants acknowledged the institution's culture, but Leal pushes the conversation further to call attention 
to those who may be your supervisor.

I've reported to two white people since then. Um, so it's almost like you have to, you have to, um, be a chameleon because you have to adapt to how their culture is and the office and the culture of your supervisor, the culture of the office. - Leal

Fayola also brought another strategic perspective on culture; she recognized that understanding the culture creates a better sense of where you are in it. Further, understanding the culture provides the opportunity to know how to leverage yourself in particular situations such as when it comes to raises, promotions, and professional development.

Another prominent discussion among participants centered on "picking your battles." Picking your battles is another idiom used within the Black community to determine what is worth the fight. Participants acknowledged that fighting every single fight is tiring, so there must be a determination of its worth and why. Besides the tiring aspect of fighting every battle, the participants also talked about how it is possible that too much complaining or too much fighting is negatively perceived. Either you could become the boy (woman) who cries wolf and is never taken seriously especially when it matters the most, or you become the person who is always known for making trouble. Sakina stated that the perception of you to others will not only change, but their reaction will cause them to avoid working with you. She was aware that there are silos in enrollment administrators and each respective office functions alone. Often, the truth of the matter is that each office needs the other. Fayola called it double consciousness-where Black women experience advocating for the student and maintaining relationships with stakeholders at the same time. Double consciousness is a theoretical concept coined by W.E.B. Du Bois (1994) that explains the complex relationship that Black people have with the world. Du Bois indicates that double consciousness requires one to reconcile with the internalize 
perceptions from the outside world, and their own. These colleagues might not have the same interests as you while working for students; nonetheless, Black women have to balance those interests.

Along with picking your battles, it is just as imperative to have people in your corner to cover you when you cannot do it yourself. The importance of allyship is also a shared theme among the participants.

But you definitely need allies. You know, you cannot survive in enrollment management without it. It's just impossible. - Fayola

The look of allyship varied, but all signs centered around having additional trustworthy people to garner insight into what to do as a leader. Mandisa indicated that allyship for her included Black women that she knows around campus, and they loosely share community. The allyship that they have allows them to prepare for situations where potential exists for the university administrators to undermine or slight one's career progress. Nationally, the term allyship has been used to mitigate the collective power of whiteness (Burke, 2020). However, allyship does not necessarily have a color. As explained by the participants, allies hold a different position than you and are not shy to advocate for you, or at minimum, give you forewarning.

More than allyship, the women deciphered the difference that makes some people coconspirators rather than allies. Both Fayola and Bolanle shared the importance of co-conspirators when moving the needle is the mission, yet it is difficult to do it alone. Co-conspirators can be those in higher positions, those of different races, or those of different influences or status. Fayola emphasized that working alone in enrollment management makes it impossible to survive. She acknowledged that the demands of enrollment management are never endingsometimes coming from different stakeholders. Abolitionist Bettina Love (2019) defines a co- 
conspirator as a person who shows up when needed. Love (2019) explained allyship and coconspirator:

Ally-ship is working towards something mutually beneficial and supportive to all parties involved, while co-conspirator functions as a verb, not a noun...can also be men who understand their privilege, and work to challenge and undo patriarchy. (p. 116)

Also, co-conspirators use their positionality to protect and defend rather than only stand by the sidelines and empathize (Love, 2019). From the enrollment management perspective, coconspirators are willing to initiate resistance for an idea and call out inequities within practices. Although the participants acknowledge the need for both allies and co-conspirators, they acknowledge that it takes both time and trust to build these relationships.

The last discussion about navigating enrollment management centers around becoming numb and normalizing. The participants shared that being in a hegemonic space such as a HWI eventually becomes normalized, and you become numb to it.

Like you could do that, but at some point, you've become a little bit more numb and normalized to the situation that it is. Um, and that normalizing doesn't mean it's okay. It just means that it's just the way in which our culture is formed right now at Ivy League University. And it hasn't changed in, I mean, I went to school at Ivy League, so I graduated in '07, and it's always been a very strong HWI and that's reflected in our professors. That's reflected in our enrollment management people. - Zena

Becoming numb is to be desensitized to injustice, institutional violence, racism, sexism, and antiBlackness. Zena confirmed that she was numb and that numbness was harmful to her. To operationalize Hoff's (2020) theory, the numbness Zena experienced epitomizes the ideal of "picked to pieces." Hoff theorizes what the institution does to Black women; pieces of you as a 
person become unrecognizable and potentially unidentifiable to your reflection. Zena acknowledged that little by little, incidents happen whether on campus with a colleague or a student that pick away at parts of your spirit until you become a physical being in a space with indifference to the world around you.

\section{Birthright Outside Boundaries}

In what ways does anti-Blackness show in enrollment management positions for Black women? Anti-Black woman racism is defined as institutional or systemic practices of racist and sexist ideologies that exploit, objectify, silence, and dehumanize Black women (Dumas \& Ross, 2016; Phillips, 2006). Responses garnered from the participants include personal narratives that portray their experiences at their institutions. Anti-Black womanism contextualizes the Black women's experience while working in enrollment. The anti-Black womanism that the participants have faced varies from blatancy to pervasiveness. Kadeesha shared an experience that she had while working with another department. Her white female counterpart carried a condescending and demeaning tone with her while they had multiple conversations of resolving an issue about the disbursement of aid for students. This counterpart poignantly believed that her tone and demeanor with Kadeesha were rational since she was stressed during a mediation session. In the same mediation session where this conflict was discussed, this counterpart shared that she also felt threatened by Kadeesha, although Kadeesha provided multiple examples where the counterpart was the aggressor. White women have often used their race, gender, and fragile femininity as weapons against Black men and women alike. The fragility of white women and white women's tears (Cooper, 2018) have created a security blanket to permit racist behavior without repercussions. As Kadeesha narrated her experience, her story was emotionally provoking for both of us. Her voice, although incredibly strong, demonstrated the hurt that she 
experienced while working at this institution. Kadeesha is well aware of her positionality at her institution. She mentioned racial battle fatigue (Smith, Allen, \& Danley, 2007), the consistent psychological trauma that Black people endure while working in an HWI. This particular experience that Kadeesha shared reflects the insidious academic environment as an administrator.

The experience that Kadeesha shared is not one that is new. Zena also referenced racial battle fatigue. She acknowledged that the experience you have as a person of color does not start and stop at the workplace; it follows you at the grocery store and through your everyday life. Zena mentioned the civil unrest after the murders of George Floyd and Ahmaud Arbery resonated with her but altered how she viewed her campus even more than any other incident that happened beforehand. Zena became conscious of how the University leaders intentionally decided to send out solidarity messages during high contentious events. The lack of care for Black people also became more apparent with Zena's office space. She began leading implicit bias training with her team that improved her relationship with those who reported to her. But, when she does need to work with others across campus, she always checks the invitees' list to know if she's going to be the "only one" or not; more often than not, she is the only one.

One experience that Zena had displayed a complex layering of anti-Black woman racism. During a campus-wide town hall event, Zena was asked to represent her office in enrollment management. Her white male counterpart watched but volunteered to support her during the event if she needed talking points during the meeting. Zena indicated that this is not something of complete altruism from her counterpart. She knows just as much, if not more than this person, and found it completely passive-aggressive and an attack of her competency to partake in the town hall meeting. At that same town hall meeting, a guest messaged all of the panelists "n*gga, 
n*gga, n*gga, n*gga, n*gga, n*gga, n*gga, n*gga, n*gga, n*gga, n*gga, n*gga, n*gga" incessantly throughout the chatbox of the Zoom. Her co-panelists had a side conversation, and they were most relieved that the guest did not send this to the entire group of participants and only to the panel. Sadly, the same panelists' naivety of the offense missed that Zena was the only Black panelist and would take it personally. She later received sympathies, but at that moment, no one spoke up. Someone made the suggestion to debrief after the meeting, but Zena had absolutely no interest and logged off before there was a chance to have a post discussion.

For one particular event, Zena experienced anti-Black woman racism before and during the event. She saved herself from the deepening trauma during the debrief of the guest's behavior. Zena experienced presumed incompetence, blatant racism, and white guilt all during one single town hall event. Presumed incompetence (Harris \& Gonzalez, 2012) address how women with marginalized identities knowledge and expertise are not valued and deemed credible in academia. Zena had to work the entire day before the town hall and returned to work the next day even though the anti-Black woman racism was so intense and traumatizing. Black women have found themselves in compromising positions to confront anti-Blackness, racism, and sexism for themselves and their students. In addition, Black women have also faced these same affronts from their students.

Bolanle shared a story about how Black students or students of color perceived that she did not have sufficient "weight" (influence) at the institution to be a vocal person in the admission and matriculation. She could discern from the conversation that the students questioned her ability to accomplish a decision in their favor. However, after receiving their acceptance, the surprise in the students' demeanor affirms her intuition. The idea of diversifying campus appeared to become sacrificial to merit. She noticed that the Black students who were 
admitted and matriculated to campus were simply random students of color and that the admissions requirements seemed not to apply. She brought attention to the simple notion that Black students can be smart and Black. Bolanle called attention to the lack of effort expended to tap into the list of applicants who are Black and have the credentials to attend such an institution and succeed. Further, she inquired if the university was doing its due diligence to find the desired students. Bolanle acknowledged that students are drawn to her institution because of its reputation. However, Zena shared that she does not want her son to attend the institution where she works even though she attended the institution as an undergraduate student. She recalls that the same issues she experienced as a student are the same issues that students before her experienced and are now the same issues students have today. Nothing has changed, and she fears her son's ability to be successful in this hostile environment.

The narratives of these women and their understanding of how they weigh themselves while they sit on two ends of one pendulum provide profound realization to the environment at HWIs. Often, Black women are required to negotiate their space in academia (Hills, 2019). Black women often have a tale of two worlds while being administrators amid administrative whiteness and holding on to pieces of their identities. Anti-Black womanism also shows up as a form of isolation for Black women. Many of the participants discussed how they were "the only one." It was rare to find more than one Black person within any division.

Zarene provided insight into her former institution, where she was the director. She shared community with other Black people even some who worked in different departments. While they were open to hearing her struggles, they could not truly empathize with her experiences because they did not understand her department's functionality. Eshe made a 
transition from one institution to another. With her move, she began to work with other Black women.

I'm always in this professional mindset, you know. I have relaxed it a little because I have like an admissions person that's near me and she's African American. Well, two, actually. And so, you know, they'll come by, you know, causing trouble. But I didn't have that before, you know, to where we could shut the door for a minute and now play around a bit or just talk, you know? - Eshe

Initially, this was a different experience for her, as she was used to going to work and straight home afterward. She did not share as much comradery with her counterparts as she does now. There are conversations and girl talk that did not exist before in her work life. Although this is not to say that she did not have meaningful relationships with previous counterparts- her community is different.

Isolation is not only a lonely experience, but it is a systemic tactic for Black women. In the trans-Atlantic slave trade era, Black people were separated from one another to prohibit conversing with another in the name of ensuring there was no kind of collusion happening against the enslavers (Kendi, 2016). Similarly, institution administrators have used the same antiquated practices to separate Black women from another. The isolation that Black women experience is intentional. Each woman at very different institutions called attention to the isolation they experienced. More significant than an underrepresentation issue, Black women are aware that being isolated in their roles might be intentional while working in these administrative higher education spaces. I argue that this systematic tactic is rooted in the white supremacy ideology of exceptionalism (Kendi, 2016). Isolation perpetuates the ideology that to be in this academic space, you are different from the "others." 
On the other side of isolation is tokenism. Tokenism exploits the individual labor of Black women (Barabino, 2018). Mandisa discussed the pattern of tokenism at her institution. At first, it began with infrequently providing presentations for incoming students- the events for students of color and Black students. Then institutional administrators asked her to commit to a commercial for the institution using her daughter and another Black man who works in enrollment management. The experience of tokenism that Mandisa encountered happened over time, but became blatant after a while. Mandisa was taken aback by the suggestion to use another enrollment management professional as her husband for the commercial. Mandisa is married and her husband would have been available if they asked. Mandisa could have fit the part with her real family including her child that also attends the university. She acknowledged that because only a few Black people worked at her institution, she became the face of diversity on campus. At that time, Mandisa declined to do the commercial put forth by the department. Tokenism is not always as apparent as that experienced by Mandisa. Furthermore, the dynamics of asking Mandisa to play in part to her Black male colleague for free, demonstrates the overuse and commodification of Black bodies. Bigger than being the face of the institution, the institution had the intent to sell a characterization of Mandisa.

Sakina shared how she was always asked to be on different committees. While grateful for the opportunities, Sakina could not complete her actual responsibilities because of all the other opportunities presented. Like Mandisa, Sakina got to a point where it became unbearable to continue to juggle activities, and she too reached a point where she said no. I argue that the experiences that both Mandisa and Sakina shared objectified them. The institutions had the intent to create proteges of Mandisa and Sakina and perpetuate the mammification (Hill, 2019) of their work relationships. Fayola inherently said that she knows the institution sees her as mammy. 
Tokenizing and commodifying Black women and their labor have more significant implications than being hyper-visible; tokenizing Black women increases the dehumanization, exploitation, and objectification of Black women. Consistently tapping on the shoulders of the very few Black women who work in enrollment management without rest is tiring.

\section{To Be Seen}

In what ways, if any, do anti-Black womanist perceptions affect workload and performance? In my first research question I set out to document and unpack the broader conversation of what it means to be a Black woman professional in enrollment management. Two main perspectives about how participants received the perceptions about them and if perceptions affected their work emerged. Some participants shared that they have to prove themselves or establish and protect their reputation, and others did not feel the need to prove themselves because they were self-confident and assured of their value. Black women have found themselves in compromising positions that require, after a while, that they say no to additional tasks. Subsequently, a review of the relationship between the participant's labor and work environments and how both either support or neglect the participants' professional wellbeing is important. The participants thought as though their labor was excessively used. They all shared at some capacity how they had to create a sense of boundaries to be able to complete the responsibilities that are a part of their job descriptions.

At one point, I was really tired. I felt like they were abusing me. Like I felt like they wanted me to be the face for everything. And I have to put the kibosh on that. Like, I don't want to be in every admissions commercial you have if you want a Black face. So you want to pick me for everything that I could do and that was too much. - Mandisa 
While the quality of Mandisa's work did not waver, over time, she recognized that the additional responsibilities and tasks were taking over her day job, and it was becoming difficult to do her day-to-day responsibilities. During the interview, she began to reflect upon how she was needed to talk to the prospective Black students, the gifted, young Black high schoolers, work expos, and be an actress in commercials. The list was extensive with the additional events and presentations that she completed.

Zena shared a similar conversation about being overworked within her role, especially regarding diversity and inclusion initiatives. Currently, Zena is leading implicit bias training for all of the employees that fall under her supervision. Zena recognized her conundrum. She experienced racism and is now responsible for teaching others how not to be racist. Zena also realized that it took emotional and psychological effort to be the same and only person to conduct the training. She indicated that helping others unlearn the complicity of racism and bias is taxing and can be harmful. Working with her team was rewarding, and she saw that they appreciated her efforts. However, there are instances where the spaces are not always collegial and supportive, particularly when she needs to challenge racist rhetoric and behaviors across campus.

It's like, you have to be the, you have to be the recipient of racism, and you also have to be the racism police and the racism professors, like it's too much to expect us to serve all of those roles. - Zena

The roles that Black women have on-campus presume that Black women should take it all. All roles involve racism and sexism from colleagues, students, and parents, and institutional structures embedded in and perpetuated by oppression. The participants' shared experiences that 
they had with both parents and students while working in their perspective enrollment management offices perpetuated some types of offensive comments or behavior.

I had a mother who didn't want to talk to me. And then she wanted my boss, and my boss was a white male. He came into the meeting and didn't say anything different than I said, but she took it verbatim from him. Alright, whatever, whatever. You know, there were a couple of times where I had to call my boss, and you know, the great white horse comes in and white male, you know, and they think that he has all the answers. So I'm like whatever. And then, you know, that makes him feel like, 'Oh, you know, she couldn't handle it. So I had to come in, you know, and he would refer back to those things all the time. Yeah. He didn't say it in the sense that I couldn't handle it. He just said it in the sense that sometimes, you know, I have to come in and I say the same thing Zar says, but you know, for some reason, they look at my, um, my title and think that I have all the answers, 'blah, blah, blah. - Zarene

The story that Zarene shared is layered. First, Zarene experienced pure racism from a parent who did not want to work with her to complete the student's matriculation. Second, everything that Zarene said was repeated by a white man, which implies her expertise is not valued. Finally, their supervisor's white savior complex fostered a sense of inadequacy within her only because the parent she spoke with did not want to talk to her because she was a Black woman. This happened earlier in Zarene's career before she became the director of her department. Mandisa reiterated that sometimes, titles matter and can lessen the perception that Black women do not hold a place in power to make decisions.

I just feel like they treat you differently when you're not the frontline person. So it makes those experiences a little easier to deal with. I feel like they should only treat them like 
they don't know anything. And so that's part of the reason I feel like sometimes it gets escalated. So then when they feel like they've got somebody with a higher title, then they're like, Oh, they might be telling me the truth. Now, this might be the real deal. -- Mandisa

For Leal, her title as an associate director has not always worked. She experienced a few occasions where students' incidents have escalated to her boss because of visitors' perceptions of her age. Both womanism (Phillips, 2006) and intersectionality (Crenshaw, 1989) takes significant consideration of identities beyond race and gender that marginalizes Black women. It is important to note that although many of the participants have leadership positions, titles and promotions have not always saved Black women from experiencing racism, sexism, or ageism. They are often told as an expectation to stay in enrollment management in the same position without growth. Nevertheless, career achievement is a goal for all the participants. For each participant, career aspirations look different; however, each woman wants more thus perpetuating the cycle of overworking and proving themselves. During this point in Eshe's interview, she expressed the decision to feel as though race or gender had affected career opportunities.

And so then sometimes, you know, there could be some missed opportunities, because someone's going with, you know, what they think you're capable of. And that's what I mean about being put in a box sometimes, you know like I can go to her to, you know, talk to any student or I can give her any upset student. I'm a hundred percent comfortable. She's going to handle it. But maybe this list that I need to be done in by 4:00 pm, I'm not going to give her that because thinking it's not my strength, but I'm just 
handling it a different way. And I'm just trying to be really a little bit more accurate than maybe somebody else who's like, "damn, I'm sending it." - Eshe

Eshe provided a profound context of how Black women are perceived with what they are capable of and what they can do in enrollment management. There is no genuine hesitation to allow a Black woman to handle contentious students and their conflicts. If anything, the participants have been praised for handling conflict with students and parents. However, the opportunity to learn new skills or to do something different outside of handling challenging situations are not evenly provided. Fayola called this "pigeon holing." Fayola was aware of how often Black people are all lumped together. She saw how her white colleagues often apply bias and stereotypes heavily to work with other Black people. While Fayola did not experience pigeon holing, there were expectations for her to be accessible in time of need.

My immediate director, he was a Black guy, and they assumed that I would assume his responsibility and continue to do everything. And it was interesting how the conversation was like, Oh yeah, we know you got, you got it here, the team respects you. You're going to get everything in line. And so people use that word respect with me a lot-I think just based on my military background. And so they know, I like a kind of discipline and order, and I respect the chain of command, but I think at some part, you know, that kind of went out the window, like, "hold on for a minute". And he came in, and it was kind of like almost like a slave master. Like you're going to keep them in line. You're going to get them to do what they need to do. And we're going to hit our numbers. Right? And I was like, hold up; we deal with people here. Like this is my team, but I formed a community with these people. These are like family. So it just doesn't work like that. Like you kinda gotta let them get over the fact that you just fired our boss, which was a Black person. 
But then he didn't really kind of want to hear it that way. And I just told him, like, this is probably not the role for me. And he kind of looked like, well, what do you mean? I said exactly what I said. This is not the role for me, I said, because it's not what you do, it's how you do it. And I think even how you let him go, you know, even though I was, you know, his counterpart, I was, uh, beneath him. I mean, you didn't have a conversation with me. You expect me to come in the next day and hit the ground running like nothing ever happened. - Fayola

While Fayola's experience did not necessarily pigeonhole her in terms of holding her back with career progression, it did create an image of her that she can and will do anything for the institution's sake. Furthermore, Fayola's experience exhibits how Black women are often dehumanized; she was denied the opportunity to emotionally process the significant shift in front of her. Her experience epitomizes the lack of care for Black personhood (Hull \& Smith, 2015) for her and her supervisor. How her supervisor was easily disregarded represent the historical worth and dispensability of Black bodies (Fields \& Fields, 2014). The imagery of Fayola's capacity came as a slight admiration that she can do the job, but it also neglected everything that she stands for. Fayola's supervisor treated her as if she would be the next mammy, mothering and disciplining subordinates to fall in line. For Fayola's experience, the anti-Black perception of Black women's will and capacity neglects self and boundaries.

\section{Plays of Perception}

What are the perceptions of Black women who work in enrollment management? Black women in enrollment management believe others perceive their jobs as necessary positions. The participants shared how their counterparts exclaimed it would be difficult to operate without them. However, there are two polarizing positions revealed about their knowledge and 
competency. On one end, the participants indicated that there is a looming presence of presumed incompetence. In contrast, participants shared that their colleagues perceived them all-knowing, and everyone was dependent on their expertise. Mandisa recalls how often her colleagues ask her how to perform processes or how to stay compliant while serving students. For Mandisa, this is contrary to how her office viewed her expertise when she first started; she was often told that she was wrong and demeaned, even when she was right. Question 2 provided an example from Zena where her colleague was comfortable and ensured that her presentation went well. Although she knows that he would have never done that for anyone else on her team. Mandisa shared an experience early in her career where a colleague made the insinuation that she did not know what she was doing. Ramla shared how she is conscious of who she is and how she could be perceived.

Ifind that in a school like mine, there are a lot of people that have never interacted with people outside of their own race, whether staff or students. So I think sometimes the way that students treat me can be a little bit different. They don't even know that, you know. This whole implicit bias thing, I feel definitely, definitely they're trying to think of other things about me. Like, you know, on Gmail, you can put a picture of yourself so that when people email you they know who they are talking to. I don't, I don't put my picture. I put our torch cause I don't want people to respond to me differently or assume things about me before they even meet me. - Ramla

Ramla does not know what her colleagues and students could think of her, but she is aware of the traditional tropes and stereotypes that are attributed to Black women. Underlying message of Ramla's narrative is the awareness of interacting with people outside of your race. Such an awareness leads to hypervigilance to ensure that everyone around you is comfortable even at 
your own expense or comfort level. The participants labeled the tropes of angry Black woman, strong Black woman, and mammy to explain how they believe their institution may perceive them. Fayola names two well-known tropes of mammy and the strong Black woman. And I think one of the other challenges is that the stereotypes that we have as Black women, being angry Black women, play the role of mammy. I think those stereotypes, if people were honest, we experienced oftentimes. I think I had a conversation with a colleague before and we're talking about one of the issues that was going on, on campus. Soon after the media got a hold of the issue, and a white woman wanted to talk to me. She was like, "Oh, I want us to talk to you." She's like," it just seems like you're angry." I said, "no." And I said, "I think what happens is you, you mistake my passion for anger." And a lot of times, we become so passionate about things that, um, people are not as affected by issues and situations that are close to home to me, as a Black woman, that I see students experience that maybe I necessarily have experience with a family member or friend. That's one of the things that really rubbed me the wrong way is the stereotype, or even like the strong Black woman comes up a lot. Even when you take the approach of just not really saying anything, or then they consider you're angry or you have, um, an issue or if you're just like, oh, I'm cool, or definitely don't express your feelings about, well, you know... what you said, kind of offended me, then you almost kind of become like a punching bag. You're a strong Black woman. And so you'll...actually even in enrollment management, I see that with Black women sometimes like Black men sometimes portray that with me in the sense of, Oh, you're good. You can handle it. -Fayola 
The strong Black woman trope is one that has shaped how Black women are viewed and what all they can and should endure. Excessive force has been used in different fields. For instance, Black women were clinically studied and tested to evaluate how much pain their bodies can endure before asking for pain relief (Kendi, 2016; Washington, 2006). According to Harris-Perry (2016), the image of a strong Black woman,

Defines the mantle that the nation, Black communities, and Black women themselves expect African American women to assume. The social construction of Black women's citizenship and identity around the theme of self-sacrificial strength is a recurrent motif in Black women's lives and politics. (p. 16)

Harris-Perry implies the strong Black woman image impersonalizes Black women and their personhoods and identities are co-opted. Black women are often expected to be the strong Black women even in the realm of higher education.

Another trope that Fayola mentioned was the angry Black woman. Other participants shared that they did not want to carry the angry woman image, but they were conscious of how they responded to adversity or even concerns about students and procedures. The emasculating matriarch (Harris-Perry, 2016) connotation defines the angry-Black-woman image and supersedes the message that often the participants want to share. Cooper (2018) proclaims she is mad as hell and provides the context of historical and personal events that ignited her anger. Often, Black women are not allowed to be mad. Needless to say, Black women often do not have the privilege to display any kind of emotion that is not aligned with the subservient nature of a nurturing, mammying trope. Withholding her true emotions dehumanizes the experience further, and more important, the livelihood of Black women professionals in enrollment management. 


\section{The Circle in the Square}

What strategies, knowledge, and skills do Black women employ to do their jobs in enrollment management at HWIs? In addressing my research questions 1 through 4, I confront the contradicting relationships Black women have within their enrollment management roles. In question 5, I provide some context for how Black women survive and persist in their roles. The most prominent strategy that Black women have used is compartmentalizing work life from personal life. Many of the participants shared regret that their journey took a while for them to understand that shutting down work is healthy when they are off the clock. The Coronavirus pandemic has also played a role for Black women to reassess what leaving work looks like when your home is also your office space. The pandemic has shifted what physical separation of work and home. Bolanle acknowledged that she may work 12-hour days, but when Friday comes, she is completely off work and dedicates her time exclusively to her family. Kadeesha had a similar account. When she leaves work, whether it be 6 p.m. or 8 p.m. she is off work and does not work once the day ends for her. She finds joy in getting lost in music and working out.

One of the biggest things I've learned and I would've told myself, I used to take the job home emotionally. It was hard to-when you got off work to let that go. I had a hard time with that at first. But once I learned to do that, not necessarily like having to work after hours was different, but like emotionally carrying that, like that would be exhausting. Like all the stuff that people don't want to do all day, especially answering the phone, wasn't doing all that. If I were to learn to let that go sooner, I think that would have saved me a few gray hairs. It just helped me grow a little faster, but that was hard for me to do. - Mandisa 
The work that Black women partake in with their jobs is all-encompassing. They are available for students in whatever capacity students need them. The nurturing mannerisms of Black women who take care of their students' needs are burdensome and can be hard to turn off. It is also difficult to walk away daily from racism and sexism in the form of microaggressive commentary and behaviors.

I usually have a vent person or two because sometimes, and normally I don't want to say I'm a hold-it-in person, but I kind of am. Sometimes I'll just like, whatever like I keep it in, but when it's work-related, for some reason, I feel like sometimes I have to get it out or else I'm gonna go into work the next day, still with attitude and that's not good for anybody. I don't wanna. I don't want to come into work angry even though a lot of stuff that gets done should make you angry. I don't want to come in like that; it's draining. Like I don't want to be angry, I'm like being mad cause it's literally draining, like when I'm really upset about something afterward, I'm like household tired. - Leal The participants shared the isolation that they feel in their roles. Underrepresentation or lack of diversity in the office creates an environment that makes it difficult for participants to share their experiences. Sharing their perspective would require too much cultural context for the coworkers to understand fully the message in their experiences. However, when the support and understanding is present, it is a beautiful thing.

I think one thing about us that's really good is we're really good at leaning on each other. I think we know the importance of who we are, what we're doing that is more than just, about us as individuals. So we're trying to support one another. And so that's one of the things that I like really appreciate, um, that we are very good at networking and staying in touch and you know, kind of that sorority thing, you know, where we are just like, 
okay, you need me, I'm here. You know, the kind of thing where there is information you need, or where you need support or a listening ear, whatever the case may be. So I think that that's been like a really good thing. And I think we are really good at trying to bring each other up. So, you know, I mentioned those. So you may find like they, they make us and maybe they don't realize that, that they're making us look bad, that they're not represented as well. But for the most part that, we support each other, not lacking, not having that jealousy, you know, I mean there was me and someone, you know, we went for this role together and obviously only one person could get it. - Sakina Sakina alluded to the idea of sisterhood. McCarthy (2013) defined what sistership means in the higher education spaces and provides contextualization for women building relationships to sustain their higher education roles. Sistership also allows for those within your friendship circle to keep each other accountable.

And I tell everybody, if you died tomorrow, shit, on Wednesday, your position is going to be posted on Monday, and I've seen it happen. And so, I believe in work-life balance, but I also believe you can't have a work-life balance unless you have a community. - Fayola Fayola considered the reality of working for a big business such as higher education and shared her experience and how she arrived at this reality. Her experience does not deter her from doing her best, but it does remind her to also take care of herself and those who are close to her to take care of themselves - people in your corner who share the broader perspective of the roles they have is invaluable.

But just having people who are ride or die in your life makes it all worth it. Like at least it makes it worth it for me. And I guess it kind of goes back to what I was saying earlier. I was talking about being your authentic self and how white people, just in my mind, just 
get to go through life, always being authentic. I was telling my brother, you have to like surround yourself with people who you can be authentic with-with that, there's no level of holding anything back... and to have that authenticity in and of itself is honestly a coping mechanism. - Zena

In conclusion, having supportive people around you, whether they are inside the office, the department, the institution, outside of the institution, or at home is imperative to persist in enrollment management. The participants were intentional with their conversation about relationships and stressed the need to have people who are able to look after each other, support you, allow you to be you, and keep you accountable for your behavior and your care for yourself.

\section{Emerging Themes}

Four themes developed from the findings that are related to the research questions. Theoretical supports were used to provide a deeper understanding of the interpretations. The emerging themes have a twofold purpose. Black women's lives meet at the consequential crossfire of their existence: being Black and being women. The polarity of Black women's lived experiences is reflective in their work world of enrollment management. The themes depict the duality that Black women experience every day. A constant battle exists, conscious or not, where Black women must choose themselves, their families and communities, or the institution. Hardly ever did the participants indicate that they were able to have it all or they had to make choices of what to prioritize throughout their careers. The dialectical elements in each theme demonstrate the polarizing experiences that Black women face within enrollment management roles. Their experiences in these roles cannot be limited to a monolithic voice and must acknowledge how they traverse the institution without providing a summative modus vivendi. These themes I identify are: 
- A Credit to the Race and Levels of Black Awareness

- Under Her Wing and Institutional Mammying

- Institutional Gatekeeping and Moving the Needle

- Black Girls Must Die Exhausted and Negotiation of Space

\section{Theme 1: A Credit to the Race and Levels of Awareness}

The dialectical elements of Black women working in enrollment management and their Black identities are covered under this theme. Several participants shared that they are often the only one within their departments. The implication of being the only one is rooted in anti-Black exceptionalism ideology. Tokenism is another concept that is adjacent to the exceptionalism ideology. The alienation that Black women experienced made them acutely aware of themselves when compared to their departmental and campus demographics. Therefore, the participants were cognizant of themselves and their positions as Black women in the field. This theme intersects the construction of whiteness through societal perceptions and critical awareness of Blackness.

Michael Eric Dyson (1996) contextualized what it means to be a credit-to-the race. He premised credit to the race on Hurston's (1942) essay, "The Pet Negro," in which Hurston implies a social race agreement of implicit subserviency to whiteness. A credit to the race layers the ideologies of individualism, exceptionalism, whiteness, and anti-Blackness (Dancy \& Edwards, 2021; Kendi, 2017). The exceptionalism ideology feeds anti-Black perceptions of Black inferiority. Exceptionalism affirms that something must be different and exceptional of those chosen for the job. Embracing the credit-to-the-race pedagogy is a manifestation of internalizing whiteness: One would believe that it is okay to be the only one. 
It's so individualistic. We're like community—Black and Brown communities, I feel like

ours is really communal, but the institution kinda like strips you from that community, like now it is so individualistic where it's literally a competition where it's like, either it's hard or like that tokenism seems like it's glorified. And the proudness people hold in being the only one. I don't feel like that is cool. —Kadeesha

Black people are considered a credit-to-the-race when positioned on a pedestal adjacent to whiteness and benefit from whiteness. The white gaze considers Black people "model Black people" as long as they uphold the social race agreement, stay in their positions, and earn whitelike benefits and white praise. Once an incident occurs that does not hold the perfect Black exceptional model, white grace evaporates and Black people are then treated like all other Black people. The credit-to-the-race phenomenon is apparent in enrollment management at HWIs. Black women are siloed within positions where they do not work with other Black people or people of color. They often experience tokenism. Because of this intentional underrepresentation, the participants were aware of their positionality at their institutions. They came to terms with the perception that they are inherently representations of Black people, particularly Black women. The positions they hold help provide access and opportunities for students, and often they are privy to insight that they would not have unless they were from privileged backgrounds or in the institution. Regardless of institutions or endowments, Black women often create ways to be resourceful to students.

Most participants are aware of their pedestals, their level of awareness of their position to whiteness, but how what that means varies among the women. Levels of participants' awareness of this trope connect to the theoretical work of Cross (1991), Fanon (1952/2004), and Clarke and Thomas (2006). The concepts of Black identity and Blackness have faced scrutiny since 
colonization. Because of this scrutinization, Cross (1991) shares that Black identity supports two factors: reference group orientation and personal identity. Reference group orientation constructs race-esteem, racial attitudes, group identity, race awareness, and race evaluation. At the same time, personal identity builds self-esteem, self-worth, unconscious-self, and self-confidence. Reference group orientation and personal identity are crucial to understanding how Black people have internalized racism and anti-Blackness. Reference group orientation "relies on people or groups as a point of reference...but which persons or groups one relies on revealing the specific nature of one's identity or reference group orientation" (Cross, 1991, p. 45). One is required to be invested with critical consciousness to be aware of internalized racial attitudes. Each participant viewed their Blackness in white spaces and the proximity to whiteness differently. Because their Blackness varied and how they navigated the institution differed, each participants' navigation looked different.

I argue the convergence of a credit-to-the-race phenomenon and levels of awareness phenomenon of Black identity illustrates the dichotomy that exists for Black women. As Black women face gendered racism, they face self's and the group's reference and perception. HWIs become one of their reference group orientations and their personal identity is affected by selfperception and external factors, which feed their self-concept of Blackness. It becomes a dangerous slope when whiteness feeds the ego, and one becomes a model credit-to-the-race Black person. Subserviency of being a credit-to-the-race individual can be conscious or subconscious based on a person's awareness level. The dialectic relationship between positionality and awareness requires critical awareness. Lack of such awareness allows participants to internalize racism and perpetuate anti-Blackness racist thinking onto students and colleagues. 
I always thought within [enrollment management], for the most part, you felt like, you didn't want to say like the token Black person, but you're that lonely person, because for the most part in a lot of areas, there is going to be one or two of us or none. So I think I was always, like, you get to be just a little conscious of that, that you're just always around this, this group where, you know, that thing, I always joke about Sesame Street. One of these things is now like the other, you know? And it's like, that's sometimes where it's just like, okay, you have to acknowledge that you are not exactly like them. - Sakina While the participants were not fearful of losing white praise, per se, they all were incredibly aware of themselves on their campuses and the implications for the representation of Black women. They knew the way they carried themselves had lasting effects that could potentially change the trajectory for themselves and other Black women after them. All of the participants knew that they were creating a pathway for those to come after them in some capacity, regardless of whether they were the first or the only one (Cross, 1991). They were all intentional with the relationships they created and maintained knowing that those experiences carried weight, not just for them, but also for all Black women.

The convergence of internalizing exceptionalism and their level of awareness also served as a vehicle to determine how the participants navigated working with other Black people and building community on campus (Dyson, 1996). Those who demonstrated more critical awareness were more likely to build community and own their Blackness. Those who showed lower levels of critical awareness acknowledged their Blackness but did not build a community. Some participants had a strong critical sense of self before their positions, which carried throughout their careers. Others experienced some loss of themselves in white praise that made them embrace their Blackness more. Institutions that center Black women in enrollment management 
as a credit-to-the-race perpetuates anti-Black womanism. If Black women internalize the antiBlack ideology, Black women will internalize the mischaracterization of themselves that only serves and perpetuates whiteness.

The institution uses Black women as non-human figures rather than people (Camp, 2004; Evans, 2007). They do not have space for errors and mistakes, nor is there space for their feelings. Upon reflection, the participants shared that they are held to different standards than others and expected to teach and train those who come after them. Throughout history, these sentiments follow us where expectations upon Black women reach unrealistic ideals to provide both labor and love to the institution (Hill, 2019).

The juxtaposition of becoming a credit-to-the-race and a low sense of Black identity and awareness shape how the participants felt about being around other Black women and what mentorship looked like for those around them. The participants that had a low sense of Black identity and believed they were a credit-to-the-race were more likely to internalize anti-Black ideals. Those who had a higher sense of Black identity and understood what a credit-to-the-race meant within the institutional structure capitalized on that structure to create opportunities for Black students, Black professionals, and other people of color.

\section{Theme 2: Under Her Wing and Institutional Mammying}

Under Her Wing and Institutional Mammying specifically communicate the dialectical relationship of how the institution commodifies and exploits Black women's goodwill and cultural values. Collins (2009) indicates that Black motherhood is "a series of ongoing renegotiated relationships with Black children, the Black community, and self"' (p. 176). The participants' intrinsic and innate motivation to play the role of othermother (Collins, 2009) to marginalized students and some colleagues becomes a benefit that the institution markets 
regardless of the method and mannerisms that each participant had. Their care for the students and the institution was the same. Each participant took pride in knowing students that they helped at some point in the matriculation process graduated and became useful adults.

"Under her wing" is a metaphor for Black women taking special care of Black students and presumably other students of color. They were able to have more authentic conversations with Black students and guided them through their encounters to ensure they could succeed at the institution. The participants were more likely to serve as a one-stop-shop for Black students by using their social capital and networks on campus to meet the students' needs. However, no student was ever intentionally treated less than anyone else. While speaking with the participants, their value to the institution became more apparent. The innate mother-like tendencies are marketable values to the institution. Hiring a Black woman for one specific job has typically led to her doing more than required, yet it is always expected.

In 2019, Hill conceptualized academic mammying while unpacking Black women's experience while working in faculty roles at HWIs. Hill provided the context of what Black women have endured as they sustained roles in the ivory towers. I appropriate Hills' academic mammying to institutional mammying. Academic mammying centers on Black women faculty's experiences, and institutional mammying provides space to center non-faculty Black women in higher education. Both academic and institutional mammying use the institution as a frame of reference to unpack the participants' experiences. The participants provided insight into the demanding complexities of their roles, specifically enrollment management. They remain student-focused as the students transition throughout the administrative processing demands of the institution. 
Institutional mammying is an exploitation of other mothering, and the participants often caught themselves trying to determine if and how the institution overused them. Other mothering (Crenshaw, 1989) explains the phenomenon of Black women mentoring, caring, and healing others. Mothering stems from the heart and goodwill; mothering is something that Black women do. When mothering is commodified, it becomes mammying. The concept of mammying addresses the socioemotional taxation that many Black women administrators and faculty members alike experience (Hill, 2019). The institution exploits the will and cultural value of Black women. The other mothering for many of the participants does not begin and end with students. Other mothering expands to the advocacy that students do not know they receive behind closed doors, to the subordinates of the administrator, peers in and out of the institution, and their supervisors.

Institutional mammying is different from other mothering. It is an exploitation of cultural values. Hill (2019) evaluated the responsibilities that Black women have at their respective institutions. Furthermore, institutional mammying contains power dynamics and exploitation of labor that other mothering does not. Institutional mammying implies subservient attitudes and behaviors to the institution's stakeholders including students, colleagues, faculty, and students' parents. The helping nature of Black women enables this servitude that caters to institutions. Many participants are happy to know that they are helping, whether that be pushing the institution forward with inclusive missions or helping individual students and positively affecting their lives to create a new, heightened social mobility for them. Institutional mammying is ultimately at the will of the institution. To provide an example, some of the participants worked for their institutions in all capacities. There were no boundaries to what the institutions were willing to ask them to do and participate in relating to recruitment and retention. The participants 
had to get to a point where they demanded boundaries from the institution because there seemed to be no end in sight for the overuse of their labor.

And so one of the things I'm wanting to have asked of me is, "what keeps you up at night?" And it's thinking about my students and them having resource access, you know. The institution that I'm in is a food desert. So even in that particular space, you know, of course you think about the academic side, but you also have to think about the well-being of your students, their mental health, you know. Are they okay with finances or their books? Do they have access to computers? So, so those are some of the things that leadership necessarily doesn't see. In enrollment management, you think about it as the numbers, you got the students, we're up in enrollment and you guys say you don't think about the whole totality of that particular student. And so that kind of know-how, even as a Black woman, um, it's in our DNA to care about people, not just being transactional. But it's genuine, we really care and make sure that the student is okay and looking at them holistically and not just to act like, Oh, we just got an enrollment. - Fayola The contention of institutional mammying and other mothering lies at the will of Black women's ability to know and say when enough is enough. Because the institution interprets Black women's innate mothering as a commodifying asset, the institution will never create boundaries to protect Black women. The participants realized that at different stages of their careers. Some tempered what they were willing to say yes to and others decided to leave and find employment elsewhere. The fine line between institutional mammying and other mothering usually balances on the tightrope of neoliberalism and how the institution can marketize their goodwill (Giroux, 2005). Seeing the fruits of the labor that the participants instilled in Black students and some colleagues gave purpose, so it was a joy to do and continue to do. 
Anti-Black womanism draws attention to the ways that Black women are exploited. Their work and bodies are capitalized and commodified for the namesake and optics of the institution. The overuse of Black women and their bodies is objectifying and dehumanizing. The institution treats Black women like robots who are capable of giving a warm-felt hug rather than humans who work for 8 hours a day, similarly to all of their counterparts. Positions in enrollment management can impersonalize Black women's experiences while simultaneously requesting them to care for everyone's socioemotional, financial, and academic needs.

\section{Theme 3: Institutional Gatekeeping and Moving the Needle}

The theme institutional gatekeeping and moving the needle speaks to the dialectical relationship of Black women's duties to progress within the institutional realm of their positions. In this section I focus on particpants' jobs as enrollment management professionals and unpack their professional duties and goals. The participants understand that their positions are complex. There are conflicting interests to diversify the campus while maintaining the institutional culture. Each office within enrollment management has its own goals; however, the workers in each department must come together to build new freshmen classes. These offices work with other departments and people across the campus for student recruitment and student retention. In their

roles, participants work on individual and institutional issues for students based on safety, academics, and housing. The complexity of enrollment management positions deepens when the participants balance the institutional demands and culture while balancing their identities and mammying students and campus partners. Huddleston (2000) introduces the theory of gatekeeping, explaining how the admissions bureaucracy functions to recruit, admit, and matriculate students to campus. Although gatekeeping is inherently the responsibility of the 
admission offices, the participants perceive that regardless of their role in enrollment management, gatekeeping has become their primary responsibility.

Gatekeeping is a selective and repressive practice that institutions use to control the student population (Huddleston, 2000; McDonough \& Robertson, 2012). Institutions look for students who can fit as a part of the campus and uphold the level of academic rigor established by the institution's reputation. While students do have the choice to pick which institutions they show interest in and apply to, they are also at the mercy of the institution that grants them admission. Gatekeeping stems from neoliberal practices of meritocracy (Markovits, 2019). While gatekeeping usually focuses on the admissions process, gatekeeping is also applicable to the hiring of diverse staff.

People hire people that look like them, and I'm not going to dispute that. I don't only hire people that look like me because I do. But I hire people with the mission that I've been put in a role to bring people of color into an organization, but I also hire the best people. And I've probably had the most diverse, uh, population in that institution. In general, student affairs is the most diverse organization in the institution. But when you look at the organization collectively, and you've been in existence for what almost 50 years, the university that is almost 50 years and you haven't moved the needle, you're not looking for diversity. — Kadeesha

Those in enrollment management and a part of the admissions selection process choose students who fit and align with the institution's goals and academic rigor. The participants see themselves as people who are helping young, emerging adults pick their life's journey. The participants called out the importance and the seriousness of being supportive for students and how their interactions with the students affect the trajectory of their lives. Concomitantly, the 
participants considered students' well-being and their success and the potential of what it could look like at the institution. Gatekeeping includes frank conversations about students' financial viability at that particular institution. In addition, gatekeeping includes discussing academic readiness with the students and giving them possible alternatives to immediate enrollment.

Gatekeeping is a repressive theory and practice (Huddleston, 2000; Markovits, 2019). It is clear that the participants understand the weight of their role in how the lives of students play out. The complexity of working in enrollment management also must adhere to federal and state regulations, institutional policies, and institutional culture. The unspoken responsibility of being an institutional gatekeeper holds its level of_complexity. The participants battled back and forth with how to be resourceful for students and be conscious of detaining themselves from setting up students to be in an environment that is not conducive and yet maintain compliance.

Being institutional gatekeepers also creates a duality for the participants, which is challenging to manage at times. The participants thought they were in compromising positions to help students decide what was best for their futures. In Chapter II, I introduce the concept of gatekeeping. Gatekeeping is a foundational building block of enrollment management, one of its first steps, and one person chooses who will attend an institution (Huddleston, 2000). Now, the roles have evolved. Black women are placed in positions, both in leadership and forward-facing, to become gatekeepers for all students but specifically for Black students, other students of color, and marginalized and minoritized groups. Kadeesha explains the complexity of moving the needle as a Black woman:

I have to tell you; enrollment management is tough. It's tough. And it's equally as tough when you, when you're trying to move the needle, and nobody wants those needles to be moved, and they can put it on people of color in those positions. — Kadeesha 
"Moving the needle" is a noun just as much as it is a verb. Moving the needle infers the labor that the participants have been a part of to change the institution's policy toward supporting Black students better and other students of color as well as colleagues of color. The concept of moving the needle spotlights its parallel nature as compared to gatekeeping. The participants shared how they contributed to making change for Black students on campus. This concept encompasses difficult questions that might require more thinking than action initially. For instance, while discussing the recruitment of Black students and other students of color on campus, a critical question to ask is, "If we bring them here, how will we keep them here?" Institutional gatekeeping is a trap, and it is a product of neoliberalism (Giroux, 2015) as it reinforces the anti-Black ideals and perceptions that portrays Black students do not deserve to attend school at these institutions. Participants' responses peel back the layers of the complexities within the systems that create enrollment management structures. There is a combination of meritocracy, free-market, individualism, and capitalism that drives enrollment management; enrollment management has become the sophisticated, bureaucratic machine that sustains settler-colonial and anti-Black ideals. The inherent oblivion to different in social capital and mobility dismisses that higher education is an item for sale, admission and discounts are circulated within the elite and middle class (Markovits, 2019; Selingo, 2020). Amid the capitalist and meritocracy traps lies anti-Blackness and anti-Black perceptions that Black women must resist for their students as well as for themselves. Many times, moving the needle consisted of fighting back against anti-Blackness to change the narrative of how Black students fit in these spaces. 


\section{Theme 4: Black Girls Must Die Exhausted and Space Negotiations}

Society praises Black women for their self-sacrificial characteristics and tendencies (Burnley, 2020). According to Hine (2020), “Black women's legacy is one that accords equal weight to service and sacrifice" (p. 55). Black women's martyrdom neglects their wants and desires for those they serve. In this fourth theme I unpack the dialectical relationship by first describing how Black women create and negotiate the space around them and sacrifice something for themselves in favor of someone else's best interest. Space negotiations include evaluating opportunity costs and prioritizing the gains more than the losses of becoming selfsacrificial.

Massey (1994) explains that space is seen as political and space/time- - space cannot be separated from time. Black Girls Must Die Exhausted is the title of Jayne Allen's 2018 novel where the main character, Tabitha, faces the clock about having a family, maintaining her career, and taking care of herself to heal her ailments. Tabitha tries to handle the complexities of her life while the words of her grandmother often play back in her mind that Black girls must die exhausted. The main character shares the same battles that my participants faced: being required to make decisions about themselves and their lives in relation to others constantly. The participants were intentional with every decision they made professionally and personally. They strategized, negotiated, and leveraged resources at work and home. They found that it was their responsibility to advocate, seek and look after Black students and students of color, push their institution's agenda, and find time for themselves and their families. The juggling act that Black women participate in daily is a requirement and the price of entering and staying in this space.

While Eshe loved working at the institution where she had the longest tenure, she realized that she probably stayed too long. She acknowledged that she stayed there for the sake 
of her children's and husband's educational attainment. Her children had the opportunity to attend the institution where she worked for free, and her husband obtained a graduate degree from the institution. Even though she realized that life could have looked different, she is aware that what she did was for her family and she did not regret it. Her career could have looked different, but she also recognized that she did not know if she was ready for more responsibilities than what she had while working, commuting, and tending to her family. The cost-benefit analysis is a process that Black women often use to exist and persist in HWI.

Bolanle provided insight into her friends who work at prestigious institutions within the local proximity of her institution. Her friends have the big fancy title and work at prestigious institutions, but they do so at the expense of their mental health. They seem to suffer from workinduced depression and anxiety because of their arduous work environments at their respective institutions. Bolanle rhetorically asked, "at what cost? Do the name and the prestige of the institution deem worthy of the loss of peace of mind?" She used their experiences to guide how she negotiates her space within her institution and relies heavily on her family for her sanity. She believes that all of the turmoil — ageism, sexism, and racism—is worth it because she is providing a comfortable life for her family.

On the other hand, some participants sacrificed their relationships for their work. Kadeesha had a prior working relationship with her current supervisor. He wanted to continue to work with her when he changed institutions, so he brought her with him. For lack of a more appropriate expression, Kadeesha has caught hell during her experience at her institution and left her supervisor-friend multiple letters of resignation but she has stayed because she knew her friend needed her. She stayed in a place that drained her to protect him because she did not want him to do it alone. Hoff (2020) conceptualizes the phenomenon of Black women "picked-to- 
pieces" when she says, "Picked to pieces is used to convey change to one's physical, psychological, spiritual, or emotional self" (p. 41). Each participant indicated that at some point of their careers, it was difficult to find any kind of balance and they all reached some type of wall where it became unsustainable; not all found what that balance meant but acknowledged how their work lives made them unrecognizable to themselves personally. Many of the participants shared how their jobs have taken significant effort to navigate and balance with their personal lives and their well-being. Throughout this study, I came to realize how Black women speculate what could be despite what is. I do not label this as something fanatical, but I recognize the world that Black women try their best to create around them even when the odds are stacked against them.

Black women's existence is political (White, 1999). Space negotiation is a political necessity, and Black women must be political agents for themselves and others. The capability to find joy in life is a component of pleasure politics. Love (2016) discusses the idea of pleasure politics and how Black people are eternally indebted to others' will; however, through the quest of liberation, they remember to find joy and become one with self, which is vital to persist. While Black women inherently care for the world, they do not have to at the expense of themselves. Walker (1989), in The Color Purple, depicts the evolution of Celie. Throughout the story, Celie undoubtedly gives all of herself to everyone around her: her sister, her father, her husband and his kids, and her lover until there was nothing left of her for her. It was not until Celie begins to revisit who she wants to be and what it will take for her to get there that her life changes and becomes meaningful. Metaphorically, Celie's story of becoming is considerably similar to my participants'; they have all shared their encounters of being overused and battered 
by the antagonist (i.e., the institution and Mister) but have had to learn how to navigate and negotiate their space to save energy and refuel themselves for the next day.

Although often implied through anti-Black perceptions, Black women do not have to die exhausted, yet this seems to be a privilege to learn and experience. Black women often experience a double burden of intersectionality: being Black and being a woman. In addition, that does not extend to nor account for other intersecting identities that Black women might have based on sexual orientation, abilities, education attainment, and socioeconomic status. Often, Black women are praised for their overexertion to fulfill everyone else's lives but called selfish when they want to preserve their energy and efforts for themselves. The idea of self-sacrificial is rooted in anti-Black womanism, which assumes that Black women must live lives that center other people. If they fail to do this, then they face being referred to as some trope that devalues them. 


\section{CHAPTER VI: FINDINGS AND RECOMMENDATIONS}

The purpose of my research was to come to understand the duality of anti-Blackness womanism faced by Black women while working in enrollment management at HWIs. In Chapter VI I provide a discussion of my prominent findings as they relate to the literature involving Black women working in higher education at HWIs. Finally, a discussion of the implications of the study, recommendations for future research, and a brief summary are included.

\section{Interpretation of Findings}

The 10 participants who participated in this study are Black women enrollment management professionals. Their professional titles spanned from advisor/counselor to chief enrollment officer. Even with varying enrollment management positions, study data show four emerging themes that substantially contextualized the experience of the participants.

The themes developed from this study are defined as follows:

- A Credit to the Race and Levels of Awareness

- Under Her Wing and Institutional Mammying

- Institutional Gatekeeping and Moving the Needle

- Black Girls Must Die Exhausted and Space Negotiation

\section{A Credit to the Race and Levels of Awareness}

Dyson's (1996) conceptualization of credit to the race acknowledges the social contract expectations for Black people to be complicit to racism and the structure of whiteness. Countering complicity to white supremacy is the level of awareness for Black identity. The repercussions of making mistakes are tediously and viciously criticized for any action that either falls out of the graces of those for whom they work or out of the tropes they are intended to live 
within, breaking the social contract aligning with whiteness. Each participant embraced her Black womanhood and viewed their roles at their institution and their Black identity was manifested in how the participants were vigilant in their work and their environments. Their awareness also demonstrated how they were in community with other Black women, Black people, and people of color across campus. The participants were aware of their image at their HWIs and how their reputation was perceived as a professional lifeline. All participants at some capacity understand that there could be implications if they are not perceived in the best light at all times. Knowing this explains the hyperawareness that the participants have of their reputations.

\section{Under Her Wing and Institutional Mammying}

All participants exerted high levels of labor for the students and the institutions where they are employed. Many of the participants assumed that it is their duty to look after students of color, and more particularly, Black students. Whenever possible, the participants pursued more candid conversations with their Black students and their families as it pertained to admissions, financial resources available to attend the perspective institution, and persistence needed to attain a degree. Furthermore, the participants found themselves being available for students outside of the realm of their work in higher education and catering to the socioemotional needs of their Black students. The participants were a part of everyday life events with their students along with big events such as graduation. A combination of mothering and mentoring was used to describe how the participants worked with the Black students on campus. Similar to the support that the participants gave their students, they were also available to address the demands of the institution. The participants volunteered to be available, and at times, thought they were obligated to meet the needs and wants of the institution by automatically being available to 
students, handling difficult situations, working hard, and overextending themselves. Institutions often capitalize and use the good will of Black women for the exploitation of labor (Hills, 2019). While they are on the front line of service to students and the institution, Black women often receive the battle wounds.

\section{Institutional Gatekeeping and Moving the Needle}

As Black women professionals, the participants faced a hard duality in their roles. Enrollment management is traditionally the first point of contact for prospective students. The offices of admissions, financial aid, and the registrar are all formative administrative offices that have the potential to shape students' higher education careers and the path of their lives. The participants are aware of the burden that they carry, and it can be emotionally taxing to deny a student access to higher education. In addition, the same participants are responsible for a plethora of metrics that determine the health of the institution: acceptance and retention rates, institutional revenue, and compliance with federal funding. These metrics represent some of the most important determinants of success and health to the institution (Markovits, 2019). Also, these metrics are not only for selective institutions, but are required to be maintained for the basic eligibility to be recognized by the Department of Education as a higher education institution (Dynarski \& Scott-Clayton, 2013).

Because of the institutional policies and practices, the participants often were in compromising positions where they questioned their ability to move the needle and they also questioned what moving the needle really means or looks like. The perception bias toward Black and poor students deemed them as unworthy and unprepared to undertake higher education at selected institutions (Jack, 2019). This is a false narrative that many of the participants tried to change. 


\section{Black Girls Must Die Exhausted and the Negotiation of Space}

Saying that Black girls must die exhausted calls attention to the overburdensome everyday labor that Black women engage in to balance their lives with respect to others. Black women are shamed for making decisions that either better serves them or their families (HarrisPerry, 2011). In addition, Black women can also be placed in the comprising spaces where they need to choose between family or work (St. Jean \& Feagin, 1999). The phrase Black girls must die exhausted acknowledges how Black women navigate their politicized lives. They must make decisions for themselves with the consideration of everyone else around them. The last theme recognizes the self-sacrificial tendencies that Black women exhibit to create a world in which they feel right about, even if that means they could possibly lose themselves in the midst of it.

\section{Implications for Theory and Research}

Anti-Black womanism is a theoretical lens used in this study to explain the experience of Black women enrollment management professionals. Anti-Black womanism is a lens that borrows from BlackCrit and womanism. Anti-Black womanism layers the complexity of Black womanhood and its relation to American history at the inception of colonization indigenous American lands. While there are many other feminist theories that attest to the experiences of women, and particularly Black women, anti-Black womanism takes heavy historical consideration of how colonization has imprinted what perceptions the world has of Black women and what are the implications of those perceptions. Anti-Black tropes of Black womanhood have distorted what Black womanhood truly is by vilifying Black women as Jezebels (Collins, 1991), commodifying cultural values such as other mothering (Collins, 1991), and demanding mammylike_-unreasonable, self-sacrificial expectations (Hill, 2019). 
Chapter II centers the historical background of Black people, education, and neoliberalism. The bodies of Black people have always found use in higher education, typically at the hands of enslaved servitude and science. The settler-colonial complex acknowledges how the exploitation and use of Black bodies held no boundaries. Neoliberalism sustains the settlercolonial complex and further deepens anti-Blackness. The tenets of neoliberalism are substantially foundational the structure of education and recognizable in legislation and practices in enrollment management. Higher education has become a marketplace (Giroux, 2005, Giroux, 2015) and Black bodies, both students and professionals, are once again viewed as a form of currency (Wilder, 2013).

Chapter III uses a historical perspective to discuss the paradoxical relationship Black women have had with the world since the inception of slavery (White, 1999). Black women have consistently backed the brunt of the world, while remaining the lowest on the transnational social hierarchy. Black women are often vilified and mischaracterized through anti-Black tropes of womanhood. Moreover, the dehumanization and exploitation of Black women's bodies is divulged through objectification and commodification. The mischaracterizations of Black women's bodies are exposed with a critical lens for how they experience racism and sexism as professionals is higher education.

\section{Implications for Practice}

Black women's relationship with mankind is complex and paradoxical since the discovery of America. This study provides insight into how Black women's intersectional identities depict the reality of their worlds: always facing the duality of their Blackness and womanhood while working in enrollment management at HWIs. The results of this study require 
a call to action for all to acknowledge the following truths (Dancy \& Edwards, 2021; Dei, 2017; Dumas \& Ross, 2016):

- The structure of higher education perpetuates anti-Black racism and sexism.

- The institutions of higher education were built on the backs of Black women whose bodies were exploited and dehumanized.

Black women need to continue to demand what they deserve and to know more than the revisionist history that was forced upon us. The colonial-settler ideals are still present today in the construction and structure of higher education. Neoliberalism has only served to create new ways to deepen systems of oppression (Giroux, 2015). As more Black women are selected to work as administrators in higher education, it is imperative to understand the historical context of the environment of HWIs to succeed.

This is not a call to make all Black women cynical of their jobs, nor is this a call to create a monolithic voice of all Black women. However, this is a call for Black women to understand the structures and systems in place that affect them just as much as those systems affect the marginalized student population that they serve.

\section{Recommendations for Future Research}

This study begins the conversation of the complex and demanding roles that Black women have at HWIs in enrollment management. Below are the following recommendations that I believe would serve to add to the literature, and most important, provide a liberatory for Black women professionals in enrollment management.

- Focus on the individual offices that comprise enrollment management; for instance, conduct a similar study that only evaluates the role of admissions professionals and the work-related implications. 
- Further understand how Black women balance the paradox of copiability and resistance to neoliberalism and anti-Blackness in enrollment management.

- Evaluate the implications of balancing an outside life and progressing as a professional in enrollment management.

- Consider a grounded discourse analysis of federal guidelines and regulations for higher education institutions.

- Conduct research studies that focus on anti-Black womanism for different levels of Black women professionals in enrollment management (i.e., advisors or counselors, processors, leaders, senior leaders).

- Examine research studies that explore in depth tropes of Black women (e.g., jezebel, mammy, angry Black woman).

- Explore mental health implications for Black women in enrollment management at HWIs.

- Evaluate how Black women perceive their roles in enrollment management.

- Explore individually parts of anti-Black womanism in enrollment management such as hypersexualization, adultification, dehumanization, or objectification.

\section{Conclusion}

The purpose of this study was to identify how anti-Black perception bias affects Black women who work in enrollment management positions at HWI. This qualitative, narrative inquiry study used the interviews of 10 participants. The participants' positions ranged from chief enrollment officer to advisor/counselor, and the array of positions provided opportunity to equivocally hear the voices of Black women about their experience in enrollment management. This study provided context for their experiences by acknowledging their journeys and their 
persistence as they moved forward to build and support Black women. Black women live in dialectical spaces while working in enrollment management at HWIs. Their experiences have shed light on the complexity of their roles and the anti-Black expectations of Black professional womanhood. Unlike any other division or sector, enrollment management was intentionally created to preserve the historical and foundational markings of higher education. Contextualizing the experience of Black women in enrollment management allows for the removal of 'rose colored glasses' to deeply understand how enrollment management perpetuate oppression. 


\section{REFERENCES}

Allen, J. (2018). Black girls must die exhausted. Los Angeles, CA: Quality Black Books. heteropatriarchy. Feminist Formations, 25(1), 8-34. https://doi.org/10.1353/ff.2013.0006

Barabino, G. A. (2019). What looks like bravery in the academy: Reflections of an African American woman engineer. In M. C. Whitaker \& E. A. Grollman (Eds.), Counternarratives from women of color academics (pp. 18-24). Routledge.

Beaubouef- Lafontant, T. (2007). "You have to show strength": An exploration of Gender, Race, and Depression. Gender \& Society. 21, 28-51.

Beckwith, A. L., Carter, R. D., \& Peters, T. (2016, June). The underrepresentation of African American women in executive leadership: What's getting in the way? Journal of Business Studies Quarterly, 7(4), 115-134.

Bell, D. A., Jr. (1995a). Serving two masters: Integration ideals and client interests in school desegregation litigation. In K. Crenshaw, N. Gotanda, G. Peller, \& K. Thomas (Eds.), Critical race theory: The key writings that formed the movement (pp. 5-19). The New Press.

Bell, D. A., Jr. (1995b). Brown v. Board of Education and the interest convergence dilemma. In K. Crenshaw, N. Gotanda, G. Peller, \& K. Thomas (Eds.), Critical race theory: The key writings that formed the movement (pp. 20-28). The New Press.

Berry, M. F. (1971). Black resistance/white law: A history of constitutional racism in America. Penguin.

Berry, D. R., \& Gross, N. K. (2020). A black woman's history of the United States: Revisioning American history. Beacon Press. 
Bih. (2020, November 3). Stop celebrating black women's pain. The Medium.

https://medium.com/age-of-awareness/stop-celebrating-black-womens-pain -1211 ed 83 fce 5

Bloomberg, L. D., \& Volpe, M. (2019). Completing your qualitative dissertation: A road map from beginning to end. Sage.

Brodie Welch, L. (1992). Perspectives on Minority Women in Higher Education. Praeger

Brooten, B. (2010). Beyond slavery: Overcoming its religious and sexual legacies. Palgrave MacMillan. https://doi.org/10.1057/9780230113893

Brown v. Board of Education,_347 U.S. 483 (1954). https://www.oyez.org/cases/1940-1955 /347us483

Burke, B., Cropper, A., \& Harrison, P. (2000, December). Real or imagined-black women's experience in the academy. Community, Work \& Family, 3(3), 297-310. https://doi.org10.1080/13668800020006811

Burke, L. (2020, October 27). Black workers at universities often are left out of conversations about race and higher education. Inside Higher Education. https://www.insidehighered.com/news/2020/10/27/black-workers-universities-often-areleft-out-conversations-about-race-and-higher

Burnley, M. (2020, June 20). Author Brittney Cooper on harnessing rage, right now. The New York Times. https://www.nytimes.com/2020/06/20/us/20IHW-black-lives-matterprotests-brittney-cooper-women.html

Camp, S. M. H. (2004). Close to freedom: Enslaved women \& everyday resistance in the plantation south. University of North Carolina Press.

Cannon, K. G. (2008). Cutting edge. Journal of Feminist Studies in Religion, 24(1), 127-134. 
Carruthers, C. A. (2018). Unapologetic: A black, queer, and feminist mandate for our movement. Boston, MA: Beacon Press.

Chapman, R. (2019). Fiery mind, full heart, brave soul: A model for women of color to thrive in historically white colleges and universities. In M. C. Whitaker \& E. A. Grollman (Eds.), Counternarratives from women of color academics (pp. 79-90). Routledge.

Chatterjee, P., \& Maira, S. (2014). Introduction: The imperial university: Race war, and the nation-state. In P. Chatterjee \& S. Maira, (Eds.), The imperial university: Academic repression and scholarly dissent. University of Minnesota Press.

Chomsky, N. (1999). Profit over people: Neoliberalism and global order. Seven Stories Press.

Chomsky, N. (2003). Hegemony or survival: America's quest for global dominance. Metropolitan Books.

Coates, T.-N. (2014, June). The Case for Reparations. The Atlantic. https://www.theatlantic.come/magazine/archive/2014/06/the-case-forreparations/361631/.

Cobb-Roberts, D., \& Agosto, V. (2011). Underrepresented women in higher education: An overview. Educational Leadership and Policy Studies, 62, 7-11. https://scholarcommons.usf.edu/els_facpub

Collier-Thomas, B. (1982). The impact of black women in education: An historical overview. Journal of Negro Education, 51(3), 173-180. https://www.jstor.org /stable/3174683

Collins, P. H. (1989). The social construction of black feminist thought. Signs, 14(4), 745-773. Collins, P. H. (1996). What's in a name? Womanism, black feminism, and beyond. The Black Scholar, 26(1), 9-17. 
Collins, P. H. (1998). It's all in the family: Intersections of gender, race, and nation. Hypatia, $13(3), 62-82$.

Collins, P. H. (2009). Black feminist thought. Routledge.

Combahee River Collective. (2017). The Combahee River collective statement. In K. Taylor (Ed.), How we get free: Black feminism and the Combahee River collective (pp. 15-24). Haymarket.

Coomes, M. D. (2000, Spring). Historical roots of enrollment management. New Directions for Student Services, 2000(89), 5-18. https://doi.org/10.1002/ss.8901

Cooper, B. (2017). Beyond respectability: The intellectual thought of race women. University of Illinois Press.

Cooper, B. (2018). Eloquent rage: A black feminist discovers her superpower. St. Martin's Press. Crenshaw, K. (1989). Demarginalizing the intersection of race and sex: A black feminist critique of antidiscrimination doctrine, feminist theory and antiracist politics. University of Chicago Legal Forum, 1989(1), Article 8. http://chicagounbound .uchicago.edu/uclf/vol1989/iss1/8

Creswell, J. W., \& Creswell, J. D. (2018). Research design: Qualitative, quantitative, and mixed methods approaches (5th ed.). Thousand Oaks, CA: SAGE.

Cross, W. E., Jr. (1991). Shades of black: Diversity in African American identity. Philadelphia, PA: Temple University Press.

Croteau, L. M., \& Maginnis, H. A. (2005). Admissions, enrollment management, and student affairs: Creating the seamless transition. The Vermont Connection, 26(2). https://scholarworks.uvm.edu/tvc/vol26/iss $1 / 2$ 
Dancy, T. E., \& Edwards, K. T. (2021). On labor and property: Historically white colleges, black bodies and constructions of (anti) humanity. In C. A. Grant, A. N. Woodson, \& M. J. Dumas (Eds.), The future is black: Afropessimism, fugitivity, and radical hope in education. Routledge.

Davis, A. Y. (1981). Women, race, \& class. Random House.

Davis, C. (2018). Taking back the power: An analysis of black women's communicative resistance. Review of Communication, 18(4), 301-318.

DeGruy, J. (2005). Post traumatic slave syndrome: America's legacy of enduring injury \& healing. Uptone Press.

Dei, G. J. S. (2017). Reframing blackness and black solidarities through anti-colonial and decolonial prisms. Springer.

Delgado, R., \& Stefancic, J. (2001). Critical race theory: An introduction. New York University Press.

Du Bois, W.E.B. (1994). The Souls of Black Folks. Dover Press.

Dumas, M. J. (2016). Against the dark: Antiblackness in education policy and discourse. Theory Into Practice, 55(1), 11-19. https://doi.org/10.1080/00405841.2016.1116852

Dumas, M. J., \& Ross, K. M. (2016). Be real black for me: Imagining blackcrit in education. Urban Education, 51(4), 415-442. https://doi.org/10.1177/0042085916628611

Dumenil, G., \& Levy, D. (2005). Capital resurgent: Roots of the neoliberal revolution. Harvard University Press.

Duniway, R. L. (2012). Benchmarking and enrollment management. New Directions for Institutional Research, 156(1), 25-36. https://doi.org/10.1002/ir.20028 
Dunton, C. (2015). Sara Baartman and the ethics of representation. Research in African Literatures, 46(2), 32-51. https://doi.org/10.2979/reseafrilite.46.2.32

Dwyer, S.C. \& Buckle, J.L. (2009). The Space Between: On Being an Insider-Outsider in Qualitative Research. International Journal of Qualitative Methods. 8(1), 54-63.

Dynarski, S., \& Scott-Clayton, J. (2013). Financial aid policy: Lessons from research. National Bureau of Economic Research, Working paper 18710. http://www.nber.org/papers/w18710

Dyson, M. E. (1996). Race rules: Navigating the color line. Vintage Books.

Eberhardt, J. L. (2019). Biased: Uncovering the hidden prejudice that shapes what we see, think, and do. Viking.

Espenshade, T. J., \& Radford, A. W. (2009). No longer separated, note yet equal: Race and class in elite college admission and campus life. Princeton University Press.

Evans, S. Y. (2007). Black women in the ivory, 1850-1954: An intellectual history. The University of Florida Press.

Fanon, F. (1952). Black skin, white masks. Grove Press.

Fanon, F. (2004). The wretched of the earth. Grove Press.

Farmer, A. D. (2017). Remaking black power: How black women transformed an era. University of North Carolina Press.

Feastinger, L. (1962). Cognitive dissonance. Scientific American, 207(4), 93-106.

Ferguson, R. A. (2017). We demand: The university and student protests. University of California Press.

Fields, K. E., \& Fields, B. J. (2014). Racecraft: The soul of inequality in American life. Verso. 
Flathery, C. (2021, January 6). Faculty members of color see illusion of inclusion. Inside Higher Education. https://www.insidehighered.com/new/2021/01/06 /faculty-members-color-see-illusion-inclusion

Freeman, A. D. (1995). Legitimizing racial discrimination through antidiscrimination law: A critical review of Supreme Court doctrine. In K. Crenshaw, N. Gotanda, G. Peller, \& K. Thomas (Eds.), Critical race theory: The key writings that formed the movement (pp. 29 -45). The New Press.

Gardner, L., Barrett, G. T., \& Pearson, C. L. (2014). African American administrators at primarily white institutions: Enablers of and barriers to career success. Journal of Diversity in Higher Education, 7(4), 235-251. https://doi.org/10.1037/a0038317

Gasman, M., \& Geiger, R. L. (Eds.). (2012). Higher education for African Americans before the civil rights era, 1900-1964. Taylor \& Francis.

Gates, H. L., Jr. (2010). Tradition and the black Atlantic: Critical theory in African diaspora. Basic Civitas.

Giddings, P. (1984). When and where I enter: The impact of black women on race and sex in America. Harper Collins.

Giroux, H. (2005). The Terror of Neoliberalism: Rethinking the Significance of Cultural Politics. College Literature, 32(1), 1-19.

Giroux, H. (2015). Neoliberalism's war on higher education. Haymarket Books.

Gladwell, M. (2005). Blink: The power of thinking without thinking. Back Bay Books.

Glesne, C. (2011). Becoming qualitative researchers: An introduction (4th ed.). Pearson.

Golden, D. (2019). The price of admission: How America's ruling class buys its way into elite colleges--and who gets left outside the gates (2nd ed.). Broadway Books. 
Goldin, C., \& Katz, L. F. (1999). The shaping of higher education: The formative years in the United States, 1890-1940. The Journal of Economic Perspectives, 13(1), 37-62.

Gordon, R. J. (1992). The venal hottentot venus and the great chain of being. African Studies, 51(2), 185-201. https://doi.org/10.1080/00020189208707756

Gordon-Chipembere, N. (2011). Introduction: Claiming Sarah Baartman, a legacy to grasp. In N. Gordon-Chipembere (Ed.), Representation and black womanhood: The legacy of Sarah Baartman (pp. 1-14). Palgrave MacMillan.

Greene, W. D. (2017, August 20). Splitting hairs: The 11th circuit's take on workplace bans against black women's natural hair in EEOC v. Catastrophe Management Solutions. University of Miami Law Review, 7. https://ssrn.com/abstract=3106089

Guinier, L. (2015). The tyranny of the meritocracy: Democratizing higher education in America. Beacon Press.

Harlow, R. (2019). You're doing what?: Leaving the academia to answer the call. In M. C. Whitaker \& E. A. Grollman (Eds.), Counternarratives from women of color academics (pp. 1-186). Routledge. https://doi.org/10.4324/9780429465505

Harris-Perry, M. V. (2011). Sister citizen: Shame stereotypes and black women in America (1st ed.). Yale University Press.

Hartman, S. V. (2006). Lose your mother: A journey along the Atlantic slave route. Farrar, Straus and Giroux.

Haynes, B. (2006). Black undergraduates in higher education: An historical perspective. Metropolitan Universities, 17(2), 8-21. 
Henderson, T.L., Hunter, A.G., \& Hildreth, G.J. (2010). Outsiders with the academy: Strategies for resistance and mentoring African American women. Michigan Family Review, 14(1), $28-41$.

Higher Education Act of 1965, Publ. L. 89-329, 79 Stat. (1965). https:www .govinfo.gov/content/pkg/STATUTE-79/pdf/STATUTE-79-Pg1219.pdf\#page=37

Hill, J. (2008). The everyday language of white racism. Blackwell.

Hills, D. D. (2019). Admirable or ridiculous? Journal of Feminist Studies in Religion, 32(2), 521.

Hine, D. C. (2008). Becoming a black woman's historian. In D. G. White (Ed.), Telling histories: Black women historians in the ivory tower. The University of North Carolina Press.

Hixson, W. L. (2013). American settler colonialism: A history. Palgrave MacMillan.

Hoff, P. T. (2020). Picked to pieces: The cost of opportunity. In Y. F. Niemann, G. G. Muhs, \& C. G. Gonzalez (Eds.), Presumed incompetent II: Race, class, power, and resistance of women in academia (pp. 39-48). University Press of Colorado.

hooks, b. (1984). Feminist theory from margin to center. South End Press.

hooks, b. (2015). Ain't I a woman: Black women and feminism. London, United Kingdom: Routledge Press.

Horton, J. O. (1985). Black education at Oberlin College: A controversial commitment. The Journal of Negro Education, 54(4), 477-499. https://doi.org/10.2307/2294710

Hossler, D. (1984). Enrollment management: An integrated approach. College Entrance Examination Board.

Hossler, D. (2006). Managing student retention: Is the glass half full or half empty, or simply empty? College and University, 81(2), 11-14. 
Hossler, D., \& Bontrager, B. (Eds.) (2015). Handbook for strategic enrollment management. Jossey-Bass.

Howard-Vital, M. R. (1989). African-American women in higher education: Struggling to gain identity. Journal of Black Studies, 20(2), 180-191.

Huddleston, T., Jr. (2000). Enrollment management. New Directions for Higher Education, 2000(111), 65. https://doi.org/10.1002/he.11107

Hughey, M. W. (2012). Racializing redemption, reproducing racism: The odyssey of magical negroes and white saviors. Sociology Compass, 6(9), 751-767. https://doi.org/10.1111 /j.1751-9020.2012.00486.x

Hull, G.T., \& Smith, B. (2015). An introduction: The politics of black women's studies. In A. G. T. Hull, P. Bell-Scott, \& B. Smith (Eds.), But some of us are brave: All the women are white, all the blacks are men - black women's studies (2nd ed.; pp. xvii-xxxii). City University of New York.

Hurston, Z. N. (1937). Their eyes were watching god. Reading Essentials.

Hurston, Z. N. (1942). The pet negro system. American Mercury.

Ifedi, R. (2019). They're coming for our jobs too! Double standards for black and white leadership in the age of Obama and Trump. In I. Harushimana, M. Alfred, \& R. D. Davis (Eds.), A paradise to regain: Post-Obama insights from educations of the black diaspora (pp. 1-10). Meyers Education Press.

Ihle, E. L. (1992). Black women in higher education: An anthology of essays, studies, and documents. Garland.

Jack, A. A. (2019). The privileged poor: How elite colleges are failing disadvantaged students. Harvard University Press. https://doi.org/10.1111/fcsr.12361 
Jackson, G. A. (1990). Financial aid, college entry, and affirmative action. American Journal of Education, 98(4), 523-550.

Jackson, M., \& Rajai, P. (2021, January 20). Does your definition of leadership exclude women of color? Harvard Business Review. https://hbr.org/2021/01/does-your -definition-of-leadership-exclude-women-of-color?registration=success

Jacobs, H. A. (1861). Incidents on the life of a slave girl, written by herself. Thayer \& Eldridge. James, J. (2019). The audacious speech of the captive maternal mute. In D. Smith, L. Carruthers, \& S. Fowler (Eds.), Womanish black girls: Women resisting the contradictions of silence and voice (pp. X-xiv).: Meyers Press.

Jefferson, S. D., \& Caldwell, R. (2002). An exploration of the relationship between racial identity attitudes and the perceptions of racial bias. Journal of Black Psychology, 28(2), 174-192.

Jones, K. M. (2019). On being powerfully vulnerable and why I love my black woman's tears. In M. C. Whitaker \& E. A. Grollman (Eds.), Counternarratives from women of color academic (Chapter 16, pp. 1-6). Routledge. https://doi.org $/ 10.4324 / 9780429465505$

Josselson, R. (2011). Interviewing for qualitative inquiry: A relational approach. The Guilford Press.

Katznelson, I. (2006). When affirmative action was white: An untold history of racial inequality in twentieth-century America. W.W. Norton. 
Kaufman, J. (2020, June 16). Mindset matters: What's next for diversity and inclusion professionals in the wake of civil unrest. Forbes. https://www.forbes.com /sites/jonathankaufman/2020/06/15/mindset-matters-whats-next-for-diversity-andinclusion-professionals-in-the-wake-of-civil-unrest/?sh=7a82c4ab353d

Kendi, I. X. (2016). Stamped from the beginning: The definitive history of racist ideas in America. Bold Type Books.

Kendi, I. X. (2019). How to be an antiracist. One World.

Kendi, I. X. (2021). A Community of Souls: An Introduction. In I. Kendi, \& K. N. Blain (Eds.), Four hundred souls: A community history America, 1619-2019 (pp. xiii-xvii). One World.

Koval, C. Z., \& Rosette, A. S. (2020, August 19). The natural hair bias in job recruitment. Social Psychological and Personality Science. https://doi.org/10.1177\%2F1948550620937937

Ladner, J. A. (1995). Tomorrow's tomorrow: The black woman with a new introduction by the author. Doubleday.

Laws, M. (2020, June 16). Why we capitalize 'Black' (and not 'white'). Columbia Journalism Review. https://www.cjr.org/analysis/capital-b-black-styleguide.php

Lenhoff, S. W. (2020). Unregulated open enrollment and inequitable access to schools of choice. Peabody Journal of Education, 95(3), 1-24. https://doi.org/10.1080/0161956X.2020 .1776072

Levidow, L. (2005). Neoliberal agendas for higher education. In A. Saad-Filho, \& D. Johnston (Eds.), Neoliberalism: A critical reader (pp. 156-162). Pluto Press. 
Lloyd-Jones, B. (2009). Implications of race and gender in higher education administration: An African American woman's perspective. Advances in Developing Human Resources. $11(5), 606-618$.

Lomax, T. (2018). Jezebel unhinged: Loosing the black female body in religion \& culture. Duke University Press.

Love, B. L. (2019). We want to do more than survive: Abolitionist teaching and the pursuit of educational freedom. Beacon Press.

Lucido, J., Hossler, D., O’Dowd, K., \& Massa, B, (2018). Strategic enrollment management quarterly: A professional body of knowledge for a nascent profession. Strategic Enrollment Management Quarterly, 6(3), 35-42.

Maguire, M., \& Delahunt, B. (2017). Doing a thematic analysis: A practical, step-by-step guide for learning and teaching scholars. All Ireland Journal of Teaching \& Learning in Higher Education [AISHE-J], 9(3), 3351-33514.

Markovits, D. (2019). The meritocracy trap. Penguin Press.

Massey, D. (1994) Space, place, and gender. University of Minnesota Press.

Mays, V. A. (2013, Spring). African-American women in public higher education administrative leadership in the State of Missouri: Perspectives on a half century of progress [Published doctoral dissertation, University of Missouri-Columbia]. ProQuest Dissertations and Theses database. https://doi.org/10.32469/10355/37794

McCarthy, M. L. (2013). Sistership: Taking back feminism. In N. Wane, J. Jagire, \& Z. Murad (Eds.), Ruptures: Anti-colonial \& anti-racist feminist theorizing (pp. 51-57). Sense. 
McChensney, J. (2018). Representation and pay of women of color in higher education:

Institutions that are getting it right [Research report]. College and University Professional Association for Human Resources. https://www.cupahr.org/wp-content/uploads/CUPAHR-Brief-Women-Of-Color.pdf

McCluskey, A. T. (1999). Representing the race: Mary McLeod Bethune and the press in the Jim Crow era. Western Journal of Black Studies, 23(4), 236-245.

McDonough, P., \& Robertson, L. (2012). Gatekeepers or marketers: Reclaiming the educational role of chief admission officers. Journal of College Admission, 214, 92-100.

Melguizo, T., \& Chung, A. (2012). College aid policy and competition for diversity. The Review of Higher Education, 35(3), 403-430.

Merriam, S. B. (2009). Qualitative research: A guide to design and implementation. Jossey-Bass.

Milem, J. F., Chang, M. J, \& Antonio, A. L. (2005). Making diversity work on campus: A research-based perspective. Association of American Colleges and Universities.

Miles, M. B., Huberman, M., \& Saldana, J. (2014). Qualitative data analysis: A methods sourcebook. SAGE.

Mills, C. M. (1998). Blackness visible: Essays on philosophy and race. Cornell University Press.

Mills, C. M. (1999). The racial contract (1st ed.). Cornell University Press.

Mitchell, R. (2020). Venus noire: Black women and colonial fantasies in ninetieth-century France. University of Georgia Press.

Morrill Act, Pub. L. No. 37-102, 12 Stat. 503 (1862).

Morrill, Act, Pub. L. No. 103-382, 26 Stat. 417 (1890). 
Morrison, T. (1971, August 22). What the black woman thinks about women's lib. New York Times. https://www.nytimes.com/1971/08/22/archives/what-the-black-woman-thinksabout-womens-lib-the-black-woman-and.html

Mosley, M. H. (1980). Black women administrators in higher education: An endangered species. Journal of Black Studies, 10(3), 295-310.

Mothoagae, I. D. (2016). Reclaiming our black bodies: Reflections on a portrait of Sarah (Saartjie) Baartman and the destruction of black bodies by the state. Acta Theologica, 36(Suppl. 24), 62-83. https://doi.org/10.4314/actat.v36i1.5S

Munden, S. D. (2015). Starting at the top: Increasing African American female representation at higher education administration in the United States [Published doctoral dissertation, Northeastern University]. ProQuest Dissertation and Theses database. https://www.repository.library.northeastern.edu/files/neu:rx

Murray, C. (2020, January). Human diversity: The biology of gender, race, and class. Twelve. Muthusamy, M. (n.d.). National Institute of Food and Agriculture: 1890 Land-Grant Institutions Programs. National Institute of Food and Agriculture. https://nifa.usda.gov/program/1890-land-grant-institutions-programs

Muzaliwa, A. I., \& Gardiner, M. E. (2014). Narrative inquiry (ni) as an exemplary method for social justice leadership. In I. Bogotch \& C. M. Shields (Eds.), International handbook of educational leadership and social (in)justice, Vol 1. Springer.

Nader, L. (1993). Controlling processes in the practice of law: Hierarchy and pacification in the movement to re-form dispute ideology. The Ohio State Journal on Dispute Resolution $9(1), 1-25$.

Nash, J. C. (2019). Black feminism reimagined: After intersectionality. Duke University Press. 
National Center for Education Statistics (NCES), Institution of Education Sciences (IES). (2016). College navigator. https://nces.ed.gov/collegenavigator $/ ? \mathrm{q}=$ university $+\mathrm{of}+\mathrm{Wisconsin}+$ madison $\& \mathrm{~s}=$ all\&id=240444\#enrolmt

Ndlovu, S. G. (2011). Body of evidence Saartjie Baartman and the archive. In N. GordonChipembere (Ed.), Representation and black womanhood: The legacy of Sarah Baartman (pp. 17-30). Palgrave MacMillan.

Parker, P. (2015). The historical role of women in higher education. Administrative Issues Journal: Connecting Education, Practice, and Research, 5(1), 3-14. https://doi.org/10.5929/2015.5.1.1

Pecher, D., \& Zwaan, R. A. (2005). Introduction to grounding cognition: The role of perceptions and action in memory, language, and thinking. In D. Pecher \& R. A. Zwaan (Eds.), Grounding cognition: The role of perceptions and action in memory, language, and thinking (pp. 1-7). Cambridge University Press.

Phillips, L. (2006). The womanist reader: The first quarter century of womanist thought. Routledge.

Plessy v. Ferguson, 163 U.S. 537, 16 S. Ct. 1138, 41 L. Ed. 256 (1896).

Powell, C. (2019). Bias, employment discrimination, and black women's hair: Another way forward. Brigham Young University Law Review, 2018(4), 933-968.

Rifkin, M. (2019). Fictions of land and flesh: Blackness, indigeneity, speculation. Duke University Press.

Rodgers, I. H. (2012). The black campus movement: Black students and the radical reconstitution of higher education, 1965-1972. Palgrave MacMillan. 
Rodney, C. (2020). Navigating being a tall black female in hostile environments. In G. J .S. Dei, E. Odozor, \& A.V. Jimenez (Eds.), Cartographies of blackness \& black indigeneities (pp. 63-82). Meyers Press Education.

Rothstein, R. (2017). The color of law: A forgotten history of how our government segregated America. Liveright.

Ross, K. M. (2021). On black education: Anti-blackness, refusal, and resistance. In C. A. Grant, A. N. Woodson, \& M. J. Dumas, (Eds.), The future is black: Afropessimism, fugitivity, and radical hope in education. Routledge.

Saad-Filho, A., \& Johnston, D. (2005). Introduction. In A. Saad-Filho \& D. Johnston (Eds.), Neoliberalism: A critical reader (pp. 1-6). Pluto Press.

Saldana, J. (2016). The coding manual for qualitative researchers (3rd ed.). SAGE.

Schulz, S. A., \& Lucido, J. A. (2009). Motivation matters: Using a multidimensional theoretical framework to assess what enrollment structures reveal about institutional priorities [Submission for publication]. citeseerx.ist.psu.edu/viewdoc/summary ?doi=10.1.1.418.9100

Selingo, J. (2020). Who gets in and why: A year inside college admissions. Scribner.

Silver, B. R. (2020). The cost of inclusion: How student conformity leads to inequality on college campus. University of Chicago Press.

Smith, A. A. (2018, April 13). Growing number of community colleges focus on diversity and inclusion. Inside Higher Education. https://www.insidehighered .com/news/2018/04/13/growing-number-community-colleges-focus-diversity -and-inclusion 
Smith, D. (1996). Womanism and me: An (un)caged black bird sings for freedom. The High School Journal, 79(3), 176-182. https://about.jstor.org/terms

Smith, D., Caruthers, L., \& Fowler, S. (2019). Three black women remembering womanish girls. In D. Smith, L. Caruthers, \& S. Fowler (Eds.), Womanish black girls: Women resisting the contradictions of silence and voice (pp. 1-14). Meyers Education Press.

Sobers, S. (2014). Can I get a witness? The resilience of four black women senior student affairs administrators at predominantly white institution. Social Science Research Network. http://dx.doi.org/10.2139/ssrn.2708491

Spies, B. M., \& Spies, B. M. (2014). Saartjie. African Arts, 47(2). 66-75.

Steele, T. (2018). Toxicity in the work environment: Retaining staff members of color at a predominantly white institution. College Student Affairs Journal, 36(1), 109-123.

Steinberg, J. (2002). The gatekeepers: Inside the admissions process of a premier college. Penguin Books.

Stevens, P. (2020, June 15). Companies are making bold promises about greater diversity but there's a long way to go. CNBC. https://www.cnbc.com/2020/06/11 /companies-are-making-bold-promises-about-greater-diversity-theres-a-long-way-togo.html

Stewart, G. (2004). Defining the enrollment manager: Visionary, facilitator and collaborator. Journal of College Admission, 21, 22-25.

St. Jean, Y., \& Feagin, J. R. (1999). Double the burden: Black women and everyday racism (1st ed.). Routledge. 
Taylor, K. (2017). Introduction. In K. Taylor (Ed.), How we get free: Black feminism and the Combahee River collective. Haymarket. https://www.haymarketbooks .org/books /1108how-we-get-free

Thelin, J. (2011). A history of American higher education. John Hopkins Press.

Thelin, J. (2014). Essential documents in the history of American higher education. John Hopkins Press.

Thomas, D. A., \& Clarke, K. M. (2006). Introduction: Globalizations and transformations of Race. In K. M. Clarke \& D. A. Thomas (Eds.), Globalization and race: Transformations in cultural productions of blackness (pp. 1-34). Duke University Press.

Titcomb, C. (2011). Key events in black higher education: JBHE chronology of major landmarks in the progress of african Americans in higher education. https://www.jbhe.com/chronology/

Tucker, V. G. (2019). My voice: Loud, strong, resented, but heard. In D. Smith, L. Caruthers, \& S. Fowler. (Eds.), Womanish black girls: Women resisting the contradictions of silence and voice (pp. 1-18). Myers Education Press.

Turnbull, H. (2014, February). The illusion of inclusion: Part I. Diversity Journal. https://diversityjournal.com/12716-illusion-inclusion/

U.S. Senate Committee on Health, Education, Labor \& Pension. (2017, November 28). Alexander: Time to Simplify the FAFSA [Press release]. https://www.help.senate.gov/chair/newsroom/press/alexander-time-to-simplify-the-fafsa Vendantuam, S. (2010). The hidden brain: How our unconscious minds elect presidents, control markets, wage wars, and save our lives. The Random House.

Walker, A. (1983). In search of our mothers' gardens: Womanist prose. Harcourt. 
Walker, A. (1989). The color purple. Harcourt Brace Jovanovich.

Washington, H. A. (2006). Medical apartheid: The dark history of medical experimentation on black Americans from colonial times to the present. Harlem Moon.

Watkins, W. (2001). The white architects of black education: Ideology and power in America, 1865-1954. Teacher College Press.

Weinbaum, A. E. (2019). The afterlife of reproductive slavery: Biocapitalism and black feminism's philosophy of history. Duke University Press.

Weiss, R.S. (1995). Learning From Strangers: The Art and Method of Qualitative Interiew Studies. Free Press

Welch, B. L. (1992). Perspectives on minority women in higher education. Praege.

White, D. G. (1999). Ar'n't I a woman? Female slaves in the plantation south. W. W. Norton.

White, D. G. (2008). Introduction: A telling history. In D. G. White (Ed.), Telling histories: black women historians in the ivory tower (pp. 1-27). University of North Carolina Press.

Wilder, C. S. (2013). Ebony and ivory: Race, slavery, and the troubled history of american universities. New York, NY: Bloomsbury Press.

Williams, H. (2005). Self-taught: African American education in slavery and freedom. The American Historical Review, 111(2), 484-485. https://doi.org/10.1086/ahr.111.2.484

Wiss, R. (1994). Lipreading: Remembering Saartjie Baartman. The Australian Journal of Anthropology, 5, 11-40.

Woods, R. L. (2001). Invisible women: The experiences of Black female doctoral students at the University of Michigan. In R. O. Makobela, \& A. L. Green (Eds.), Sisters of the academy: Emergent black women scholars in higher education (pp. 105-116). Stylus. 
Wright, A. E. (2013). The hottentot venus: An Alternative conography. The British Art Journal, 14(1), 59-70.

Wright, D., Taylor, J. D., Burrell, C., \& Stewart, G. (2006). African American administrators and staff. Metropolitan Universities, 17(2), 58-68.

Wycoff, J. H. (2020). Honors of inequality: How colleges work for some. Historia Research Press.

Wytsma, K. (2017, April). The myth of equality: Uncovering the roots of injustice and privilege. InterVarsityPress. 


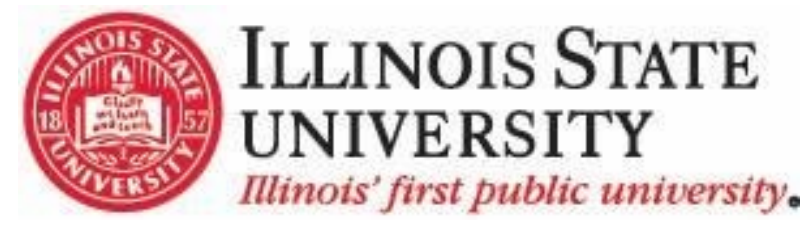

May 15, 2020 11:16 AM CDT

Pamela Hoff

Ed. Admin. \& Foundations

Re: Initial - IRB-2020-178 Womanist Ways in a Man's World: Unpacking Anti-Blackness in Higher Education Enrollment Management Roles

Dear Dr. Pamela Hoff:

Illinois State University Institutional Review Board has determined that revisions are required for your study titled: Womanist Ways in a Man's World: Unpacking Anti-Blackness in Higher Education Enrollment Management Roles.

How to Address the Reviewer's Comments:

The required revisions can be seen by navigating to the submission in Cayuse IRB. Once there, you can click on the edit button to go into the submission and make revisions.

- For sections of the study requiring revision, a gray "bubble" will show in place of the green check-

- mark.

- You will need to indicate that the comment is addressed before you can resubmit the submission.

- Any revisions to attached documents must be highlighted and re-uploaded. Any revisions that are made to the submission must be made within the submission instead of as a - "reply" to the comment.

The "reply" function should only be used if the researchers want to describe how they addressed a comment.

Once you have addressed all of the comments, mark the submission complete and have the PI certify the submission to resubmit it for review. Research activities in accordance with this submission may not begin until this committee has received a response to these requests and issued a final approval.

If you do not respond to the committee's comments provided above within 30 days, your protocol will be administratively closed per IRB policy.

Sincerely,

Jessie Krienert, $\mathrm{PhD}$.

IRB Chair

Professor of Criminal Justice Science 


\section{APPENDIX B: STUDY INVITATION TO PARTICIPANTS}

Hi there!

You are being asked to participate in a research study conducted by Mesha Garner, $\mathrm{Ph}$. D Candidate in Education Administration and Foundations, under the supervision of Pamela Hoff at Illinois State University. The purpose of this study is to gain an understanding of perception biases for Black women in Enrollment Management positions at Historically White Institutions. Historically White Institutions are those with a population of $50 \%$ or more of white students.

Why are you being asked?

You have been asked to participate because you identity as Black, a woman, currently works full time at a Historically White Institution (HWI) and works in any enrollment management office (Registrar, Financial Aid, or Admissions). Your participation in this study is voluntary. You will not be penalized if you choose to skip parts of the study, not participate, or withdraw from the study at any time.

What would you do?

If you choose to participate in this study, participants will first complete a brief demographic survey and subsequently take part in individual, one-on-one virtual interviews via Zoom or Microsoft Teams. In total, your involvement in this study will last approximately 75 minutes. The virtual interviews will be recorded and transcribed for accuracy. The recordings of the interview will only use de-identified data for analysis. To participate in this study please continue, the link is provided below.

Are any risks expected?

I need to make you aware that in certain research studies, it is our legal and ethical responsibility to report any life-threatening situation and/or illegal activity on the ISU campus, campuscontrolled locations, or involving ISU students to appropriate authorities. However, we are not seeking this type of information in our study nor will you be asked questions about these issues. Will your information be protected?

I will use all reasonable efforts to keep any provided personal information confidential. Personal information shared will be stored on an electronic data storage that requires multiple levels of password authentication. Information that may identify you or potentially lead to reidentification will not be released to individuals that are not on the research team. You will also have the option to choose a pseudo name of your choice that will not be shared with anyone else.

However, when required by law or university policy, identifying information (including your signed consent form) may be seen or copied by authorized individuals.

Could your responses be used for other research?

We will not use any identifiable information from you in future research, but your de-identified information could be used for future research without additional consent from you.

Who will benefit from this study?

This study will not only contribute to the literature and provide an understanding of Black women's experience at Historically White Institutions, but the study will also provide a liberatory experience to share your story on a platform that it may not have other than been heard on. 
Whom do you contact if you have any questions?

If you have any questions about the research or wish to withdraw from the study, contact Mesha Garner at mcgarne@ilistu.edu or Pamela Hoff at pthoff@ilstu.edu.

If you have any questions about your rights as a participant, or if you feel you have been placed at risk, contact the Illinois State University Research Ethics \& Compliance Office at (309) XXXXXXX or IRB@ilistu.edu.

\section{$\underline{\text { Documentation of Consent }}$}

By continuing to fill out the survey, you are indicating your consent for the study.

https://illinoisstate.az1.qualtrics.com/jfe/form/SV_8ernLcDcqVWJrVj

Best,

Mesha Garner

$\mathrm{Ph}$. D Candidate

College of Education

Education Administration and Foundations 


\section{APPRENDIX C: PARTICIPANT CONSENT FORM}

\section{Consent Form}

You are being asked to participate in a research study conducted by Mesha Garner, $\mathrm{Ph}$. D Candidate in Education Administration and Foundations at Illinois State University. The purpose of this study is to gain understanding of perception biases for Black women in Enrollment Management positions at Historically White Institutions.

\section{Why are you being asked?}

You have been asked to participate because you identity as Black, a woman, currently works full time at a Historically White Institution (HWI) and works in any enrollment management office (Registrar, Financial Aid, or Admissions). Your participation in this study is voluntary. You will not be penalized if you choose to skip parts of the study, not participate, or withdraw from the study at any time.

\section{What would you do?}

If you choose to participate in this study, participants will first complete a brief demographic survey and subsequently take part in individual, one-on-one virtual interviews via Zoom or Microsoft Teams. In total, your involvement in this study will last approximately 75 minutes. The virtual interviews will be recorded and transcribed for accuracy. The recordings of the interview will only use deidentified data for analysis.

\section{$\underline{\text { Are any risks expected? }}$}


Participants may be sharing information that is relevant to traumatic or stressful events, as participants share, you may be reliving past experiences. To reduce these risks of trauma, there will be a debrief after the interview and resources for long-term self-care outside of my supervision.

\section{Will your information be protected?}

I will use all reasonable efforts to keep any provided personal information confidential. Personal information shared will be stored on an electronic data storage that requires multiple levels of password authentication. Information that may identify you or potentially lead to reidentification will not be released to individuals that are not on the research team. You will also have the option to choose a pseudo name of your choice that will not be shared with anyone else.

However, when required by law or university policy, identifying information (including your signed consent form) may be seen or copied by authorized individuals.

I need to make you aware that in certain research studies, it is our legal and ethical responsibility to report any life-threatening situation and/or illegal activity on the ISU campus, campuscontrolled locations, or involving ISU students to appropriate authorities. However, we are not seeking this type of information in our study nor will you be asked questions about these issues.

\section{Could your responses be used for other research?}

We will not use any identifiable information from you in future research, but your deidentified information could be used for future research without additional consent from you.

\section{Who will benefit from this study?}

This study will not only contribute to literature and provide an understanding of Black women's experience at Historically White Institutions, but the study will also provide a liberatory experience to share your story on a platform that it may not have other than been heard on. 
Whom do you contact if you have any questions?

If you have any questions about the research or wish to withdraw from the study, contact Mesha Garner at mcgarne@ilistu.edu or Pamela Hoff at pthoff@ilstu.edu.

If you have any questions about your rights as a participant, or if you feel you have been placed at risk, contact the Illinois State University Research Ethics \& Compliance Office at (309) XXX-XXXX orIRB@ilstu.edu.

\section{Documentation of Consent}

Sign below if you are 18 or older and willing to participate in this study. If you cannot physically sign this form, there is the option for an electronic signature via doc-u-sign. Please contact Mesha Garner if you choose to use doc-u-sign.

Signature

Date

Your signature below indicates that you agree to be recorded.

Signature

Date

You can print this form for your records. 


\section{APPENDIX D: DEMOGRAPHIC SURVEY}

1. Participant's Name First and Last Name

2. Name of the Participants Institution of Employment

3. What is your working job title?

4. Function of Enrollment Management Employed

5. Years of Service Employed Full-Time in Enrollment Management

6. What is the name of the department/ function/ division you work for?

7. What is your highest degree earned?

8. What is the name of the department/ function you work for? 


\section{APPENDIX E: INTERVIEW PROTOCAL}

\section{Interview Questions:}

1. Age Range; Highest Degree Earned; Race; Institution Region:

2. 2. How did you begin your professional journey in enrollment management?

3. Please define what it means to be a Black woman administrator in an HWI?

4. Are there any specific experiences that support your response?

5. Do you feel appreciated and valued as an employee within your HWI?

6. Have your current and/or prior organizations valued diversification among its administration?

7. What are the challenges and experiences being a black woman administrator in higher education?

8. In your opinion, has your gender and/or race impacted your work relationships and overall influence in the university?

9. From your perspective, does racial and/or gender stereotypes impede your leadership opportunities within your HWI?

10. Please rank options in order in regard to the following statement: The greatest obstacle facing Black women administrators in academe is: Race, Gender, Organizational Culture, N/a

11. Has your HWI done enough to address issues facing Black women in their administration: Yes, No, Other

12. What coping strategies do African-American women utilize to successfully manage the conflicts they encounter?

13. What suggestions (i.e. systemic, technological, etc.). can you recommend to increase opportunities for future Black women seeking administrative positions at HWIs? 